San Jose State University

SJSU ScholarWorks

Master's Theses

Master's Theses and Graduate Research

Fall 2011

\title{
Life History Characteristics of the Starry Skate, Raja stellulata, from California waters
}

Kelsey James

San Jose State University

Follow this and additional works at: https://scholarworks.sjsu.edu/etd_theses

\section{Recommended Citation}

James, Kelsey, "Life History Characteristics of the Starry Skate, Raja stellulata, from California waters" (2011). Master's Theses. 4096.

DOI: https://doi.org/10.31979/etd.6gxw-wqdd

https://scholarworks.sjsu.edu/etd_theses/4096

This Thesis is brought to you for free and open access by the Master's Theses and Graduate Research at SJSU ScholarWorks. It has been accepted for inclusion in Master's Theses by an authorized administrator of SJSU ScholarWorks. For more information, please contact scholarworks@sjsu.edu. 


\title{
LIFE HISTORY CHARACTERISTICS OF THE STARRY SKATE, RAJA
}

\section{STELLULATA, FROM CALIFORNIA WATERS}

\author{
A Thesis \\ Presented to \\ the Faculty of Moss Landing Marine Laboratories and \\ San José State University \\ In Partial Fulfillment \\ of the Requirements for the Degree \\ Master of Science
}

by

Kelsey Christine James

December 2011 
(C) 2011

Kelsey Christine James

ALL RIGHTS RESERVED 
The Designated Thesis Committee Approves the Thesis Titled

LIFE HISTORY CHARACTERISTICS OF THE STARRY SKATE, RAJA STELLULATA, FROM CALIFORNIA WATERS

\author{
by \\ Kelsey Christine James \\ APPROVED FOR MOSS LANDING MARINE LABORATORIES \\ SAN JOSÉ STATE UNIVERSITY
}

December 2011

$\begin{array}{ll}\text { Dr. Gregor M. Cailliet } & \text { Moss Landing Marine Laboratories } \\ \text { Dr. James T. Harvey } & \text { Moss Landing Marine Laboratories } \\ \text { Dr. David A. Ebert } & \text { Moss Landing Marine Laboratories }\end{array}$




\section{ABSTRACT \\ LIFE HISTORY CHARACTERISTICS OF THE STARRY SKATE, RAJA STELLULATA, FROM CALIFORNIA WATERS \\ by Kelsey Christine James}

The order Rajiformes, or skates, is a morphologically conservative group that exhibits a wide range of life history characteristics. This inter-species variability warrants species-specific research. This study investigates the age, growth, reproduction, and habitat of the Starry Skate, Raja stellulata, which is endemic to the U.S. West Coast. Age and growth parameters were determined using two preparation techniques: gross sectioning and histological sectioning. The assumption that gross sections deposit one band pair a year was indirectly validated with centrum edge analysis and marginal increment ratio. It was not indirectly validated with histological sections. Age estimates from gross sections ranged from 0 to 11 years, and growth was best described by the two parameter von Bertalanffy growth function in which $L_{\infty}=865 \mathrm{~mm}$ TL and $\mathrm{k}=0.15$. Age estimates from histological sections ranged from 0 to 15 years, and growth was best described by the Gompertz function in which $L_{\infty}=845 \mathrm{~mm}$ TL, $\mathrm{g}=0.15$, and $\mathrm{k}=1.53$. Histological section results are recommended for describing growth of $R$. stellulata because the longevity is more conservative. Raja stellulata exhibits year-round reproduction and attains $50 \%$ maturity at $632 \mathrm{~mm}$ TL, and 11.2 years old for females and $603 \mathrm{~mm}$ TL, and 11.5 years for males. Raja stellulata was collected most often on hard substrate between 70 and $150 \mathrm{~m}$ depth. An age/depth trend within the central California skate assemblage was found where increased habitat depth correlated with increased longevity. 


\section{ACKNOWLEDGEMENTS}

This project was funded by the NOAA/NMFS National Shark Research Center and the Pacific Shark Research Center, the National Sea Grant College Program Grant R/F-199, the David and Lucile Packard Foundation, the Earl and Ethel Myers Oceanographic and Marine Biology Trust, and the American Elasmobranch Society Travel Award.

First, I would like to thank my committee members Drs. David A. Ebert, Gregor M. Cailliet, and James T. Harvey. The guidance and knowledge you provided made this work possible. The time and resources that you provide to your students are what really sets MLML apart. Together you have shaped the scientist that I am today.

I would like to thank everyone outside of MLML who helped collect Raja stellulata throughout the years: Southwest Fisheries Science Center Santa Cruz Laboratory: Churchill Grimes, Don Pearson, John Field, E.J. Dick, and Alex McCall and the Northwest Fisheries Science Center Fisheries Resource Analysis and Monitoring Division: Elizabeth Clark, Beth Horness, Aimee Keller, Dan Kamikawa, Keith Bosley, Victor Simon, and Erica Fruh, the fishermen and their vessels, and the countless volunteers who went to sea and collected without even knowing what project they were helping.

I would like to acknowledge two wonderful resources that made the habitat portion of this study possible: the California State University Monterey Bay Seafloor 
Mapping Laboratory and the Pacific States Marine Fisheries Commission Pacific Coast Marine Habitat Program. Your online resources and the data you share are irreplaceable.

Next I would like to thank Dr. Lisa Natanson. She opened her laboratory and home to a fellow student and me. Her knowledge made a large portion of this thesis possible and she really is at the cutting edge of chondrichthyan age and growth.

The Pacific Shark Research Center was the community behind this thesis. I would like to thank Jenny Kemper, Megan Winton, Shaara Ainsley, Jasmine Maurer, Erin Loury, Joe Bizzarro, James Knuckey, Jenny Bigman, Mariah Boyle, Simon Brown, Diane Haas, and Wade Smith for the amazing knowledge and all the good times, scientific or otherwise.

I would like to give a special thanks to Brynn Hooton, Stephen Martenuk, Kimberly Smelker, and again Jenny Kemper for making work outside of my thesis so enjoyable, and even more so for times outside of any type of work including trivia, diving, and the Santa Cruz Beach Boardwalk. I also would like to give a special thanks to Ben Bennett. He always has been supportive of my work and helped me keep a good balance between my thesis and enjoying life.

Finally I extend my deepest gratitude to my parents: Nancy and Jon James. They have always supported my endeavors and I cannot express in words how much they have done for me above and beyond the parenting requirement. I couldn't have done any of this without them. Thank you. 


\section{TABLE OF CONTENTS}

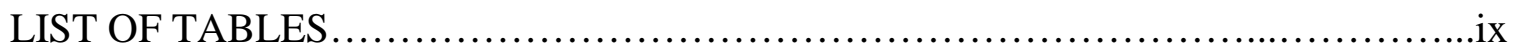

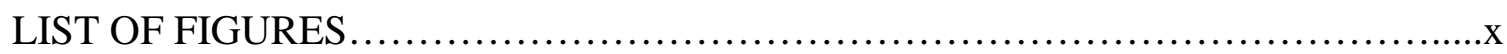

General Introduction........................................................

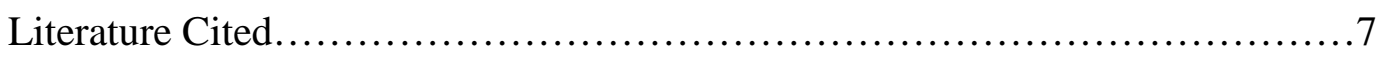

Chapter One: Age and Growth.................................................

Introduction........................................................ 10

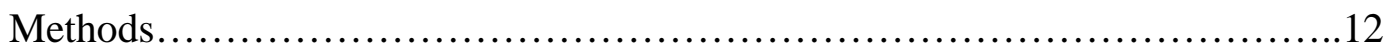

Results.............................................................22

Discussion........................................................ 48

Literature Cited.........................................................54

Chapter Two: Reproduction.............................................59

Introduction.....................................................60

Methods................................................................61

Results............................................................65

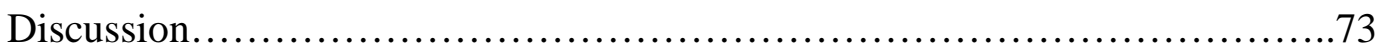

Literature Cited....................................................... 76

Chapter Three: Habitat Classification and Distribution............................ 81

Introduction........................................................ 82

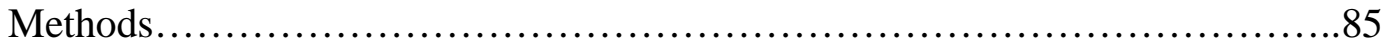

Results............................................................... 87

Discussion.....................................................95 
Literature Cited.......................................................... 99

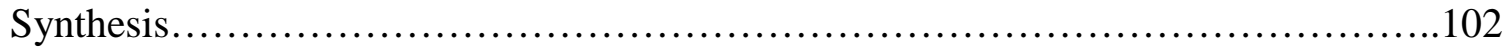

Literature Cited.................................................... 107 


\section{LIST OF TABLES}

Chapter One: Age and Growth

1. Percent agreement (PA) by TL .....................................28

2. Growth model parameters for females, males and sexes pooled of seven growth functions for a) gross sections, and b) histological sections................................................................. 42

3. Goodness-of-fit table for each of the seven growth models..................44 


\section{LIST OF FIGURES}

\section{General Introduction}

1. California commercial skate (Rajiformes) landings, 1916-2008..............4

\section{Chapter One: Age and Growth}

1. Distribution of collection sites of $R$. stellulata ...........................13

2. Raja stellulata specimen with locations of vertebrae and caudal thorn removal........................................................14

3. Size frequency distribution by sex of $R$. stellulata specimens...............23

4. Linear relationship of mean centrum diameter and total length..............24

5. Linear relationship of mean centrum diameter of posterior samples and total length................................................ 25

6. Linear relationship of thorn base and total length.......................26

7. Caudal thorn of $R$. stellulata lacking surface bands.....................27

8. Age bias plot of read 2 age estimates versus mean read 3 age estimates of gross sections.

9. Ages bias plot of posterior age estimates versus mean anterior age estimates of gross sections

10. Age bias plot of reader one's age estimates versus mean reader two age estimates of gross sections

11. Age bias plot of read 2 age estimates versus mean read three age estimates of histological sections....

12. Age bias plot of posterior age estimates versus mean anterior age estimates of histological sections

13. Comparison of gross section to histological section .36 
14. Age bias plot of gross section age estimates versus mean histological age estimates

15. Monthly variation in mean marginal increment ratio and centrum edge type for gross sections.

16. Monthly variation in mean marginal increment ratio and centrum edge type for histological sections

17. Seven growth curves fit to gross section data of $R$. stellulata.

18. Seven growth curves fit to histological section data of $R$. stellulata

\section{Chapter Two: Reproduction}

1. Relationship between oviducal gland width and total length..................66

2. Relationship between inner clasper length and total length...................67

3. Maturity ogives for males and females by total length.....................68

4. Maturity ogives for males and females by estimated age...................69

5. Average female GSI by month......................................... 70

6. Average male GSI by month..............................................

7. Average maximum ovum diameter and average number of mature ova by month......................................................

Chapter Three: Distribution and Habitat Characteristics

1. Photographs by SCUBA divers of $R$. stellulata on rocky habitat.............84

2. Map of $R$. stellulata collection sites assigned a substrate consolidation

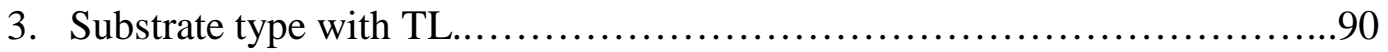

4. Mean a) latitude and b) longitude of different substrate types.................93 
5. Relationship of maximum estimated age of central California skates with mean depth................................................94 


\section{General Introduction}


Elasmobranchs are generally characterized as having slow growth, late age at maturity, and extended longevity, making this group susceptible to targeted and incidental fishing pressures (Holden 1973, Stevens et al. 2000). There is, however, considerable variation in life history characteristics within this group (Smith et al. 1998, Walker 1998, Cortés 2002). Cortés (2002) examined the demography of 38 species of sharks and developed a "fast-slow" continuum based on life history characteristics that highlights this inter-species variability. Species at the fast end of the continuum mature early in life, have a short lifespan, and relatively large litters, whereas species at the slow end mature late in life, have a long lifespan, and relatively small litters (Cortés 2002). This variability in life history characteristics also is observed within the skate order, Rajiformes (Dulvy et al. 2000, Ebert et al., 2007, 2009). Recent research indicates that skate species live between seven and thirty-seven years and mature between three and twenty-three years (Cailliet and Goldman 2004, Gallagher et al. 2004, Ebert et al. 2009, Ainsley et al. 2011). This variability warrants a species-specific approach to the research and fisheries management of skates.

Despite the evidence of inter-species variability, skates often are managed in aggregate categories such as "unspecified skate" or "other species" (Dulvy et al. 2000). This is mainly because skates are predominantly landed as bycatch, and are rarely sorted to species (Dulvy et al. 2000). Skates constitute a large percentage of bycatch in some regions, which raises concerns about the impacts of fishing pressure on skate populations (Matta et al. 2006). The use of such aggregate categories can mask species-specific fishing impacts (Walker and Hislop 1998, Dulvy et al. 2000). A study conducted on 
several species from the northeast Atlantic skate assemblage indicated that fisheries catch had remained relatively stable through time, but populations of larger skate species were decreasing, while populations of smaller skate species were increasing (Dulvy et al. 2000). The use of aggregate categories for skate bycatch, therefore, ignores inter-species variability and can mask declines of certain species. This indicates the importance of species-specific life history data.

Sporadic fishing for skates has occurred along the California coast since the mid1880s, with most interest coming from Asian communities that consume the pectoral fins, or "wings" (Haas 2010). Skate landings have varied dramatically during the years, with a peak of 1,362 metric tons landed in 1997 and a large decrease in 2002 due to reduced Asian demand (Fig. 1; CDFG 2009, Haas 2010). In the five Pacific U.S. states, nearly $100 \%$ of skate catch is taken indirectly (Camhi 1999), and a large proportion of the catch is discarded without documentation (CDFG 2009, Haas 2010). Those skates that are retained are most commonly marketed as "unspecified skate", which until 2009 could include all eleven species of skates in California waters (CDFG 2009, Haas 2010). After 2009, one of the eleven species, Raja rhina, was removed from the "other species" category and was sorted to species; the rest were still lumped as "other species" (CDFG 2009, Haas 2010). 


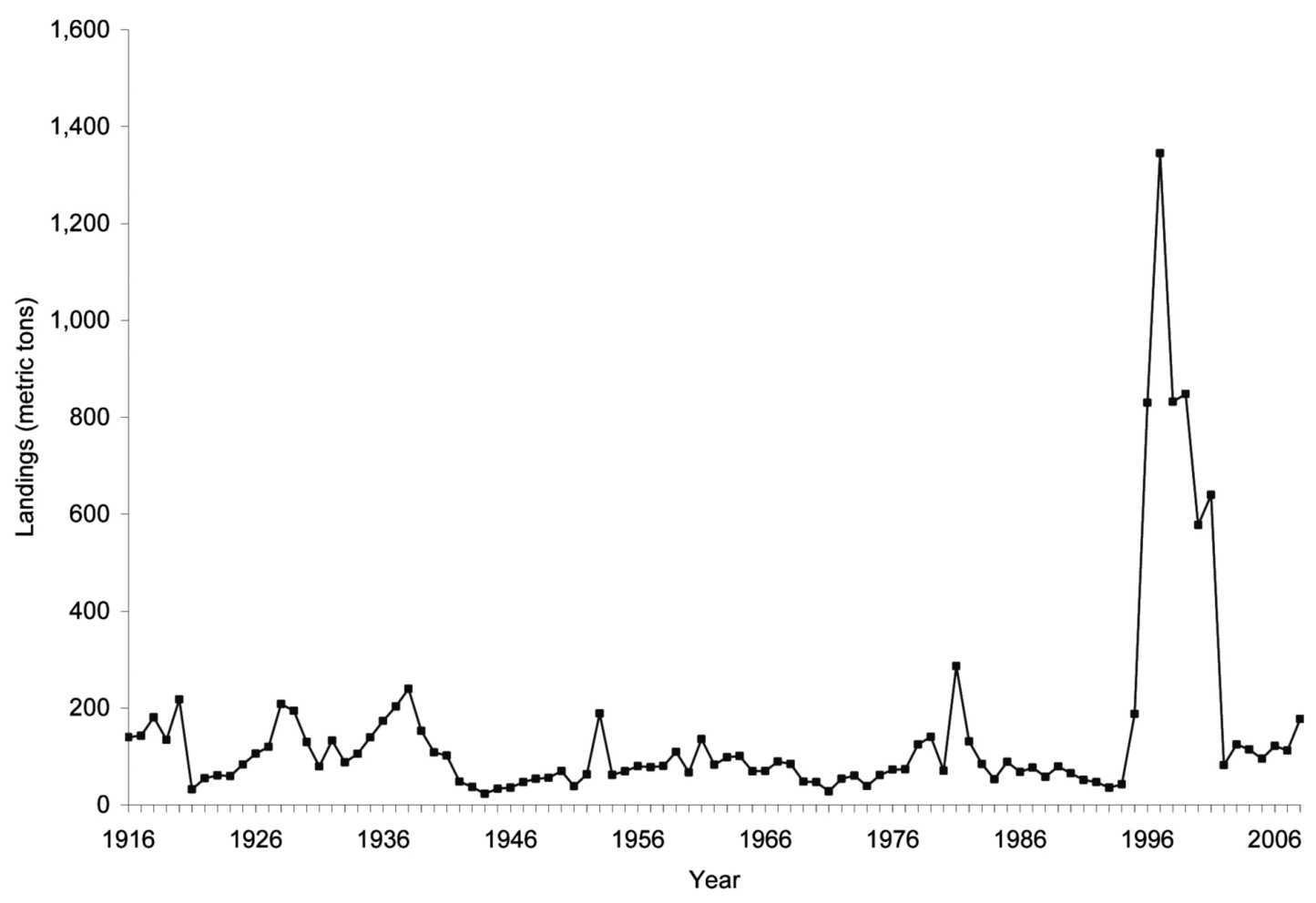

Figure 1. California commercial skate (Rajiformes) landings, 1916-2008. Adapted from CDFG (2009).

The skates off of central California, along the U.S. West Coast, belong to two families: Arhynchobatidae and Rajidae. The Arhynchobatidae, or softnose skates, generally occur on the continental slope below $200 \mathrm{~m}$ depth. The two most common species are the Sandpaper Skate, Bathyraja kincaidii, and the Roughtail Skate, $B$. trachura. The Rajidae, or hardnose skates, generally occur in shallower depths on the continental shelf and upper slope, usually less than $200 \mathrm{~m}$. The four most common species are the Big, Raja binoculata, California, $R$. inornata, Longnose, $R$. rhina and Starry Skate, $R$. stellulata. An additional five species occur in U.S. Pacific coastal waters, but occur deeper and are encountered much less frequently (Ebert 2003). 
The four species of hardnose skates are more vulnerable to exploitation due to their shallower depth range and subsequent proximity to coastal fishing. Raja binoculata, $R$. inornata, and $R$. rhina are the most commercially important skate species in California but are rarely sorted to species, with $99 \%$ of those landed in 2008 marketed as "unspecified skate" (CDFG 2009). Despite the prominence of these species in fisheries bycatch, there is little information on their life histories in California waters. The diet of $R$. binoculata, $R$. inornata, and $R$. rhina has been examined in central California (Bizzarro et al. 2007, Robinson et al. 2007), and one study examined the age and growth of $R$. binoculata and $R$. rhina in central California (Zeiner and Wolf 1993). Otherwise little is known about these species, especially $R$. stellulata.

Raja stellulata is a medium to small sized skate with a maximum total length (TL) of $761 \mathrm{~mm}$. It occurs from Baja California, Mexico to Barkley Sound, British Columbia, Canada, nearshore to $982 \mathrm{~m}$ depth but it is most commonly found at about $100 \mathrm{~m}$ depth along the continental shelf. Raja stellulata occupies a different habitat than other skates, usually occurring on hard substrate near rocky reefs with some vertical relief (Dave Ebert, pers. comm.). It is distinguished from other skate species by a brown dorsal surface with numerous light and dark spots, an eyespot on each pectoral fin, and starshaped prickles, its namesake, covering most of the dorsal surface (Ebert 2003). Its diet includes crustaceans, cephalopods, and teleosts including small Lingcod, Ophiodon elongatus, and rockfishes, Sebastes spp. Research on R. stellulata has been minimal; after the original description by Jordan and Gilbert (1880), it has appeared rarely in the 
scientific literature except for an occasional taxonomic note, an unpublished diet study, and the description of its egg case (Ebert and Davis 2007).

The purpose of this study was to describe the life history characteristics of $R$. stellulata. The overall objectives include 1) determining the age and growth of $R$. stellulata (Chapter One), 2) assessing maturity and reproductive seasonality of $R$. stellulata (Chapter Two), and 3) classifying the habitat of $R$. stellulata and identifying trends in the central California skate assemblage (Chapter Three). 


\section{Literature Cited}

Ainsley, S.M., D.A. Ebert, and G.M. Cailliet. 2011. Age, growth and maturity of the whitebrow skate, Bathyraja minispinosa, from the eastern Bering Sea. ICES Journal of Marine Science 68(7): 1426-1434.

Bizzarro, J.J., H.J. Robinson, C.S. Rinewalt and D.A. Ebert. 2007. Comparative feeding ecology of four sympatric skate species off central California, USA. Environmental Biology of Fishes 80: 197-220.

Cailliet, G.M. and K.. Goldman. 2004. Age determination and validation in chondrichthyan fishes. In. J.C. Carrier, J.A. Musick, and M.R. Heithaus (eds.) Biology of sharks and their relatives. pp. 399-447. Boca Raton, FL. CRC Press LLC.

Camhi, M. 1999. Sharks on the line II: an analysis of Pacific state shark fisheries. National Audubon Society. 116 pp.

California Department of Fish and Game (CDFG). 2009. Review of selected California fisheries for 2008: Coastal pelagic finfish, market squid, ocean salmon, groundfish, California spiny lobster, spot prawn, white seabass, kelp bass, thresher shark, skates and rays, Kellet's whelk, and sea cucumber. Fisheries Review: CalCOFI Report 50: 14-42.

Cortés, E. 2002. Incorporating uncertainty into demographic modeling: application to shark populations and their conservation. Conservation Biology 16(4): 1048-1062.

Dulvy, N.K., J.D. Metcalfe, J. Glanville, M.G. Pawson and J.D. Reynolds. 2000. Fishery stability, local extinctions and shifts in community structure in skates. Conservation Biology 14(1): 283-293.

Ebert, D.A. 2003. Sharks, rays and chimaeras of California. University of California Press. 284 pp.

Ebert, D.A. and C. Davis. 2007. Descriptions of skate egg cases (Chondrichthyes: Rajiformes: Rajoidei) from the eastern North Pacific. Zootaxa 1393: 1-18.

Ebert, D.A., J.R. Maurer, S.M. Ainsley, L.A.K. Barnett and G.M. Cailliet. 2009. Life history and population dynamics of four endemic Alaskan skates: determining essential biological information for effective management of bycatch and target species. North Pacific Research Board Final Report 715. 120 pp. 
Ebert, D.A., W.D. Smith, D.L. Haas, S.M. Ainsley and G.M. Cailliet. 2007. Life history and population dynamics of Alaskan skate: Providing biological information for effective management of bycatch and target species. North Pacific Research Board Final Report 510. 124 pp.

Haas, D. 2010. Skates and Rays. In: Lavinto, T. (ed.) Status of the Fisheries Report - An Update Through 2008. California Department of Fish and Game. 17 pp. http://www.dfg.ca.gov/marine/status/report2008/skates.pdf. 16 December 2010.

Holden, M.J. 1973. Are long-term sustainable fisheries for elasmobranchs possible? Rapports et Procès Verbaux des Rèunions du Conseil International pour l'Exploration de la Mer 164: 360-367.

Gallagher, M.J., C.P. Nolan and F. Jeal. 2004. Age, growth, and maturity of the commercial ray species from the Irish Sea. Journal of Northwest Atlantic Fisheries Science 35: 47-66.

Matta, B., S. Gaichas, S. Lowe, D. Stevenson, G. Hoff and D. Ebert. 2006. Bering Sea and Aleutian Islands skates. Stock assessment and fishery evaluation of skate species (Rajidae) in the Gulf of Alaska. In. Stock assessment and fishery evaluation report for the groundfish resources of the Gulf of Alaska for 2007. North Pacific Fishery Management Council. Anchorage, Alaska.

Robinson, H.J., G.M. Cailliet, and D.A. Ebert. 2007. Food habits of the longnose skate, Raja rhina (Jordan and Gilbert, 1880), in central California waters. Environmental Biology of Fishes 80: 165-179.

Smith, S.E., D.W. Au and C. Show. 1998. Intrinsic rebound potentials of 26 species of Pacific sharks. Marine and Freshwater Research 49: 663-678.

Stevens, J.D., R. Bonfil, N.K. Dulvy and P.A. Walker. 2000. The effects of fishing on sharks, rays and chimaeras (chonrichthyans), and the implications for marine ecosystems. ICES Journal of Marine Science 57: 476-494.

Walker, T.I. 1998. Can shark resources be harvested sustainably? A question revisited with a review of shark fisheries. Marine and Freshwater Research 49: 553-572.

Walker, P.A. and J.R.G. Hislop. 1998. Sensitive skates or resilient rays? Spatial and temporal shifts in ray species composition in the central and north-western North Sea between 1930 and present day. ICES Journal of Marine Science 55: 392-402.

Zeiner, S.J. and P. Wolf. 1993. Growth characteristics and estimates of age at maturity of two species of skates (Raja binoculata and Raja rhina) from Monterey Bay, California. NOAA Technical Report NMFS 115: 87-99. 


\section{Chapter One: Age and Growth}




\section{Introduction}

Age and growth parameters describe the growth characteristics and lifespan of a species. These parameters are determined through size-at-age estimates and growth modeling and are used for calculations of mortality and population growth rates, which are crucial to demographic analyses. Once a population has been assessed using age and growth parameters and demography, fisheries management agencies are better equipped to create sustainable management plans.

Hard structures that accrue calcified material over time are the most reliable material to estimate the age of chondrichthyans. Structures used for chondrichthyan ageing include vertebral centra, dorsal fin spines, neural arches, and caudal thorns (Cailliet and Goldman 2004). The calcified material is deposited as concentric bands within the hard structure, which grows proportionally with the individual. Skates have been most reliably aged using band counts in vertebral centra, which are often sagitally sectioned (Campana 2001).

A pair of opaque and translucent bands, a band pair, represents one year of growth. Annual band pair deposition has been confirmed in several species of skate including Amblyraja radiata, Leucoraja erinacea, L. ocellata, Malacoraja senta, and Raja texana (Natanson 1993, Sulikowski et al. 2005, Natanson et al. 2007, Sulikowski et al. 2007, McPhie and Campana 2009).

One difficulty of skate ageing is poor band resolution within the ageing structure. Several staining methods have been developed to enhance the banding pattern of chondrichthyan hard structures including mineral oil, crystal violet, silver nitrate, and 
histology (Cailliet and Goldman 2004). To determine which method enhances the banding pattern best, some recent researchers of skate age and growth have compared age estimates between two techniques: gross sections and histological sections (Natanson et al. 2007, Ainsley 2009, Maurer 2009, Winton 2011). Gross sections are sagittal vertebral sections with either no enhancement or mineral oil only, whereas histological sections are decalcified sagittal vertebral sections that are embedded in a wax then stained with Harris hematoxylin (Natanson et al. 2007). A comparison between gross sections and histological sections will be completed in this study to assess which preparation technique provides the clearest band resolution.

Some skate species have been successfully aged using an alternative hard structure, caudal thorns (Gallagher et al. 2006, Matta and Gunderson 2007, Moura et al. 2007). Ridges and troughs present on the surface of the caudal thorn can be counted to make age estimates (Gallagher and Nolan 1999). Usually one ridge and one trough represent one year of growth, although this has not been validated (Gallagher and Nolan 1999). However, this structure has not been reliable for ageing many other species (Davis et al. 2007, Ainsley 2009, Maurer 2009, Perez et al. 2011, Winton 2011). Caudal thorns, if shown to be a useful ageing structure, would be a non-lethal method to age skates, thus eliminating the need to sacrifice individuals for age and growth studies. One crucial assumption of an age and growth study is one band pair deposited a year. To test this assumption, validation is used to lend credibility to age estimates (Campana 2001, Cailliet and Goldman 2004, Cailliet et al. 2006). Direct validation is the confirmation of the fish's absolute age, while indirect validation determines the 
frequency of a growth increment (Campana 2001). Direct validation, including methods such as bomb radiocarbon, mark-recapture of chemically tagged fish and captive rearing, is preferred, but it is imperative to assess the periodicity of band pair deposition to give credibility to age estimates (Campana 2001, Cailliet and Goldman 2004, Cailliet et al. 2006). Indirect validation methods include centrum edge analyses that examine the edge band type (opaque or translucent), and the edge band pair width against the penultimate band pair width (Campana 2001, Cailliet and Goldman 2004, Cailliet et al. 2006). If the edge type or band pair width exhibit a distinct pattern and vary significantly during the course of a year, then the periodicity of band deposition can be sufficiently described to verify the age estimates (Simpfendorfer et al. 2000, Smith et al. 2007).

The goal of this chapter is to provide knowledge on the age and growth parameters of Raja stellulata. The research objectives of this chapter were to 1) identify and quantify band pairs within the vertebral centra, 2) compare band enhancement between gross and histological preparation techniques, 3) assess caudal thorns as an alternative, potentially non-lethal, ageing structure, 4) estimate size-at-age, 5) verify these band pair counts using centrum edge analysis and marginal increment ratio, and 6) calculate theoretical maximum size, longevity, and growth.

\section{Methods}

\section{Collection}

Specimens of $R$. stellulata were obtained from two separate surveys along the U.S Pacific Coast. From 2002 through 2005, the National Marine Fisheries Service, 
Southwest Fisheries Science Center, Santa Cruz Laboratory (SWFSC-SCL) conducted demersal longline and trawl surveys off central California from Davenport (ca. $37^{\circ} 00^{\prime} \mathrm{N}$, $122^{\circ} 11^{\prime} \mathrm{W}$ ) to Monterey (ca. $36^{\circ} 36^{\prime} \mathrm{N}, 121^{\circ} 53^{\prime} \mathrm{W}$; Fig. 1). Additional specimens were collected from 2006 to 2010 by the National Marine Fisheries Service, Northwest Fisheries Science Center (NWFSC) during the Fishery Resource and Monitoring division's (FRAM) annual coast-wide groundfish survey extending from the U.S. border with Canada (ca. $48^{\circ} 28^{\prime} \mathrm{N}, 124^{\circ} 54^{\prime} \mathrm{W}$ ) to the U.S. border with Mexico (ca. $32^{\circ} 31^{\prime} \mathrm{N}$, $117^{\circ} 11^{\prime}$ W; Fig. 1).

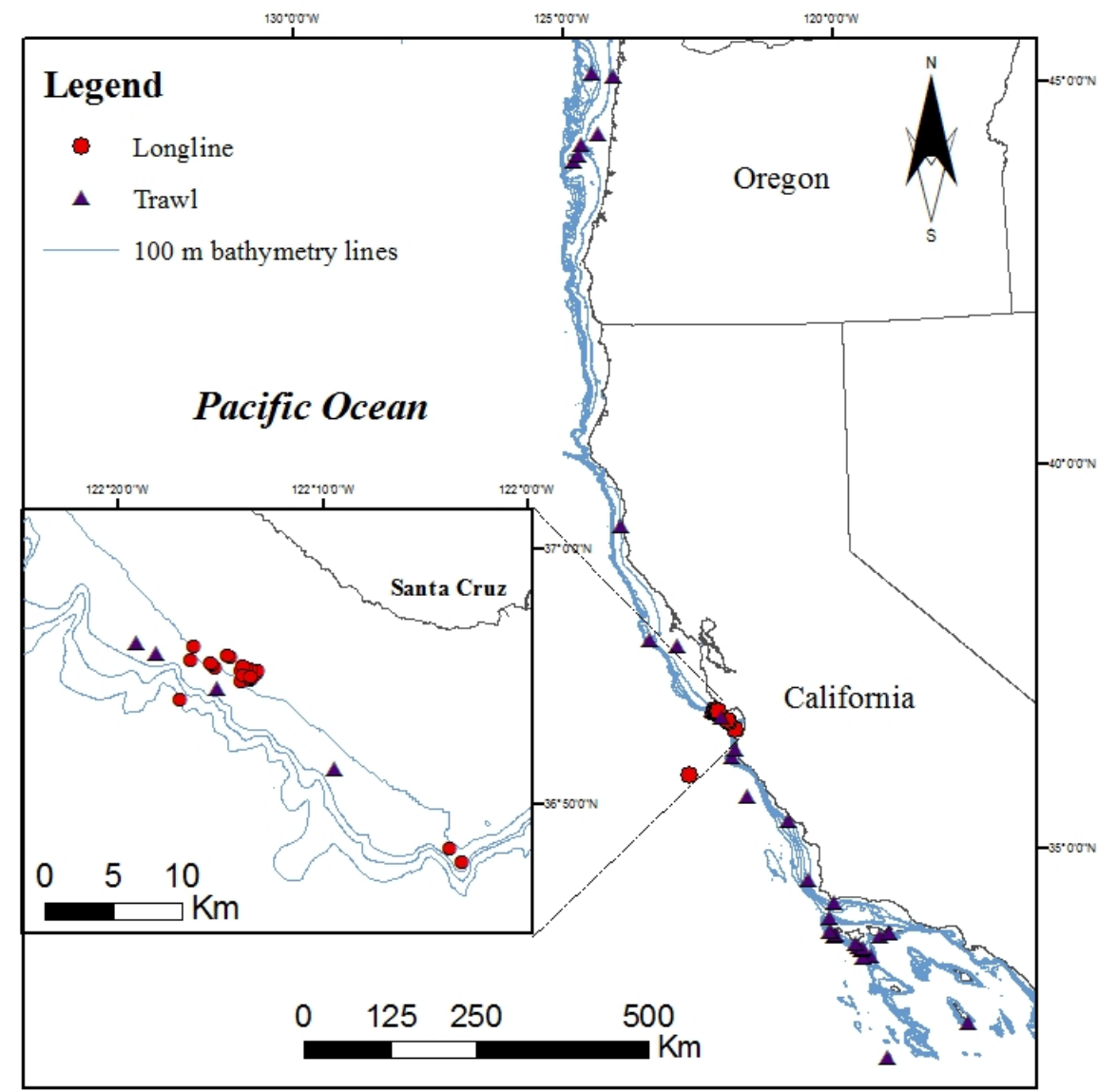

Figure 1. Distribution of collection sites of Raja stellulata $(\mathrm{n}=58)$. Red circles were collection by longline, and purple triangles were collection by trawl. Inset is northwest Monterey Bay. 
Specimens were returned whole to Moss Landing Marine Laboratories (MLML) for processing. For each, individual total length (TL) were measured to the nearest millimeter from snout tip to tail tip and disc widths (DW) measured from one wing tip to the other wing tip. Each specimen was weighed and assigned a sex and maturity status following the system of Ebert (2005). Relationships between TL and DW and between TL and mass were determined. A segment of at least eight vertebrae was excised from each specimen between the $5^{\text {th }}$ and $20^{\text {th }}$ vertebrae (Fig. 2). A subsample of individuals also had vertebrae removed from the posterior region of the vertebral column, starting at least 10 vertebrae behind the anterior sampling location to determine if centrum growth is uniform along the vertebral column. A second subsample had 5-7 caudal thorns excised from behind the tail insertion (Fig. 2).

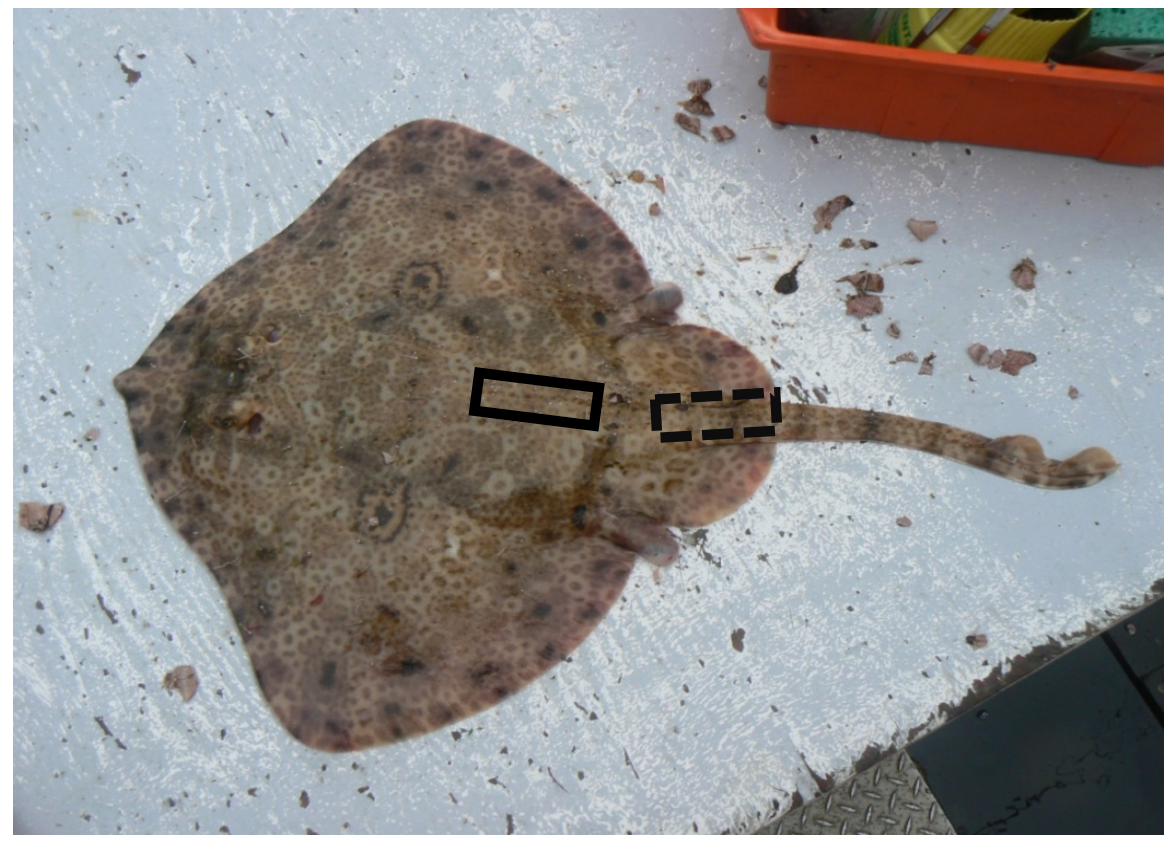

Figure 2. Raja stellulata specimen with locations of vertebrae and caudal thorn removal. Black box encompasses anterior vertebrae sampling. Dashed box encompasses posterior vertebrae and caudal thorn area of sampling. 


\section{Age Structure Preparation}

Four anterior vertebrae per specimen were separated into individual centra and cleaned of excess tissue. Two centra were dried and stored in an air-tight container for gross sectioning. The other two were stored in $70 \%$ ethanol for at least two months before histological preparation. One dried vertebra from each specimen was selected, and two perpendicular measurements of the centrum diameter $(\mathrm{mm})$ were recorded. The mean centrum diameter was calculated and plotted against TL to verify that vertebral growth was in proportion to organismal growth.

For the gross sectioning technique, each vertebra was mounted on a merchandise tag with polyester casting resin. One vertebra from each specimen was sagitally cut through the focus using a low speed saw (Buehler Isomet@, Lake Bluff, IL, USA) with paired diamond-edged blades to a thickness of $0.4-0.6 \mathrm{~mm}$. Sections were then mounted on microscope slides with Cytoseal ${ }^{\mathrm{TM}} 60$ and polished to an optimal viewing thickness using 1,200 grit wet sandpaper.

The histological technique followed Natanson et al. (2007). Centra were decalcified using $\mathrm{RDO} \circledast$ rapid decalcifying agent, rinsed with water, and returned to $70 \%$ ethanol. Vertebrae next underwent a nine-step embedding process, which involved submerging the centra in decreasing concentrations of ethanol, tert-butyl alcohol, and increasing concentrations of Paraplast Plus ${ }^{\circledR}$ (McCormick Solutions, St. Louis, MO). The vertebrae were then sectioned to a thickness of $80-100 \mu \mathrm{m}$ with a sledge microtome. Three to five sections closest to and including the focus of the centrum were retained in tissue capsules and immersed in 100\% xylene baths that removed the Paraplast Plus ${ }^{\circledR}$. 
Sections were stained with Harris hematoxylin and gradually moved through baths to $100 \%$ glycerin, after which they were mounted on microscope slides and sealed with clear nail polish.

The subsample of posterior vertebrae also were prepared using gross sectioning and the histological technique to assess potential differences in the banding pattern along the vertebral column.

\section{Caudal Thorns}

Caudal thorns were prepared for ageing as a possible non-lethal alternative to vertebral centra. Excess tissue was removed from thorns by boiling water and scrubbing with a toothbrush. Thorns were dried and examined under a dissecting microscope using reflected light. The thorn base was measured from anterior to posterior and plotted against specimen TL to determine if thorns grow in proportion to TL. Age 0 was determined by identifying the protothorn, the tip of caudal thorn lacking growth bands. Each subsequent ridge and trough were considered a band pair, and counted for an age estimate. In an attempt to resolve band pairs a subsample of thorns was stained with a $1.0 \%$ aqueous crystal violet.

\section{Ageing}

Sections prepared using both techniques were photographed under a dissecting microscope with transmitted light. Photographs were analyzed using ImagePro Plus® 4.1.0 imaging software (Media Cybernetic, L.P. 1993-1999). The birthmark, age 0, was 
determined as the first fully formed band pair beyond the focus that was associated with an angle change in the corpus calcareum (Cailliet and Goldman 2004). Each opaque and translucent band thereafter was considered a band pair and assumed, as with many skate species, to represent one year of growth (Ebert et al. 2007, 2009).

Age was determined for each individual without knowledge of length, sex, collection date, or previous band pair count. The number of band pairs was counted three times by one reader and final ages were assigned based on the final ageing round. Read 1 was used to familiarize the reader with the banding pattern, and to confirm good ageing criteria so it was excluded from further analysis. A fourth read was conducted if the previous reads disagreed by two or more years. If, after a fourth read, agreement within one band pair was not reached, the vertebra was not used in this study (Neer and Thompson 2005). A subsample of gross sectioned vertebrae was read by a second reader to compare precision and accuracy of age estimates.

\section{Precision and Bias}

Precision analysis among reads of each centrum was determined using the following measures: index of average percent error (IAPE) (Beamish and Fournier 1981), coefficient of variation (CV), and index of precision (D) (Chang 1982). The IAPE was calculated as:

$$
I A P E=100 \% * \frac{1}{N} \sum_{j=1}^{N}\left[\frac{1}{R} \sum_{i=1}^{R} \frac{\left|X_{i j}-X_{j}\right|}{X_{j}}\right],
$$


where $N$ is the total number of samples, $R$ is the number of reads, $X_{i j}$ is the $i^{\text {th }}$ age estimate of the $j^{\text {th }}$ individual and $X_{j}$ is the mean age estimate for the $j^{\text {th }}$ individual. $\mathrm{CV}$ is an alternative precision analysis that uses the standard deviation rather than the absolute deviation. It was calculated as:

$$
C V_{j}=100 \% * \frac{\sqrt{\sum_{i=1}^{R} \frac{\left(X_{i j}-X_{j}\right)^{2}}{R-1}}}{X_{j}}
$$

Index of precision (D) is a measure of the percent error for each read of an ageing structure:

$$
D_{j}=\frac{C V_{j}}{\sqrt{R}}
$$

Variables of $\mathrm{CV}$ and $\mathrm{D}$ are described above in the IAPE. $\mathrm{CV}_{\mathrm{j}}$ and $\mathrm{D}_{\mathrm{j}}$ are both individual calculations that are averaged among individuals to produce mean values (Ebert et al. 2009). Age 0 individuals were excluded from calculations of IAPE, CV, and D (Ebert et al. 2009). Percent agreement also was assessed among ages and by $100 \mathrm{~mm}$ TL bins (Goldman 2004).

To determine the source of differences between reads, either systematic bias or random error, age bias plots and contingency tables analyzed by chi-squared tests of symmetry were conducted (Bowker 1948, Campana et al 1995, Hoenig et al 1995, Evans and Hoenig 1998). All the above precision and bias analyses also were conducted to test for differences in age estimates between readers. Bias analyses also were conducted between anterior and posterior of both gross sectioning and histological sectioning and between anterior gross and histological sections. 


\section{Indirect Validation}

Periodicity of band pair deposition was assessed using centrum edge analysis (CEA) and marginal increment ratio (MIR) (Tanaka and Mizue 1979, Campana 2001, Cailliet and Goldman 2004). CEA examines the final band, half of a band pair, of each sample placing it in one of four categories 1) narrow/translucent, 2) broad/translucent, 3) narrow/opaque, and 4) broad/opaque (Smith et al. 2007). The proportion of band types was plotted by month and tested with a non-parametric Kruskal-Wallis test to detect seasonal differences in edge type.

MIR was calculated as (Conrath et al 2002):

$$
M I R=\frac{M W}{P B W}
$$

where $M W$ is the margin width of the forming band pair, and $P B W$ is the width of the penultimate band pair. Mean MIR was calculated for each month, and plotted by month to determine periodicity of band pair deposition. Differences among months were tested using a non-parametric Kruskal-Wallis test (Simpfendorfer et al. 2000, Smith et al. 2007).

\section{Growth Modeling}

Multiple growth functions were fit to size-at-age estimates for each sex and sexes combined. Growth model parameters were estimated with non-linear least-squares regression methods in SigmaPlot version 12.0 (SPSS Software Inc., 2011). The first growth model applied, and the most common to describe chondrichthyan growth, was the three parameter von Bertalanffy growth function (3 VBGF) calculated as: 


$$
L_{t}=L_{\infty}\left(1-e^{-k\left(t-t_{0}\right)}\right),
$$

where $L_{t}$ is the age at length $\mathrm{t}, L_{\infty}$ is the theoretical asymptotic total length, $k$ is the von Bertalanffy growth coefficient, and $t_{0}$ is the theoretical age at zero length (Ricker 1979).

The modified two parameter von Bertalanffy growth function (2 VBGF) incorporates a known size-at-birth rather than $t_{0}$ and was calculated as:

$$
L_{t}=L_{\infty}-\left(L_{\infty}-L_{0}\right) e^{-k t}
$$

$L_{t}, L_{\infty}$, and, $k$ are defined above, and $L_{0}$ is the known length at birth, $151 \mathrm{~mm}$ (this study).

The Gompertz growth function (modified from Ricker 1979) was the third function applied, and was calculated as:

$$
L_{t}=L_{\infty} e^{\left(-k e^{-g t}\right)}
$$

where $L_{t}, L_{\infty}$, and $t$ are described above $g$ is the instantaneous growth coefficient and $k$ is a dimensionless parameter. The Gompertz function has been postulated as more appropriate to describe oviparous elasmobranch species growth (Cailliet and Goldman 2004).

The fourth growth equation was the logistic model (modified from Ricker 1979) and was calculated as:

$$
L_{t}=\frac{L_{\infty}}{1+e^{-g\left(t-t_{0}\right)}}
$$

where $L_{t}, L_{\infty}$, and $t$ are described above, $g$ is the instantaneous growth rate and $t_{0}$ is the inflection point. 
Finally, three models developed by Schnute (1981) and modified by Quinn and Deriso (1999) commonly used to model fish growth were applied. Case 1 was calculated as:

$$
L_{t}=\left(L_{1}^{\gamma}+\left(L_{2}^{\gamma}-L_{1}^{\gamma}\right) \frac{1-e^{-\kappa\left(t-\tau_{1}\right)}}{1-e^{-\kappa\left(\tau_{2}-\tau_{1}\right)}}\right)^{\frac{1}{\gamma}}
$$

Case 3 was calculated as:

$$
L_{t}=\left(L_{1}^{\gamma}+\left(L_{2}^{\gamma}-L_{1}^{\gamma}\right) \frac{t-\tau_{1}}{\tau_{2}-\tau_{1}}\right)^{\frac{1}{\gamma}}
$$

Case 4 was calculated as:

$$
L_{t}=L_{1} e^{\left(\ln \left(\frac{L_{2}}{L_{1}}\right) \frac{t-\tau_{1}}{\tau_{2}-\tau_{1}}\right)}
$$

where $L_{1}$ and $L_{2}$ are the estimated lengths at selected reference ages $\tau_{1}$ and $\tau_{2}$, which were selected to be 1 and 6 years respectively, and $\kappa$ and $\gamma$ are parameters describing the curve shape. Schnute's Cases 2 and 5 are equivalent to the Gompertz and 3 VBGF respectively, and so they were excluded (Schnute 1981).

Goodness-of-fit for each model was determined using Akaike's Information Criterion adjusted for small sample size ( $\mathrm{AIC}_{c}$, Burnham and Anderson 2002). AIC $\mathrm{A}_{\mathrm{c}}$ was calculated from least squares regression statistics assuming normally distributed deviations with constant variance as:

$$
A I C_{c}=n \times \log \left(\sigma^{2}\right)+2 K+\frac{2 K(K+1)}{n-K-1}
$$

with

$$
\sigma^{2}=\frac{R S S}{n}
$$


where $n$ is the total number of samples, $K$ is the number of parameters estimated by the growth function including $\sigma^{2}$, and $R S S$ is the residual sum of squares. The $\mathrm{AIC}_{\mathrm{c}}$

differences were calculated as: $\Delta_{\mathrm{i}}=\mathrm{AIC}_{\mathrm{c}}-\mathrm{AIC}$ min for all growth models. Models with $\Delta_{\mathrm{i}}$ $<4$ have substantial support whereas those with $\Delta_{\mathrm{i}}>10$ have essentially no support (Burnham and Anderson 2002). Model selection was based on goodness-of-fit, biological relevance, and comparability with other studies. Likelihood ratio tests also were applied to determine differences in growth parameters between sexes (Kimura 1980, Haddon 2001).

\section{Results}

\section{Collection}

A total of 194 specimens was collected by SWFSC-SCL between 2002 and 2005 $(n=128)$ and by NWFSC-FRAM between 2006 and $2010(n=66)$. Specimens collected were representative of the size range of this species, from 151 to $761 \mathrm{~mm}$ TL (Fig. 3). The ratio of females $(n=101)$ to males $(n=93)$ was nearly even. The TL to DW relationship was best described by a power function $\left(\mathrm{r}^{2}=0.981, \mathrm{DW}=0.78 * \mathrm{TL}^{\wedge} 0.98, \mathrm{n}\right.$ $=194)$. The TL to mass relationship also was best described by a power function $\left(\mathrm{r}^{2}=\right.$ 0.937, Mass $\left.=1.02 * 10^{-9} * \mathrm{TL}^{\wedge} 3.31, \mathrm{n}=194\right)$. 


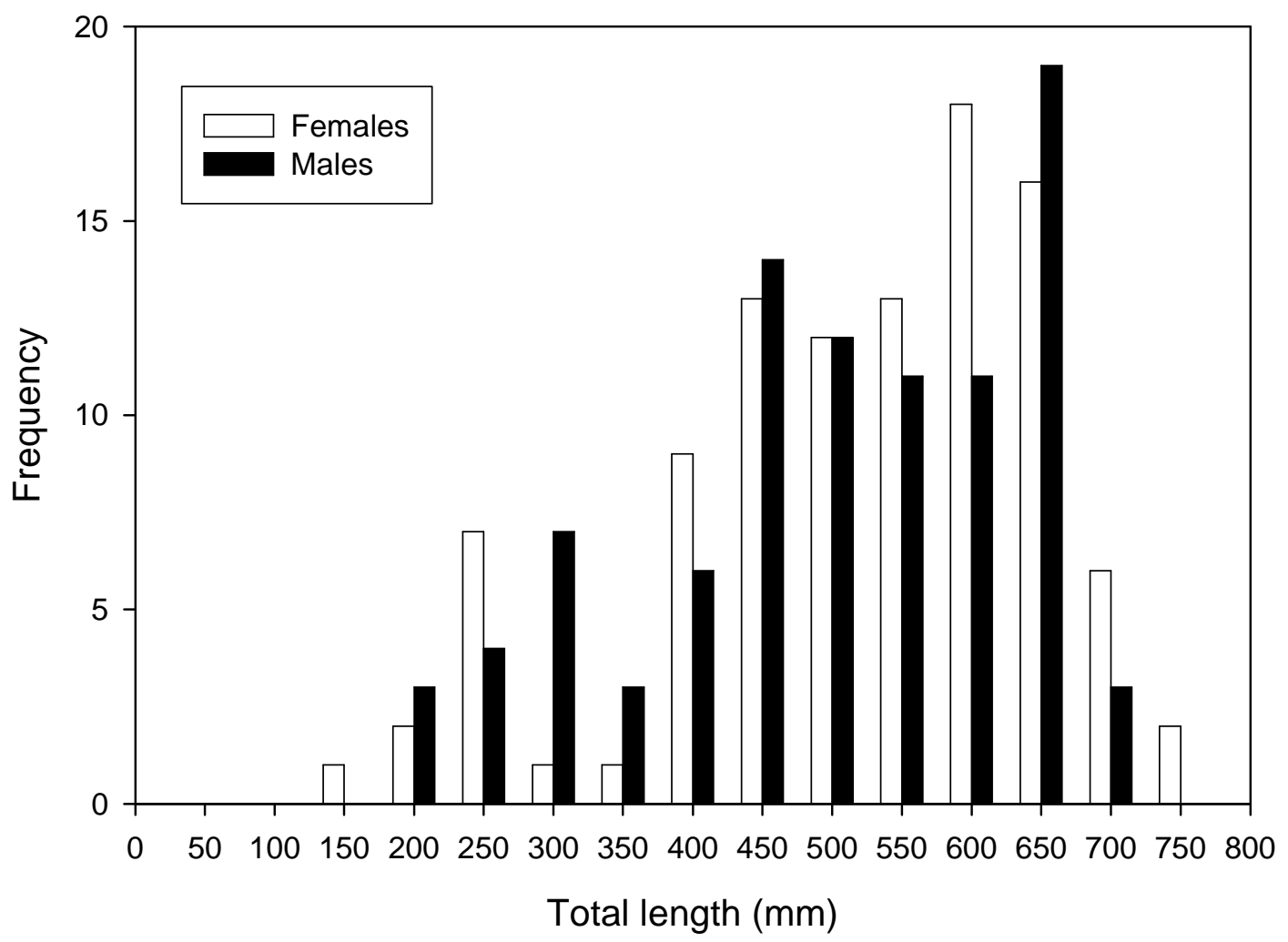

Figure 3. Size frequency distribution by sex of Raja stellulata specimens $(\mathrm{n}=194)$. Open bars are females and black bars are males.

\section{Age Structure Preparation}

Mean centrum diameter was linearly related to TL $\left(r^{2}=0.939, \mathrm{MCD}=0.01 * \mathrm{TL}\right.$ $0.53, \mathrm{n}=192$; Fig. 4 ) that was not significantly different between sexes (two-sample ttest: $\mathrm{t}=1.16, \mathrm{df}=190, \mathrm{p}=0.249)$. Two centra were unavailable for measurement. This indicated that centra grew in proportion to TL. A total of 193 vertebral centra was prepared for ageing using the gross sectioning technique, the centrum of one individual was missing. A total of 71 centra was prepared using the histological technique due to 
time and financial constraints. A subsample of 18 individuals also had vertebrae removed from a posterior region of the vertebral column. These posterior vertebrae also had a positive linear relationship with TL $\left(\mathrm{r}^{2}=0.888, \mathrm{MCD}=0.01 * \mathrm{TL}-0.11, \mathrm{n}=18\right.$;

Fig. 5) that did not significantly differ between sexes $(t=-0.06, d f=16, p=0.954)$. All eighteen were prepared for ageing using both techniques.

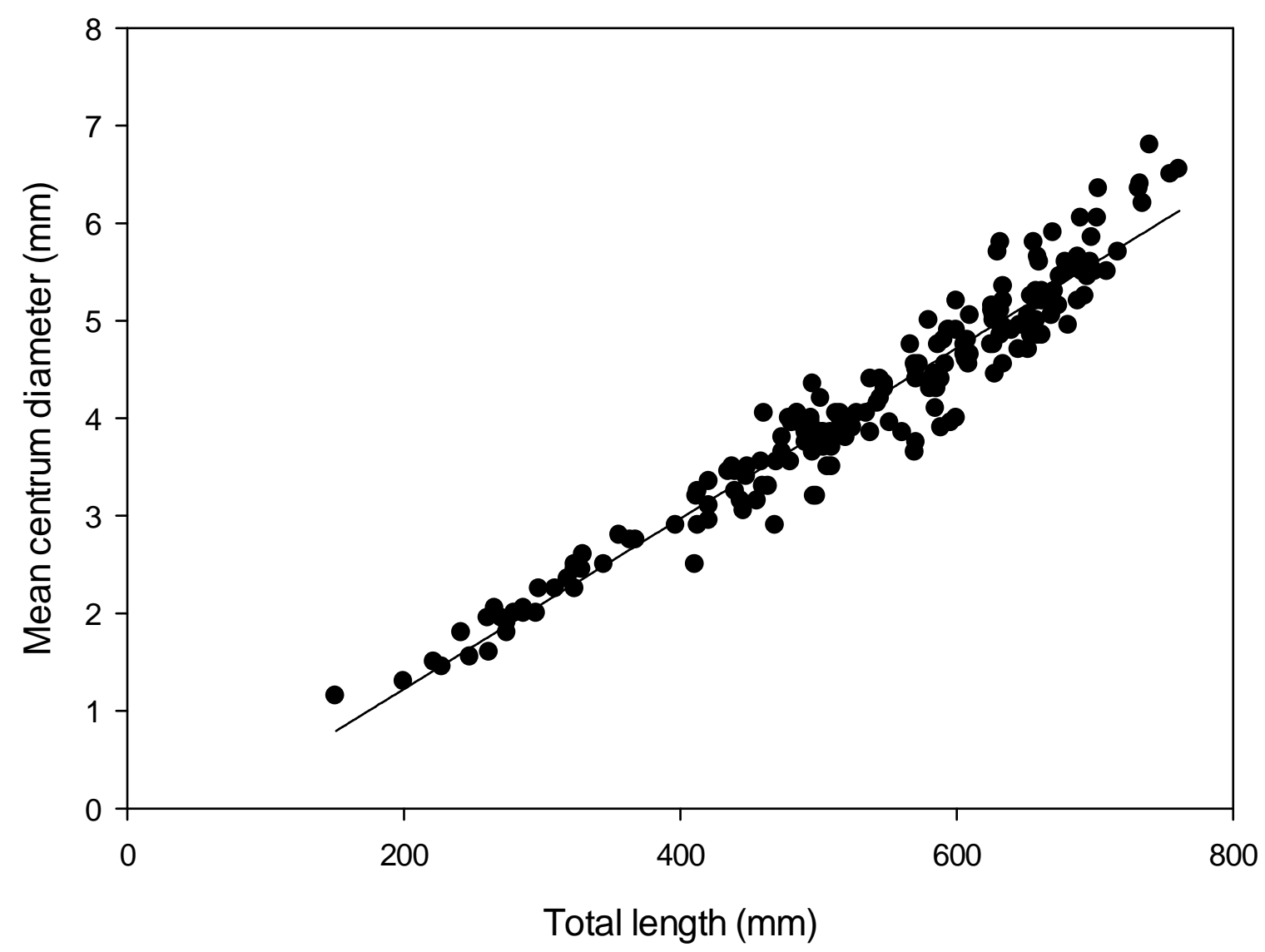

Figure 4. Linear relationship of mean centrum diameter and total length $\left(r^{2}=0.939\right.$, $\mathrm{MCD}=0.01 * \mathrm{TL}-0.53, \mathrm{n}=192$ ). 


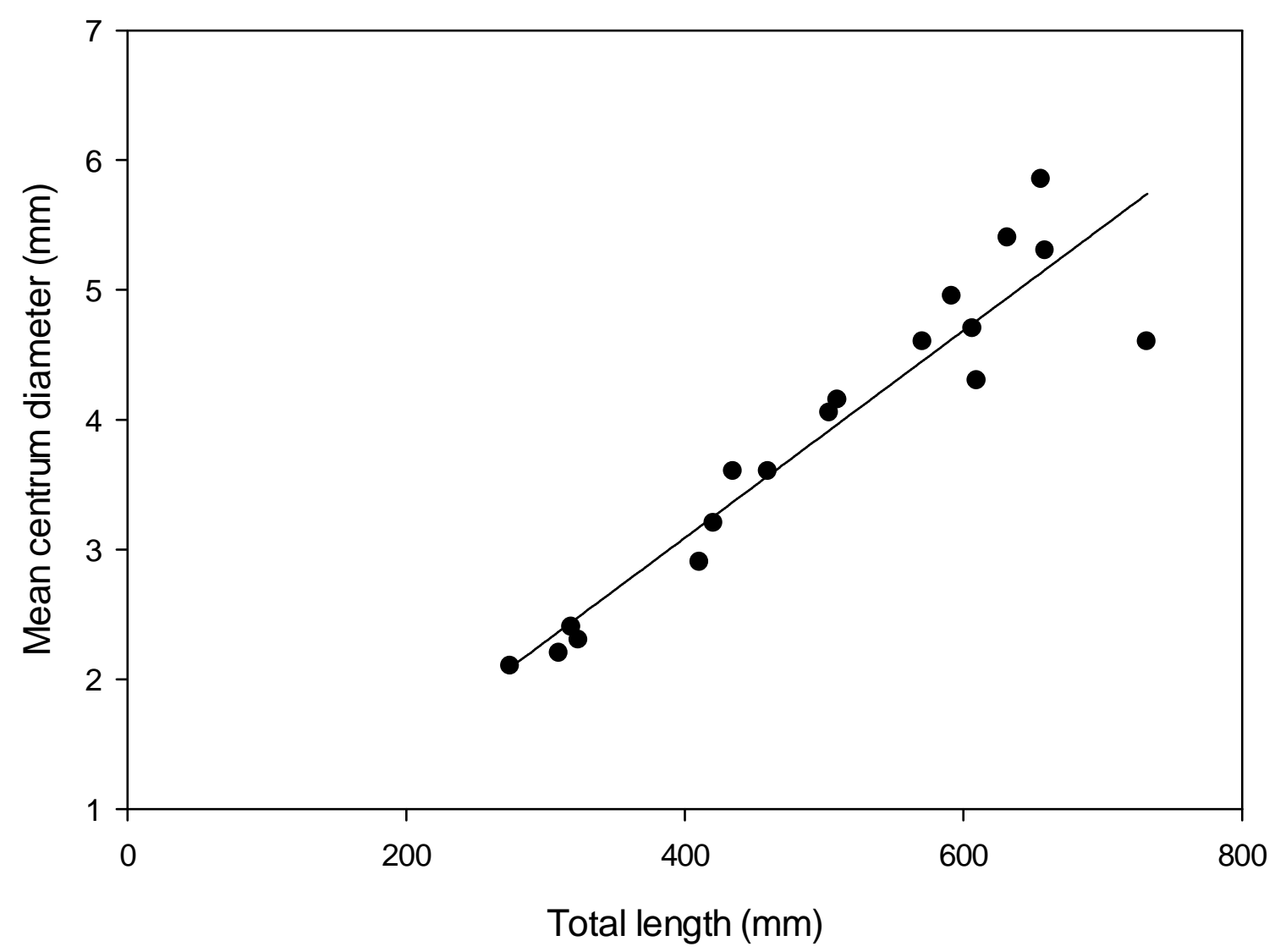

Figure 5. Linear relationship of mean centrum diameter of posterior samples and total length $\left(\mathrm{r}^{2}=0.888, \mathrm{MCD}=0.01 * \mathrm{TL}-0.11, \mathrm{n}=18\right)$.

\section{Caudal Thorns}

Caudal thorns were removed from 57 specimens and prepared for ageing. The measurement of the thorn base, anterior to posterior, had a weak positive linear relationship with $\mathrm{TL}\left(\mathrm{r}^{2}=0.631\right.$, Thorn length $=0.01 * \mathrm{TL}+1.11, \mathrm{n}=57$; Fig. 6$)$ that was not significantly different between sexes $(t=-0.74, d f=55, p=0.465)$. Upon examination no banding pattern was evident on the thorn surface of dried thorns (Fig. 7) 
or of thorns stained with $1.0 \%$ crystal violet solution; therefore, no age estimates were conducted with caudal thorns.

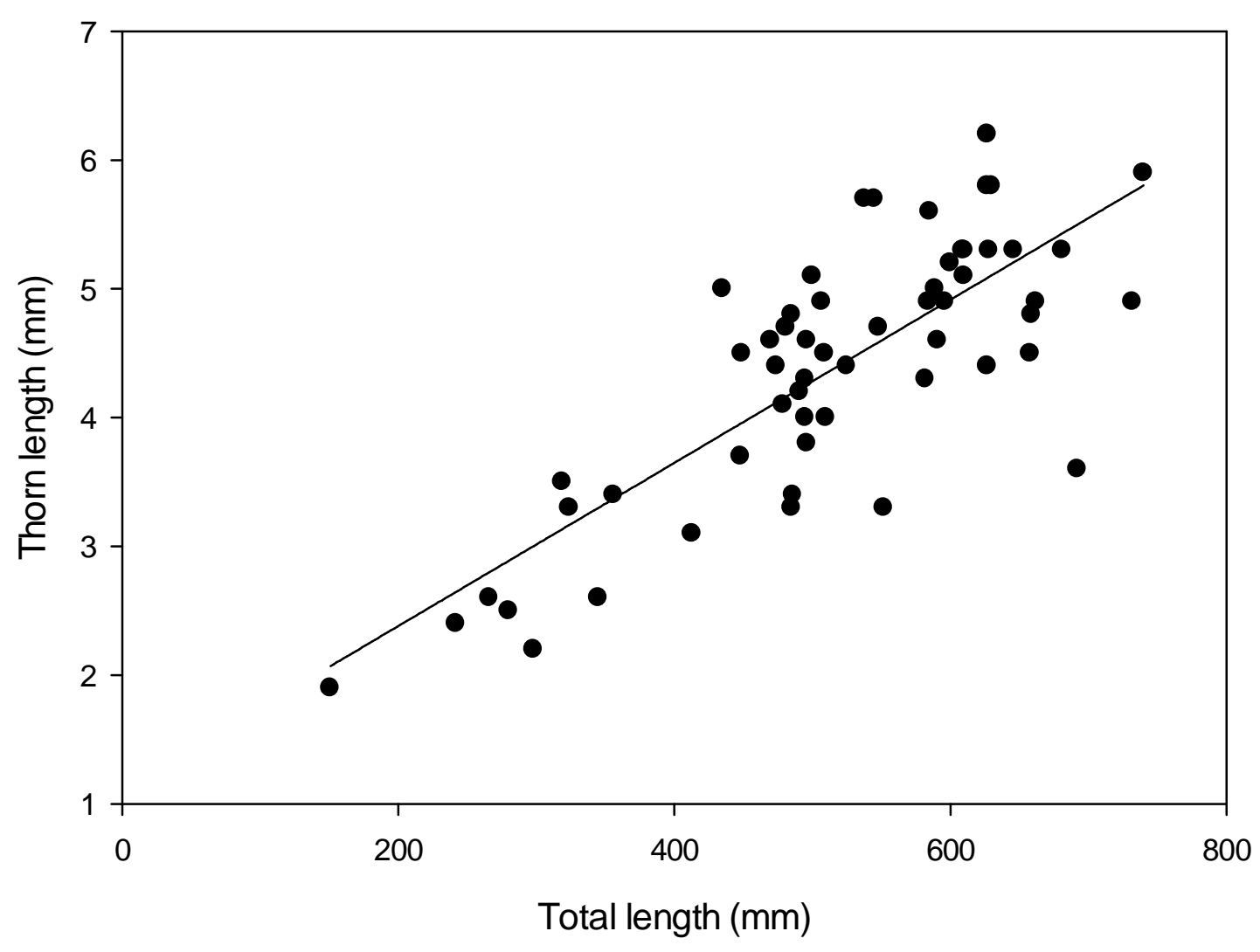

Figure 6. Linear relationship of thorn base and total length $\left(r^{2}=0.631\right.$, Thorn length $=$ $0.01 * \mathrm{TL}+1.11, \mathrm{n}=57$ ). 


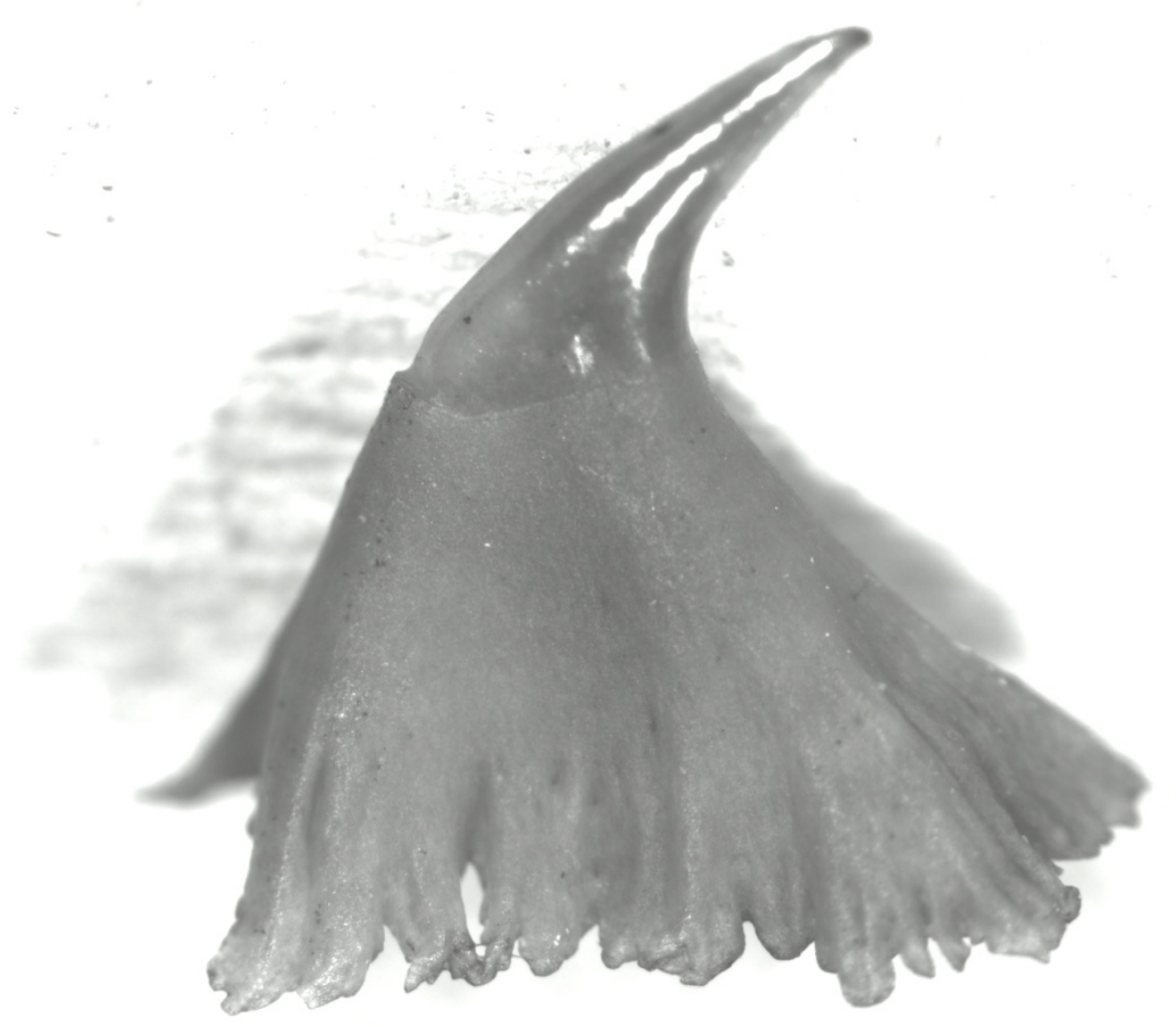

Figure 7. Caudal thorn of $R$. stellulata lacking surface bands.

\section{Ageing, Precision and Bias}

Four $(2.1 \%)$ gross sectioned vertebrae were deemed unreadable and were excluded from further analysis. Age estimates were made for 189 individuals. Final age estimates were assigned from read 3 or in a few cases $(n=22)$ read 4 . Precision between read 2, read 3 and read 4 was good $(\mathrm{IAPE}=5.74 \%, \mathrm{CV}=8.03 \%, \mathrm{D}=5.38 \%)$. Percent agreement also was great, with $47.6 \%$ of age estimates agreeing \pm 0 years, $92.0 \%$ agreeing \pm 1 year, and $100 \%$ agreeing within \pm 2 years. Percent agreement by TL was great, with $100 \%$ agreement of ages estimates for individuals less than $200 \mathrm{~mm}$ TL (Table 1a). Age estimates for individuals larger than $200 \mathrm{~mm}$ TL agreed by at least 
$88.7 \% \pm 1$ year and $100 \% \pm 2$ years. An age bias plot indicated no bias between read 2 and the mean of read 3 age estimates (Fig. 8). The Bowker's, Evans-Hoenig, and McNemar's $\chi^{2}$ tests of symmetry detected no bias between read 2 and read 3 (Bowker's: $\chi^{2}=26.6, \mathrm{df}=20, \mathrm{p}=0.150 ;$ Evans-Hoenig: $\chi^{2}=4.38, \mathrm{df}=2, \mathrm{p}=0.112 ;$ McNemar's: $\chi^{2}$ $=1.71, \mathrm{df}=1, \mathrm{p}=0.191)$.

Table 1. Percent agreement (PA) by TL. a) gross sections $(n=189)$ and b) histological sections $(\mathrm{n}=68)$ at $100 \mathrm{~mm}$ intervals for ages of $R$. stellulata.

a)

\begin{tabular}{ccccc}
\hline Length $(\mathbf{m m})$ & Total Read & PA $\pm \mathbf{0}$ & $\mathbf{P A} \pm \mathbf{1}$ & $\mathbf{P A} \pm \mathbf{2}$ \\
\hline $0-199$ & 1 & 100.00 & & \\
$200-299$ & 16 & 50.00 & 93.75 & 100.00 \\
$300-399$ & 12 & 58.33 & 91.67 & 100.00 \\
$400-499$ & 41 & 51.22 & 90.25 & 100.00 \\
$500-599$ & 46 & 43.48 & 97.83 & 100.00 \\
$600-699$ & 62 & 43.55 & 88.71 & 100.00 \\
$700-799$ & 11 & 54.55 & 90.91 & 100.00 \\
\hline
\end{tabular}

b)

\begin{tabular}{cccccc}
\hline Length $(\mathbf{m m})$ & Total Read & $\mathbf{P A} \pm \mathbf{0}$ & $\mathbf{P A} \pm \mathbf{1}$ & $\mathbf{P A} \pm \mathbf{2}$ & $\mathbf{P A} \pm \mathbf{3}$ \\
\hline $0-199$ & 1 & 100.00 & & & \\
$200-299$ & 3 & 33.33 & 100.00 & & \\
$300-399$ & 7 & 28.57 & 71.43 & 100.00 & \\
$400-499$ & 13 & 46.15 & 76.92 & 92.31 & 100.00 \\
$500-599$ & 22 & 31.82 & 72.73 & 90.91 & 100.00 \\
$600-699$ & 15 & 20.00 & 53.33 & 73.33 & 100.00 \\
$700-799$ & 7 & 71.43 & 100.00 & & \\
\hline
\end{tabular}




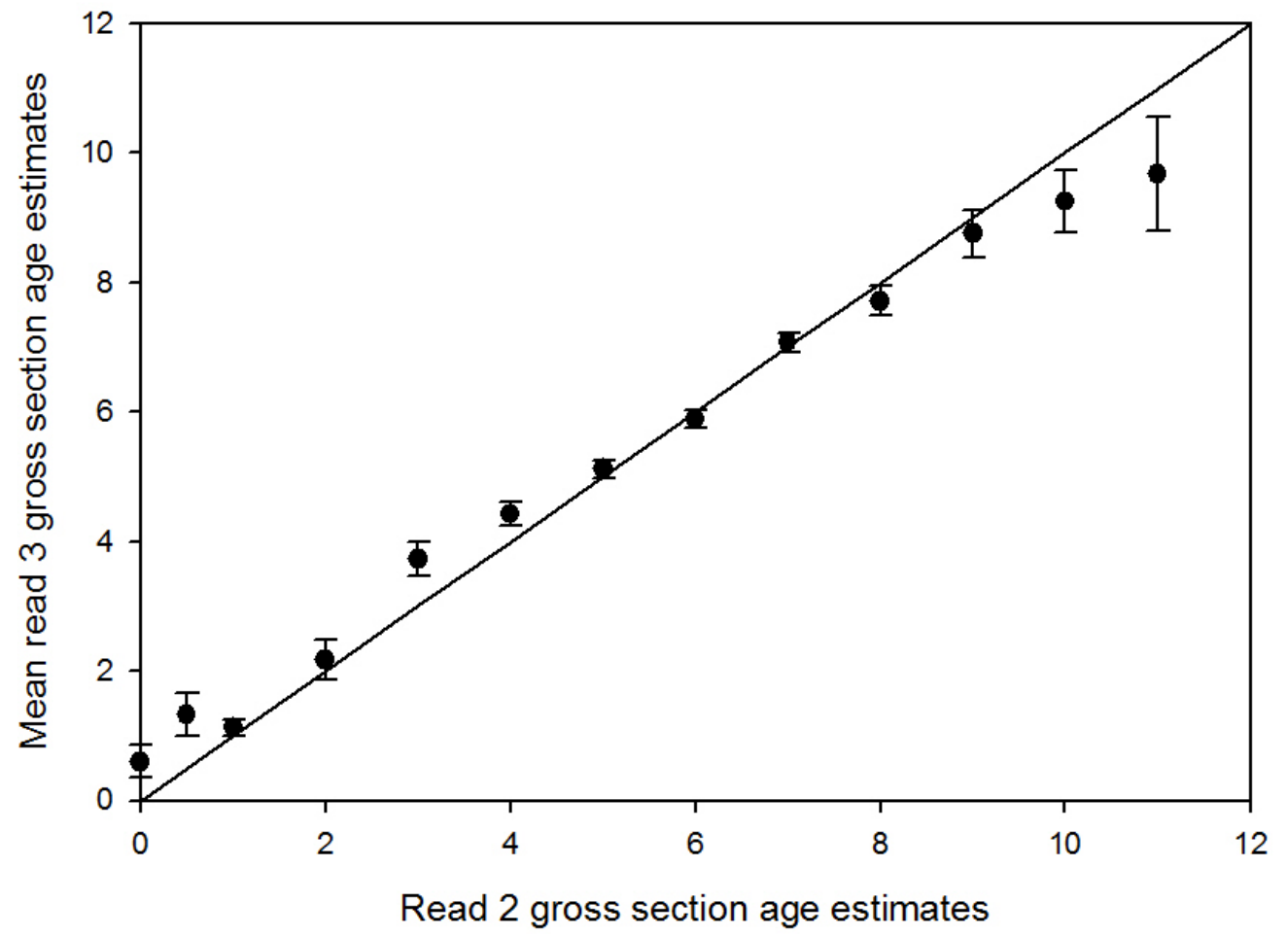

Figure 8. Age bias plot of read 2 age estimates versus mean read 3 age estimates of gross sections $(n=189)$. Error bars represent one standard error. 
One $(5.6 \%)$ of the eighteen posterior vertebrae was deemed unreadable and excluded from further analysis. Seventeen posterior sections were aged to compare against anterior sections. An age bias plot revealed no bias in age estimates between vertebral column locations (Fig. 9). All three $\chi^{2}$ tests of symmetry detected no bias between anterior and posterior ages (Bowker's: $\chi^{2}=10.3, \mathrm{df}=9, \mathrm{p}=0.320$; EvansHoenig: $\chi^{2}=0.29$, df $=1, p=0.257$; McNemar's: $\chi^{2}=0.60, \mathrm{df}=1, \mathrm{p}=0.439$ ). This indicated that $R$. stellulata deposits calcified material in a uniform way throughout the vertebral column. Anterior sections were used to produce age estimates for this species due to their larger size.

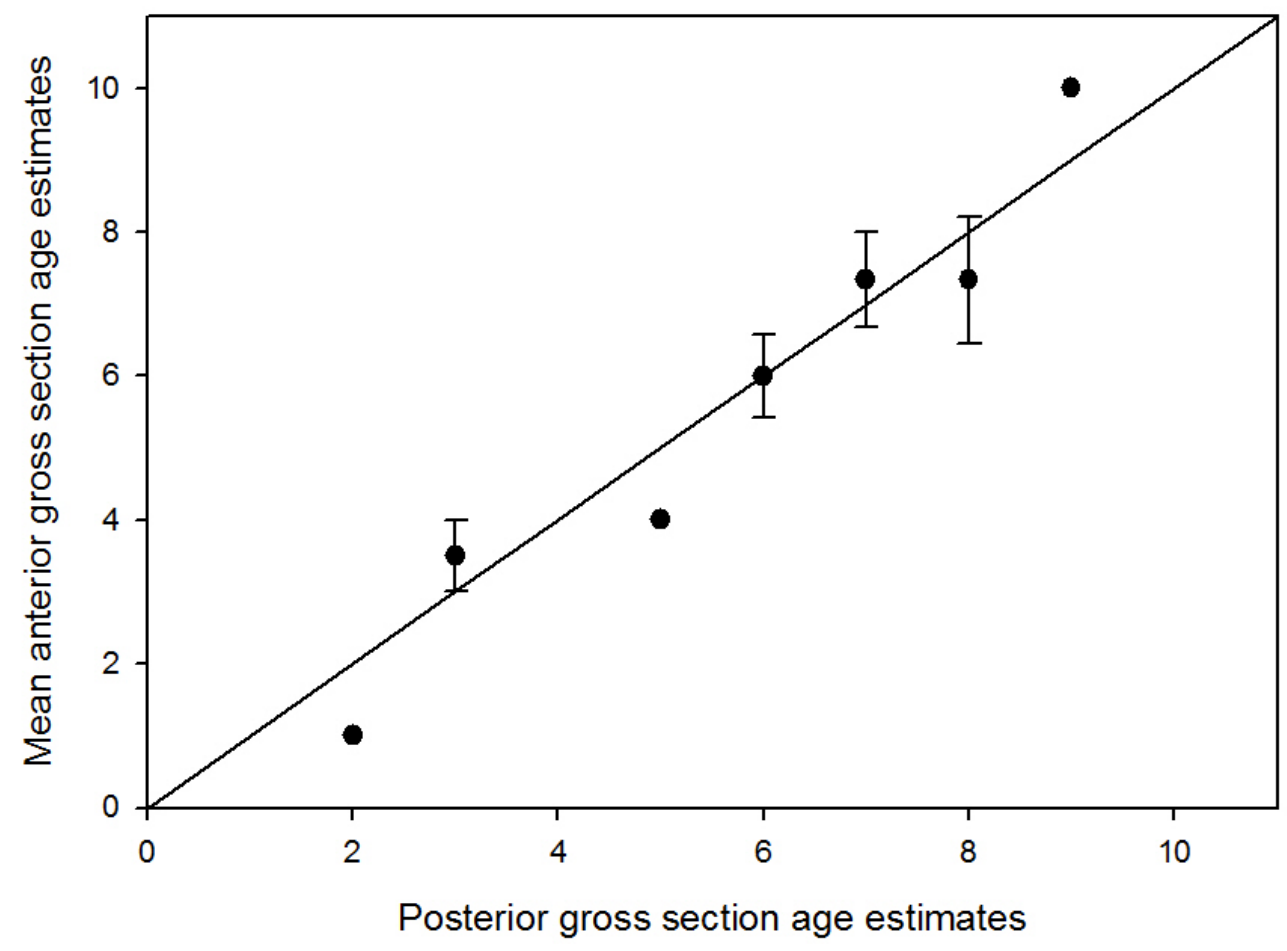

Figure 9. Ages bias plot of posterior age estimates versus mean anterior age estimates of gross sections $(\mathrm{n}=17)$. Error bars represent one standard error. 
A second reader aged a subsample $(n=51)$ of gross sectioned anterior vertebrae. Precision between readers was deemed acceptable $(\mathrm{IAPE}=7.61 \%, \mathrm{CV}=10.76 \%, \mathrm{D}=$ $7.61 \%$ ), as was percent agreement with $33.3 \%$ agreeing \pm 0 years, $77.1 \%$ agreeing \pm 1 years, $97.9 \%$ agreeing \pm 2 years, and all ages agreeing \pm 3 years. An age bias plot detected a slight bias, with reader one producing older age estimates from ages five to ten (Fig. 10). The Bowker's $\chi^{2}$ test of symmetry did not detect any bias between readers $\left(\chi^{2}=\right.$ 15.9, $\mathrm{df}=12, \mathrm{p}=0.200)$, however, the Evans-Hoenig and McNemar's test did detect a bias for ages 4-6 (Evans-Hoenig: $\chi^{2}=12, \mathrm{df}=2 . \mathrm{p}=0.002$; McNemar's: $\chi^{2}=10.71, \mathrm{df}=$ $1, p=0.001)$, where reader one assigned older ages than reader two. Age estimates of reader one were used despite the slight bias between readers.

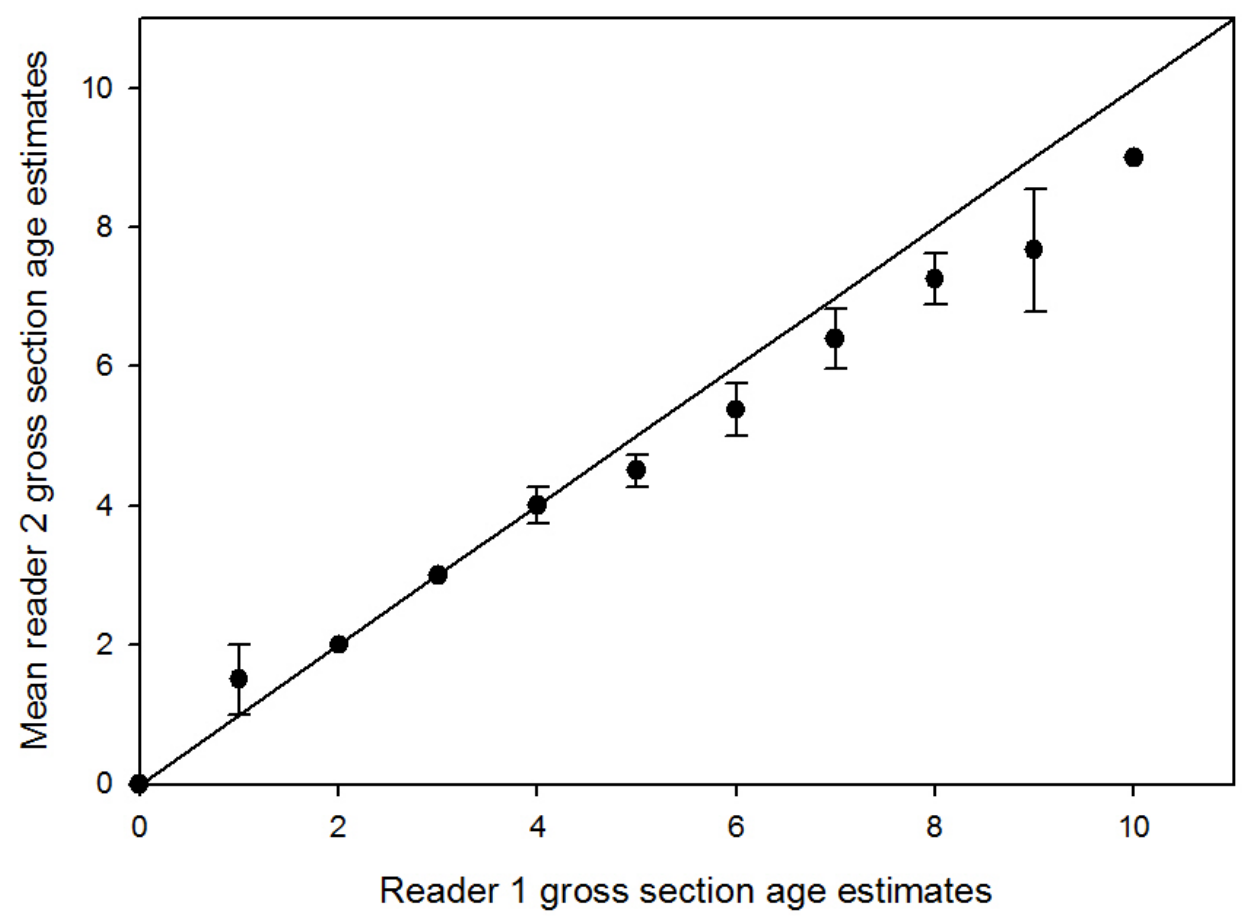

Figure 10. Age bias plot of reader one's age estimates versus mean reader two age estimates of gross sections $(n=51)$. Error bars represent one standard error. 
Three (4.2\%) histologically sectioned vertebrae were deemed unreadable and were excluded from further analysis. Age estimates were determined for 68 vertebrae. Precision between reads was high $(\mathrm{IAPE}=6.58 \%, \mathrm{CV}=9.01 \%, \mathrm{D}=5.78 \%)$ and percent agreement was deemed acceptable, with age estimated for $36.8 \%$ of samples agreeing within \pm 0 years, $70.6 \%$ within \pm 1 year, $89.7 \%$ within \pm 2 years, and $100 \%$ within \pm 3 years. Percent agreement by TL was great; age estimates for $100 \%$ of individuals less than $300 \mathrm{~mm}$ TL and greater than $700 \mathrm{~mm}$ TL agreed \pm 1 year (Table 1b). Age estimates for all other size classes agreed by at least $73.3 \%$ within \pm 2 years and $100 \%$ within \pm 3 years. An age bias plot indicated bias between ageing rounds of reader one, where ages from read 3 were greater than those of read 2 (Fig. 11). All three tests of symmetry detected the same bias (Bowker's: $\chi^{2}=41, \mathrm{df}=23, \mathrm{p}=0.01$; Evans-Hoenig: $\chi^{2}=32.57$, $\mathrm{df}=2, \mathrm{p}<0.001 ;$ McNemar's: $\left.\chi^{2}=31.87, \mathrm{df}=1, \mathrm{p}<0.001\right)$.

Four $(22.2 \%)$ histologically sectioned posterior vertebrae were deemed unreadable and were excluded from further analysis. Fourteen posterior sections were aged to compare with anterior sections. An age bias plot between histological sections of posterior and anterior centra did not observe a bias between age estimates from the two vertebral column locations; however, estimates for older age classes had more variability (Fig. 12). The three tests of symmetry did not detect a bias (Bowker's: $\chi^{2}=8, \mathrm{df}=10, \mathrm{p}$ $=0.630$; Evans-Hoenig: $\chi^{2}=1.2, \mathrm{df}=2, \mathrm{p}=0.549 ;$ McNemar's: $\chi^{2}=0, \mathrm{df}=1, \mathrm{p}=1.000$ ), which was the same result as between anterior and posterior sections prepared as gross sections. 


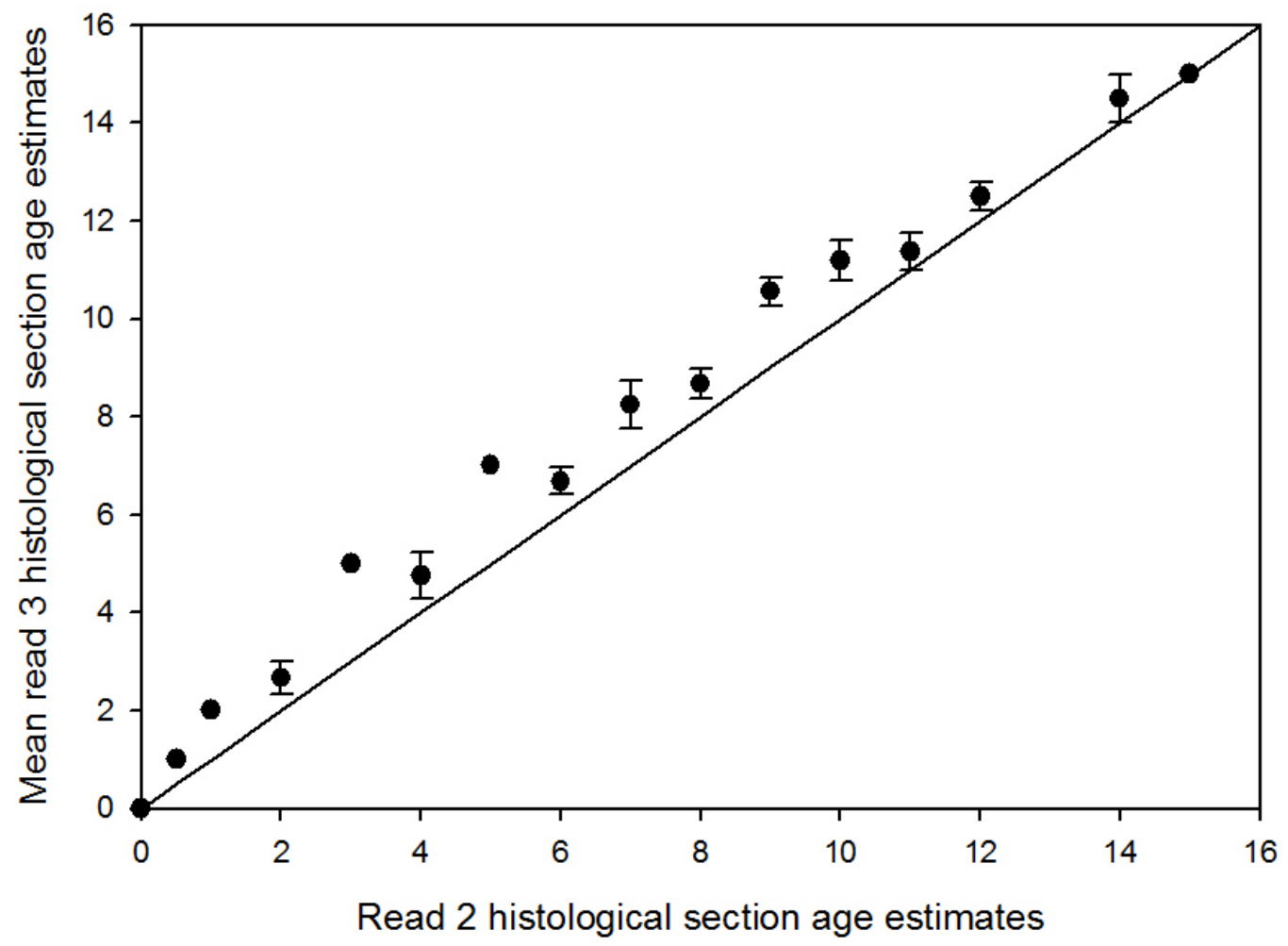

Figure 11. Age bias plot of read 2 age estimates versus mean read three age estimates of histological sections $(n=68)$. Error bars represent one standard error. 


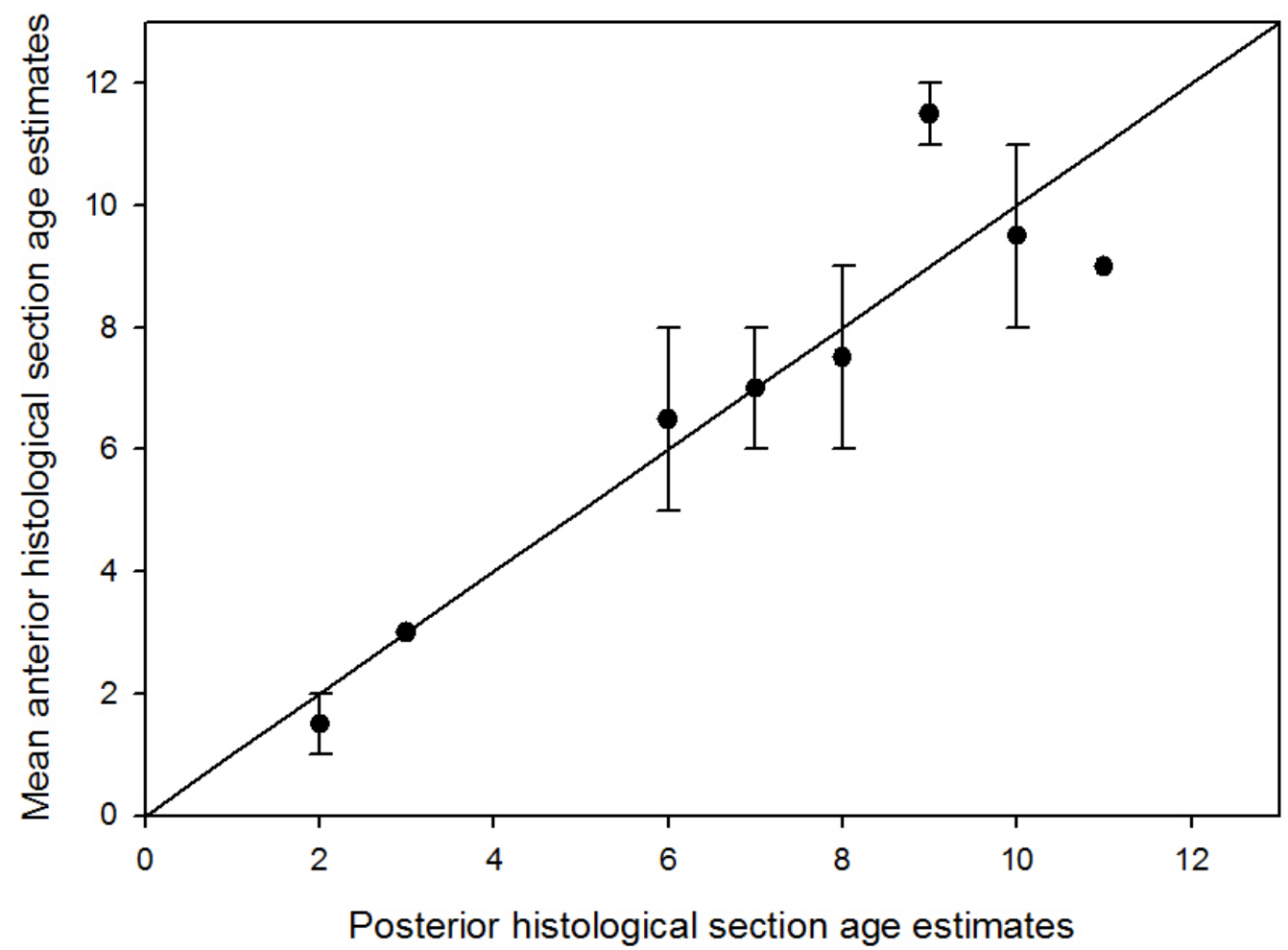

Figure 12. Age bias plot of posterior age estimates versus mean anterior age estimates of histological sections $(n=14)$. Error bars represent one standard error. 
Qualitatively, histological sections had a more visible banding pattern, but it was more difficult to discern whether a band extended completely across the corpus calcareum and intermedialia because the hematoxylin did not stain the corpus calcareum evenly. Faint bands were more distinct with the histological preparation technique, and more likely counted as a band rather than considered a check as with the gross sectioning technique. Some vertebrae prepared by the gross sectioning technique had a clear banding pattern. However, even for those individuals, more banding was apparent when processed using the histological technique (Fig. 13). Five individuals were given the same age estimate between preparation techniques, and one individual was assigned a lower age estimate based upon the histological technique. Five histological sections were assigned an age seven years older than the gross sections and another five were assigned an age six years older than the gross sections. An age bias plot comparing gross sections to histological sections $(n=68)$ indicated a strong bias, in which histological sections consistently produced older age estimates than gross sections (Fig. 14). This bias was detected by all three tests of symmetry (Bowker's: $\chi^{2}=58.3$, df $=36, p=0.01$; EvansHoenig: $\chi^{2}=57.67, \mathrm{df}=6, \mathrm{p}<0.001$ McNemar's: $\left.\chi^{2}=57.07, \mathrm{df}=1, \mathrm{p}<0.001\right)$. 


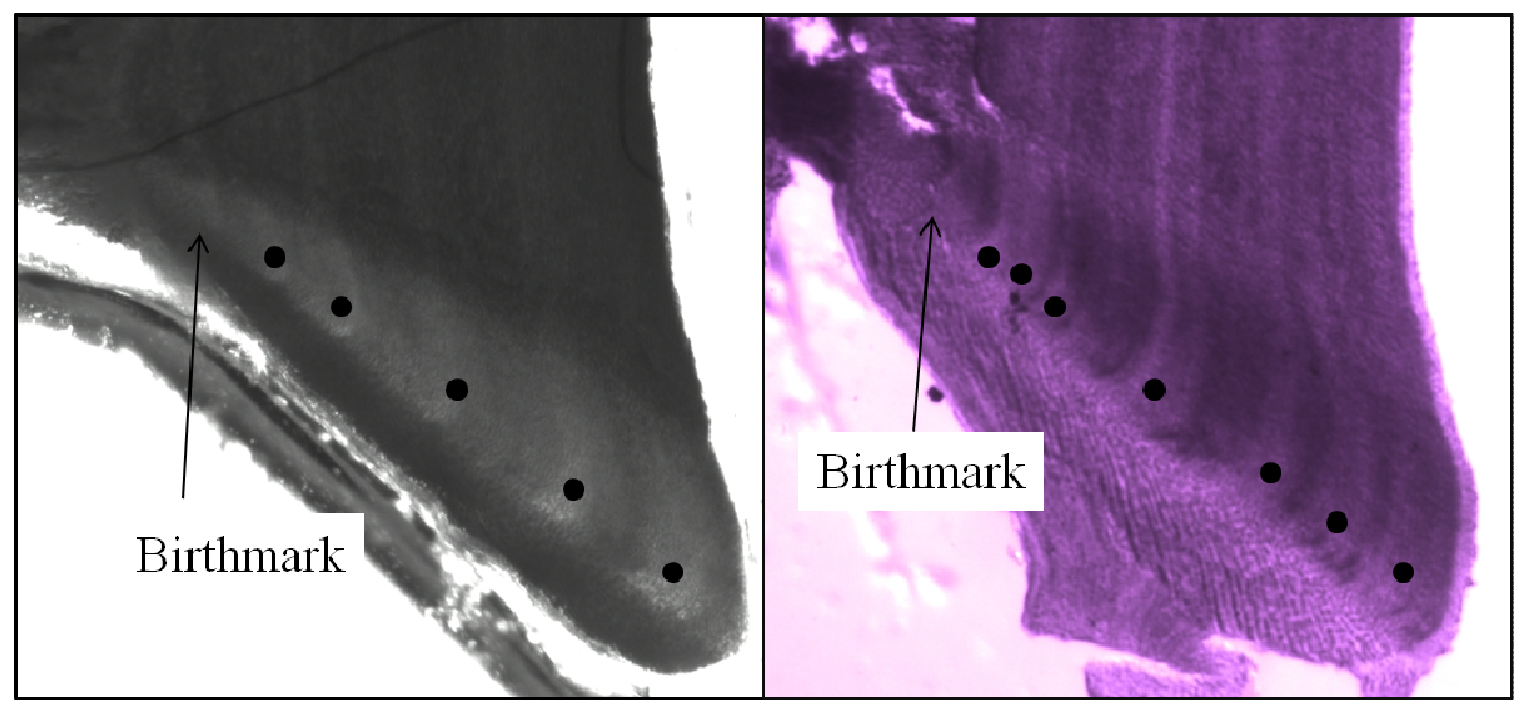

Figure 13. Comparison of gross section to histological section. Both centra are from the same $R$. stellulata individual. The gross section (on left) was estimated as five years old, whereas the histological section (on right) was estimated as seven years old. 


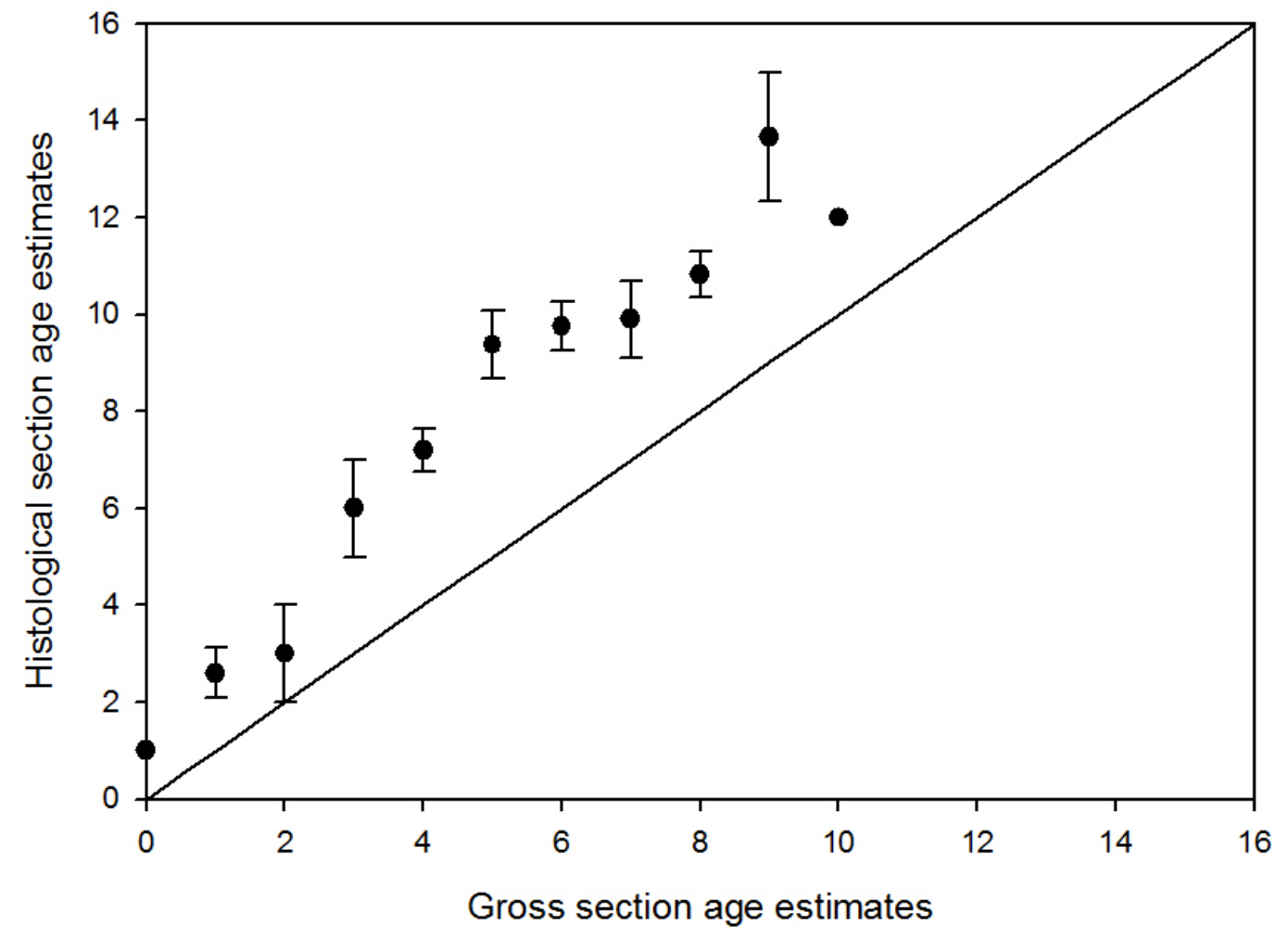

Figure 14. Age bias plot of gross section age estimates versus mean histological age estimates $(n=66)$. Error bars represent one standard error. 


\section{Indirect Validation}

Individuals age 0 or age 1 were excluded from indirect validation analyses. CEA of gross sections exhibited a clear pattern, in which a majority of the edge types were opaque from February to July and translucent from September to January (Fig. 15). A nonparametric Kruskal-Wallis test did detect a significant trend of proportion opaque edge type during twelve months $(\mathrm{K}=18.86, \mathrm{df}=10, \mathrm{p}=0.042, \mathrm{n}=119)$.

The MIR also displayed a semiannual pattern with values approaching one in July and August and values markedly less from October to January (Fig. 15). MIR values of gross sections were tested over months with a nonparametric Kruskal-Wallis test and a significant difference among months was detected $(K=18.74, \mathrm{df}=10, \mathrm{p}=0.044, \mathrm{n}=$ 172). Both indirect validation methods indicated semiannual banding pattern with opaque bands present mostly in spring and summer and translucent bands present on the centrum edge mostly in fall and early winter.

CEA and MIR also were performed for histological sections. A visual difference among months was detected for CEA with translucent bands dominating during fall, but no trend was detected for MIR. One-way ANOVAs of CEA and MIR for histological sections were not significantly different among months $(\mathrm{CEA}: \mathrm{F}=0.41$, $\mathrm{df}=7, \mathrm{p}=$ 0.708; MIR F = 0.63, df =7, p=0.889; Fig. 16). 


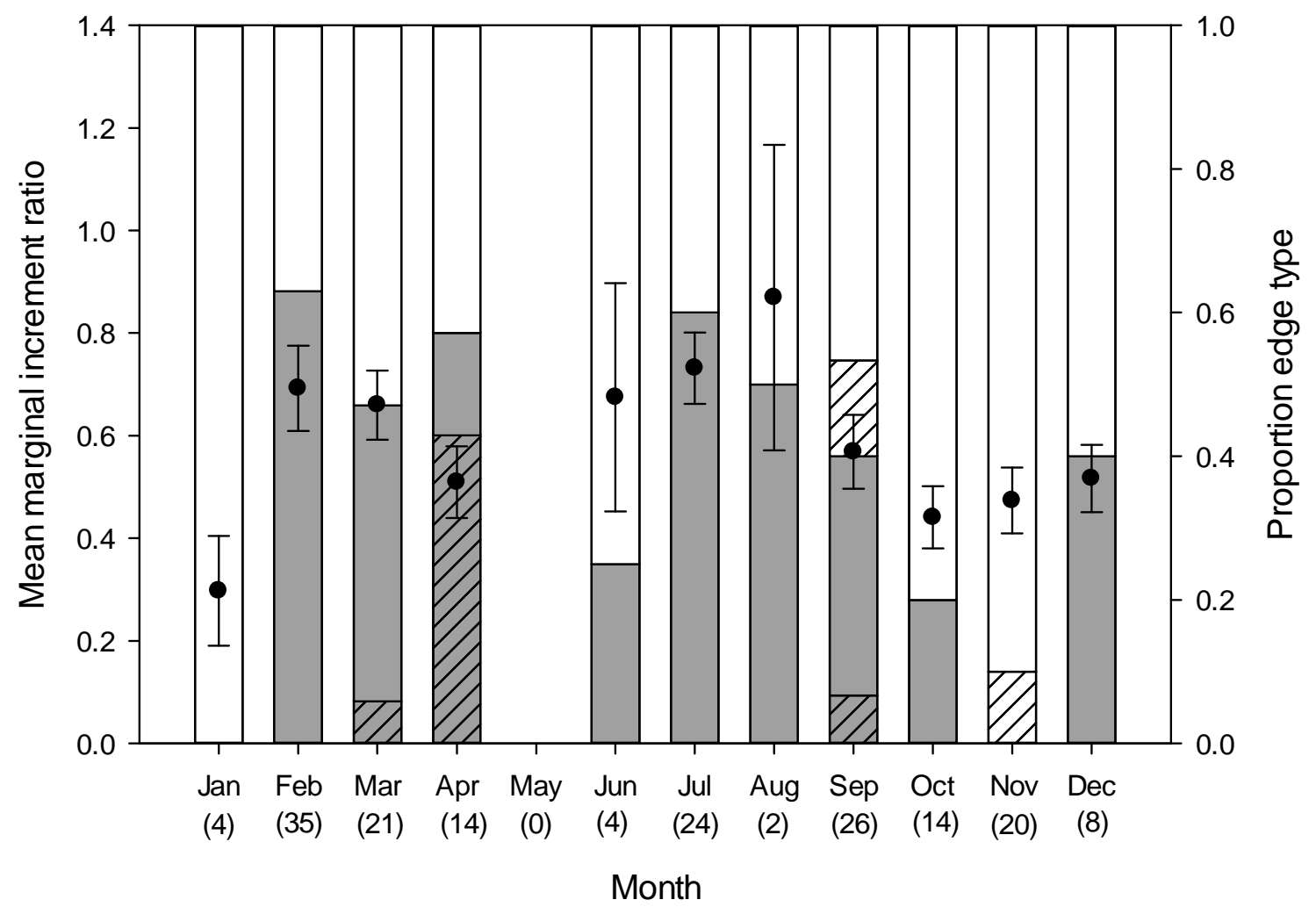

Figure 15. Monthly variation in mean marginal increment ratio and centrum edge type for gross sections. Sample sizes for MIR $(\mathrm{n}=172)$ are below each month in parentheses. Sample size for CEA is 119. Error bars represent one standard error. Hatched grey is a narrow opaque edge, solid grey is a broad opaque edge, hatched white is a narrow translucent edge and solid white is a broad translucent edge. 


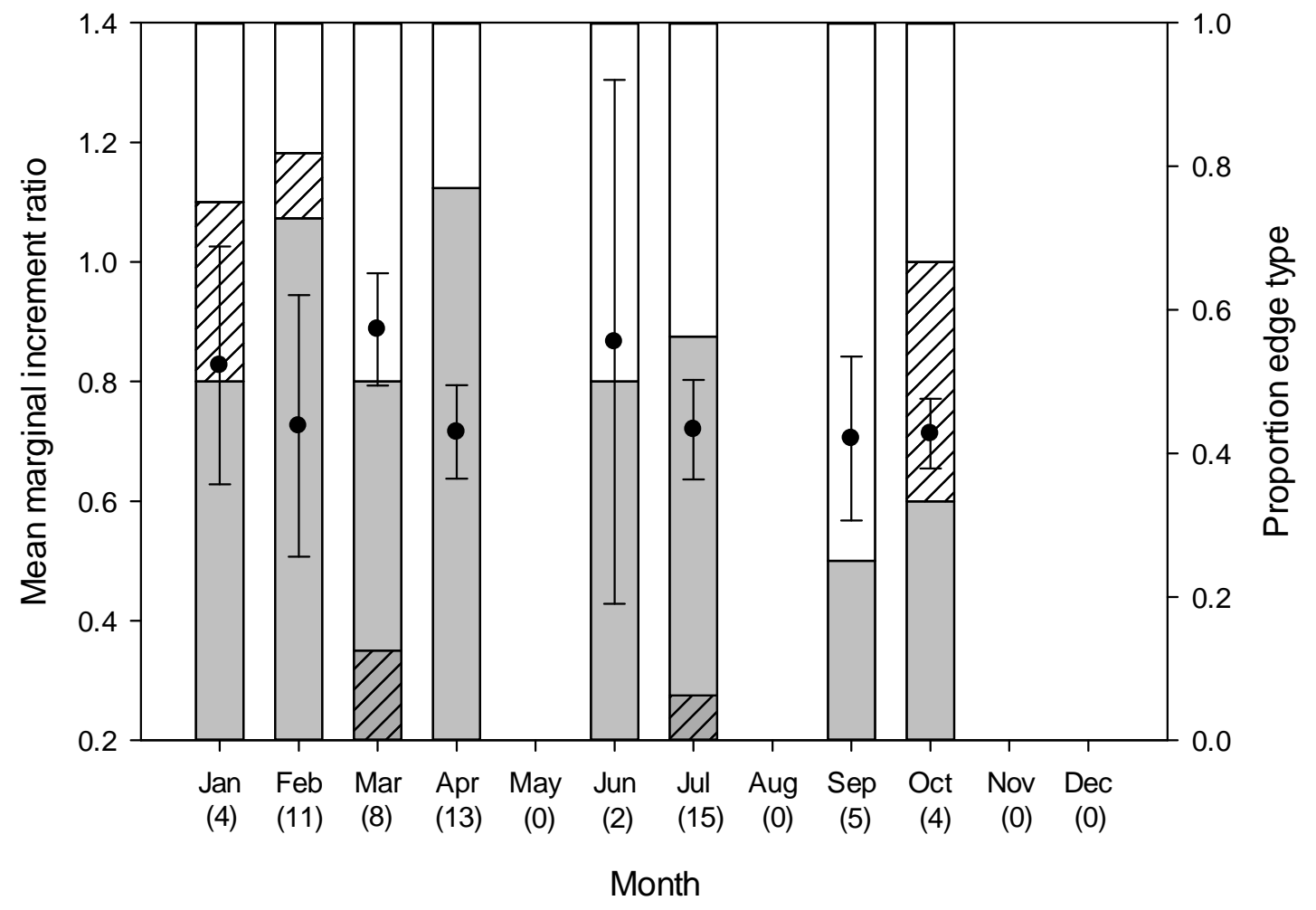

Figure 16. Monthly variation in mean marginal increment ratio and centrum edge type for histological sections. Sample sizes $(n=62)$ are below each month in parentheses. Error bars represent one standard error. Hatched grey is a narrow opaque edge, solid grey is a broad opaque edge, hatched white is a narrow translucent edge and solid white is a broad translucent edge. 


\section{Growth Modeling}

Age estimates of females using gross sections were 0 to 11 years $(n=99)$ and male age estimates were 0 to 10 years $(n=90)$. Age zero was assigned to a $151 \mathrm{~mm}$ TL female and a $222 \mathrm{~mm}$ TL male, indicating a birth size of 150-225 mm TL. The largest female, $761 \mathrm{~mm}$ TL, was estimated at 10 years old, whereas the oldest females (11 years old) were 733 and $702 \mathrm{~mm}$ TL. The largest male, $717 \mathrm{~mm}$, was 7 years old, whereas the oldest male (age estimate of 10) was $658 \mathrm{~mm}$ TL.

For gross sections, the two parameter von Bertalanffy growth function best described the growth of $R$. stellulata. Growth model parameters of all seven models for gross sections are presented in Table 2a. Likelihood ratio tests for six of the seven growth functions indicated no evidence of significant difference between sexes; therefore, sexes were pooled $(\mathrm{p}>0.182)$. The seventh growth function, the Gompertz, indicated that male and female growth were significantly different $(\mathrm{p}<0.001)$. All growth functions fit the data "well" or "reasonably well" using $\mathrm{AIC}_{\mathrm{c}}$ values, except the Schnute Case 4 (Table 3a; Fig. 17). The 2 VBGF was chosen as the best model based on $\mathrm{AIC}_{\mathrm{c}}$ value, biological relevance, and comparability. The $2 \mathrm{VBGF}$ parameters were $\mathrm{L}_{\infty}=$ $865 \mathrm{~mm}$ TL, and $\mathrm{k}=0.15$. 


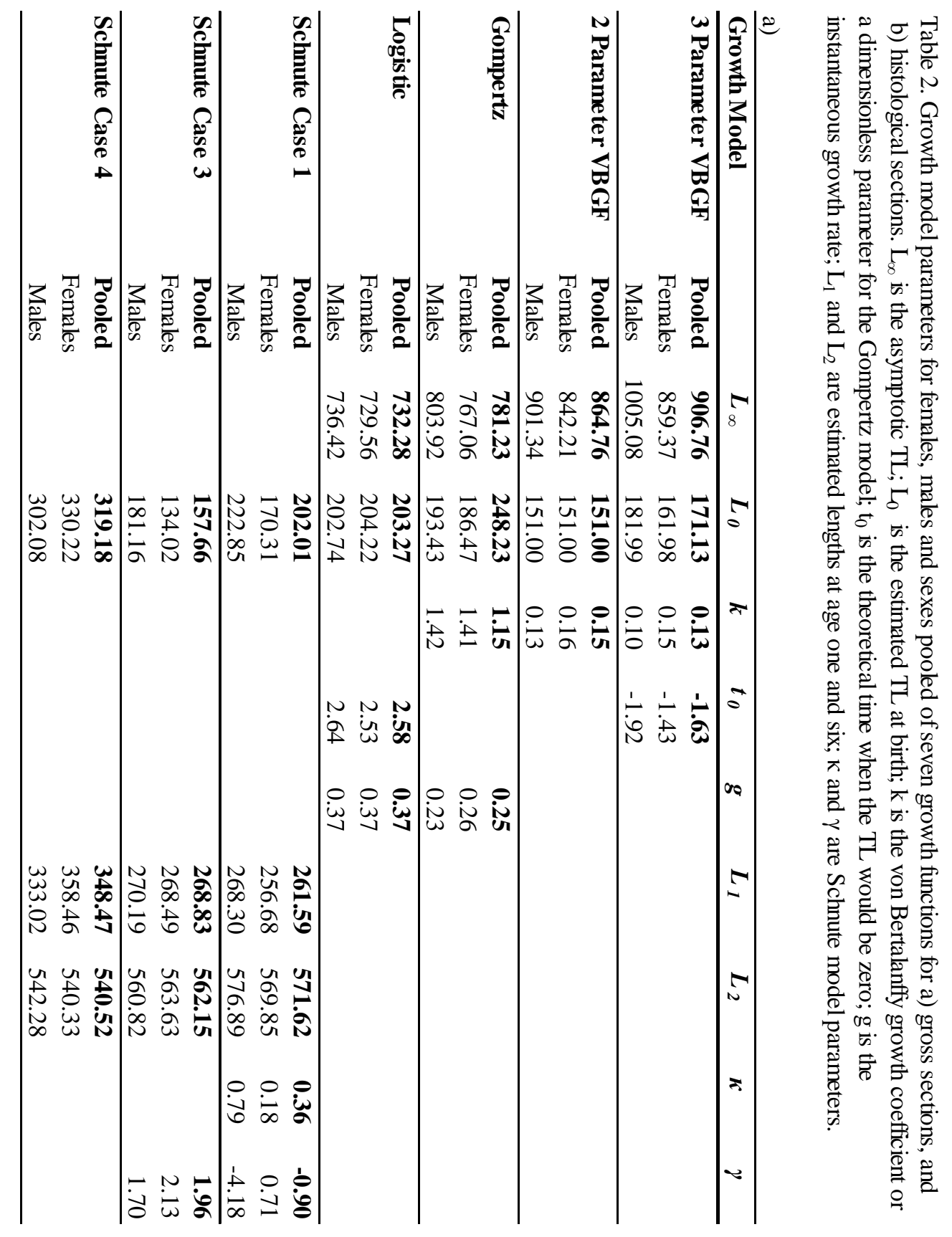




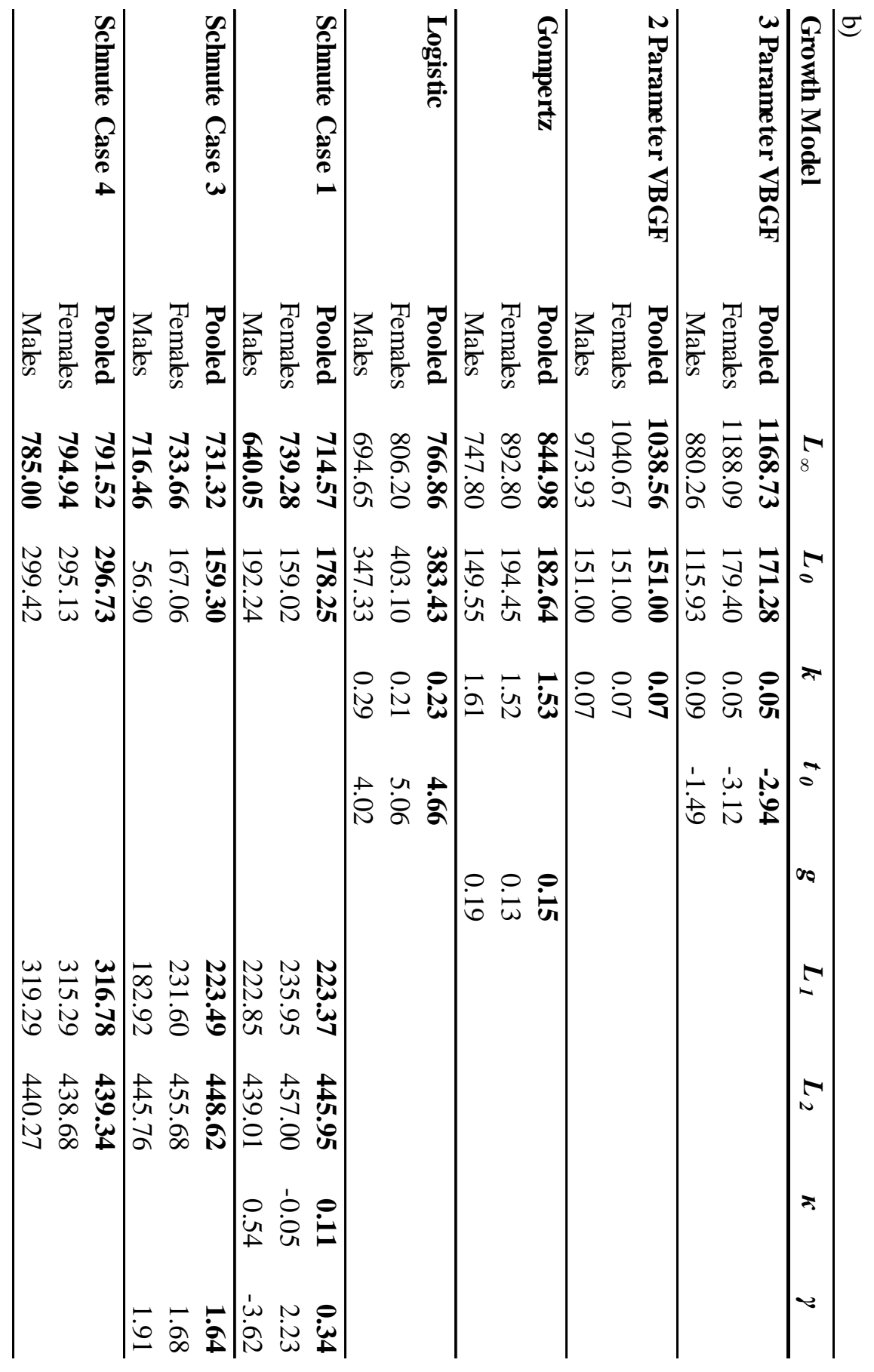


Table 3. Goodness-of-fit table for each of the seven growth models. a) gross sections and b) histological sections. Models are ordered from best to worst fit according to $\mathrm{AIC}_{\mathrm{c}} . k$ is the number of model parameters; $A I C_{c}$ is the small-sample, bias corrected form of the Akaike's information criterion; $\Delta_{i}$ is the Akaike difference; $S E E$ is the standard error estimate.

a)

\begin{tabular}{lccccc}
\hline Growth Model & $\boldsymbol{k}$ & $\mathbf{a d j} \boldsymbol{r}^{2}$ & $\boldsymbol{A} \boldsymbol{I} \boldsymbol{C}_{\boldsymbol{c}}$ & $\boldsymbol{\Delta}_{\boldsymbol{i}}$ & $\boldsymbol{S E \boldsymbol { E }}$ \\
\hline 2 VBGF & 3 & 0.787 & 682.76 & 0.00 & 61.99 \\
Logistic & 4 & 0.789 & 683.43 & 0.67 & 61.62 \\
3 VBGF & 4 & 0.786 & 684.47 & 1.71 & 62.01 \\
Schnute Case 1 & 5 & 0.788 & 685.54 & 2.77 & 61.79 \\
Schnute Case 3 & 4 & 0.782 & 686.22 & 3.47 & 62.68 \\
Schnute Case 4 & 3 & 0.704 & 709.66 & 26.95 & 72.99 \\
Gompertz & 4 & 0.789 & 712.36 & 29.61 & 61.70 \\
\hline
\end{tabular}

b)

\begin{tabular}{lccccc}
\hline Growth Model & $\boldsymbol{k}$ & $\mathbf{a d j} \boldsymbol{r}^{\mathbf{2}}$ & $\boldsymbol{A} \boldsymbol{I C}_{\boldsymbol{c}}$ & $\boldsymbol{\Delta}_{\boldsymbol{i}}$ & $\boldsymbol{S E \boldsymbol { E }}$ \\
\hline 2 VBGF & 3 & 0.806 & 244.07 & 0.00 & 57.61 \\
Gompertz & 4 & 0.804 & 246.19 & 2.12 & 57.91 \\
3 VBGF & 4 & 0.804 & 246.24 & 2.18 & 57.97 \\
Logistic & 4 & 0.803 & 246.35 & 2.28 & 58.08 \\
Schnute Case 3 & 4 & 0.803 & 246.41 & 2.34 & 58.13 \\
Schnute Case 1 & 5 & 0.801 & 248.51 & 4.44 & 58.35 \\
Schnute Case 4 & 4 & 0.750 & 251.62 & 7.55 & 65.47 \\
\hline
\end{tabular}




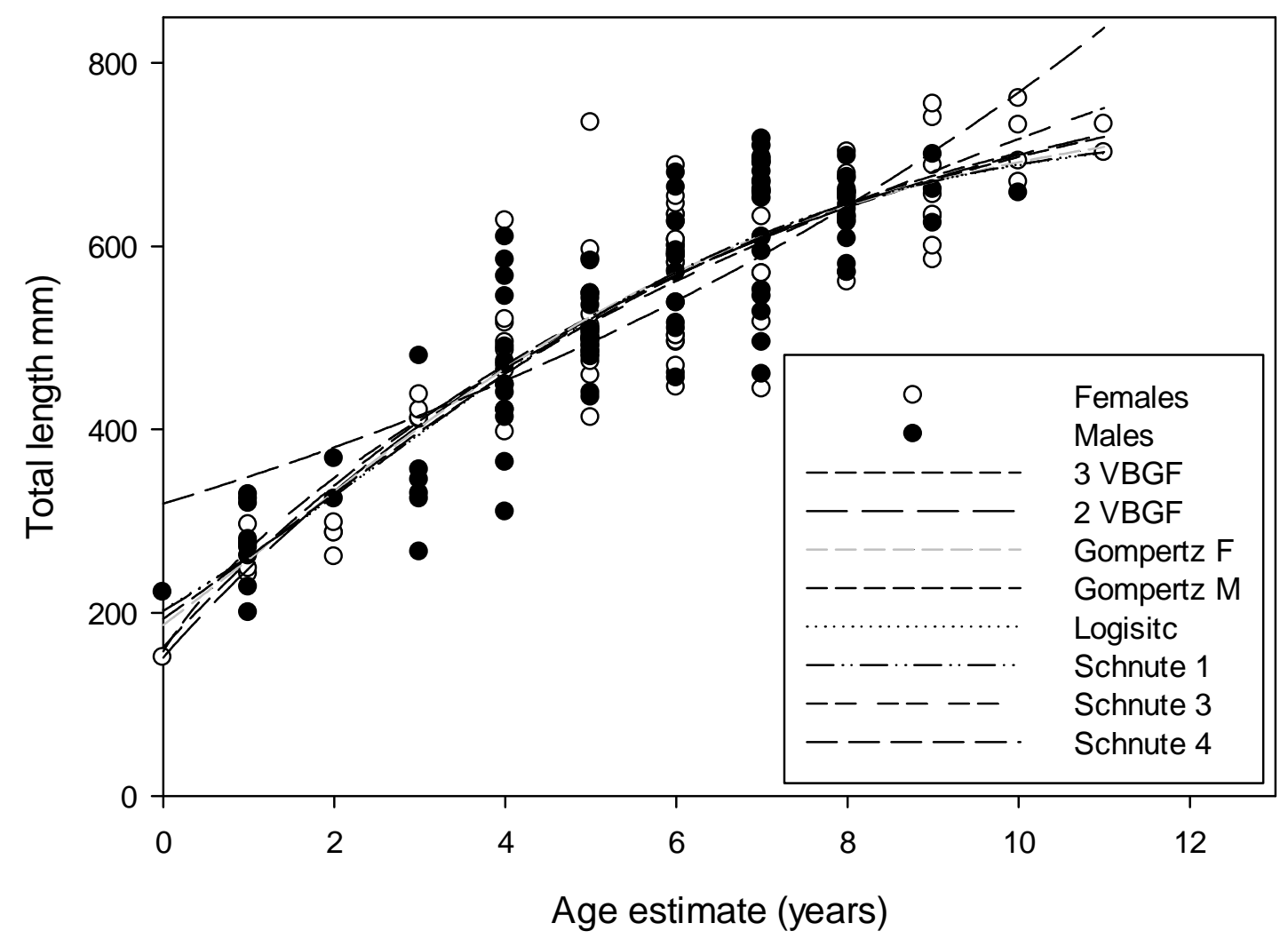

Figure 17. Seven growth curves fit to gross section data of $R$. stellulata $(\mathrm{n}=189)$. Sexes were combined for six of the seven functions. Light grey and black short dash lines represent the Gompertz growth function for females and males respectively. 
Age estimates of females using histological sections were 0 to 15 years $(n=34)$ whereas males were 2 to 14 years $(n=34)$. Age zero was assigned to a $151 \mathrm{~mm}$ TL female, supporting the estimated birth size of 150-225 mm TL. The largest female with a histological sample was $755 \mathrm{~mm}$ TL and 15 years old, as was the second largest female, which measured $740 \mathrm{~mm}$ TL. The youngest male was 2 years and $319 \mathrm{~mm}$ TL, whereas the smallest male was $271 \mathrm{~mm}$ TL and 3 years of age. The largest male using the histological technique was $717 \mathrm{~mm}$ TL and 12 years old, whereas the oldest male, estimated at 14 years, was the second largest male at $709 \mathrm{~mm}$ TL.

For histological sections, the Gompertz growth function best described the growth of $R$. stellulata (Table 2b). Likelihood ratio tests indicated that all growth functions used did not provide evidence of significant differences between sexes. Therefore, the data were pooled ( $\mathrm{p} \geq 0.539$; Table $2 \mathrm{~b}$ ). All models applied fit the data well, except Schnute Case 1 and Schnute Case 4 (Table 3b; Fig. 18). The model with the smallest AIC value (244.067; $\left.\Delta_{\mathrm{i}}=0.000\right)$ was the $2 \mathrm{VBGF}$ (Table $3 \mathrm{~b}$ ); however the $L_{\infty}$ was much greater (a difference of $278 \mathrm{~mm}$ ) than the observed maximum TL. The model with the second smallest AIC value $\left(246.19 ; \Delta_{\mathrm{i}}=2.12\right)$ was the Gompertz model, which had a biologically relevant $L_{\infty}$ of $845 \mathrm{~mm}$ TL. Therefore, based on $\mathrm{AIC}_{\mathrm{c}}$ values and biological relevance, the Gompertz model was chosen as the best model. However, five of the seven growth functions were deemed acceptable with $\mathrm{AIC}_{\mathrm{c}}$ values less than 4 (Table $3 \mathrm{~b}$ ). The Gompertz parameters were $\mathrm{L}_{\infty}=845 \mathrm{~mm}, \mathrm{~g}=0.15$, and $\mathrm{k}=1.53$. 


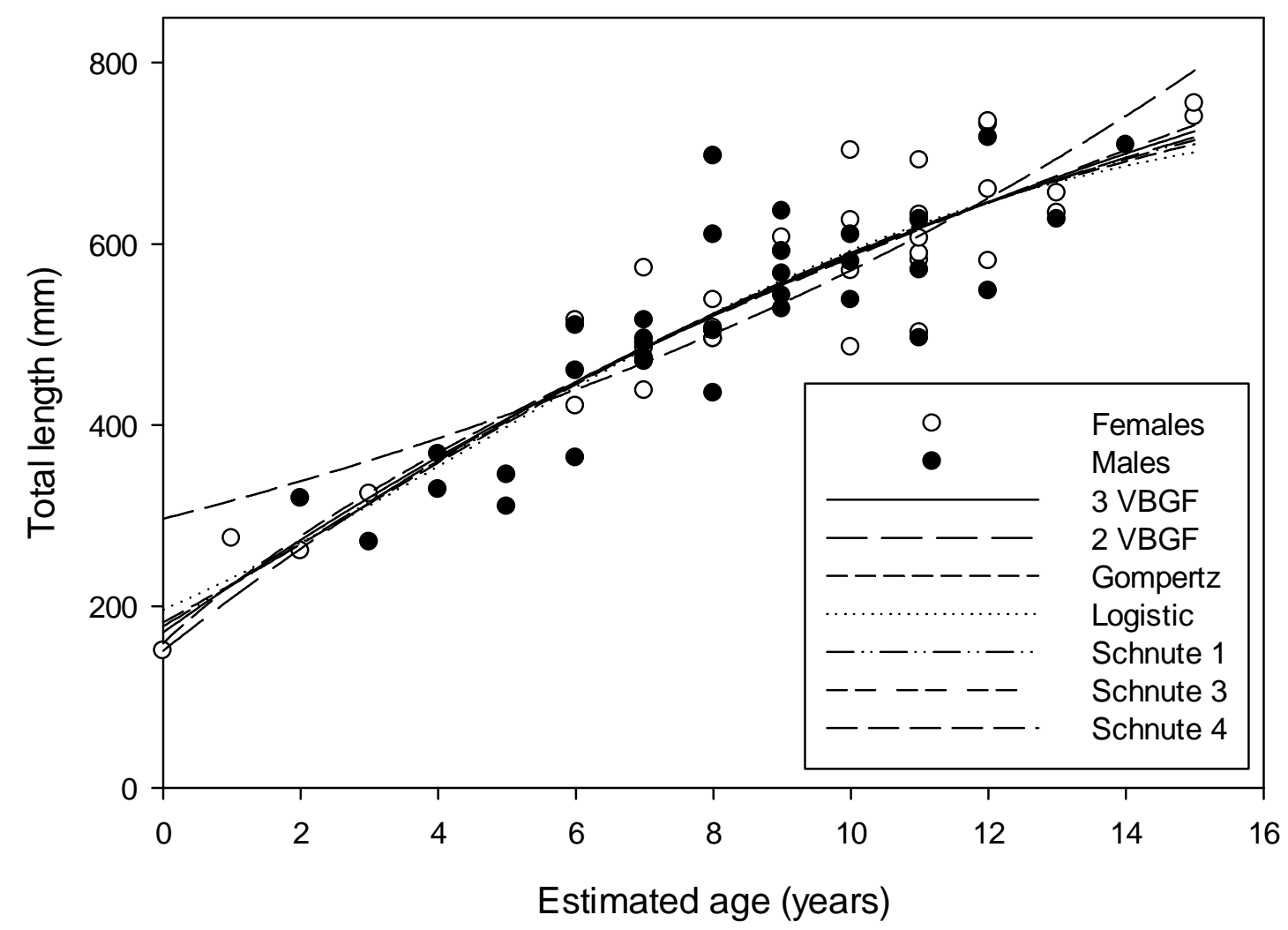

Figure 18. Seven growth curves fit to histological section data of $R$. stellulata $(\mathrm{n}=68)$. Sexes were combined for all functions. 


\section{Discussion}

The vertebrae of $R$. stellulata exhibited a clear banding pattern when processed with the gross sectioning technique, but by using the histological technique, the same individuals had up to seven additional band pairs than their gross section counterparts. Various methods of band enhancement have been used on chondrichthyan vertebrae to make ageing more accurate and precise. The gross sectioning technique requires basic sectioning equipment and is relatively inexpensive. Many skates, however, do not exhibit strong banding patterns and require band enhancement for improved readability (Licandeo et al. 2006, McFarlane and King 2006, Ainsley 2009, Winton 2011). The histological sectioning technique requires specialized equipment and chemicals and is more expensive and labor intensive than the gross sectioning technique. It has been shown, however, to greatly enhance the banding pattern of several skates, which in turn can improve accuracy and precision of age estimates (Natanson et al. 2007, Ainsley 2009, Maurer 2009, Winton 2011). The histological technique undoubtedly enhances the banding pattern revealing bands that might not be observed using the gross sectioning technique.

Caudal thorns have not been an appropriate ageing structure for several species of skate, including Bathyraja interrupta (Ainsley 2009), B. kincaidii (Perez et al. 2011), B. lindbergi, B. maculata, (Maurer 2009), B. minispinosa, B. taranetzi (Ebert et al. 2009), B. trachura (Davis et al. 2007, Winton 2011), and Raja clavata (Gallagher 2000, Gallagher et al. 2005). Furthermore, a complete lack of banding has been observed in Raja brachyura, R. montagui, and Leucoraja naevus (Gallagher 2000, Gallagher et al. 2005). 
The caudal thorns of $R$. stellulata do grow in proportion to TL like other skates, but do not express a banding pattern, making caudal thorns an inappropriate ageing structure. Gallagher (2000) suggested that the absence of ridge and trough banding may be due to the smoother transition between seasonal bands experienced by faster growing temperate skate species as compared with deeper, slower growing species. This may be the case, but more research into band deposition in caudal thorns is warranted to explain presence or absence of a banding pattern.

Precision and bias analyses confirm the consistency of the reader and assess the readability of the age structures. Gross sections had slightly greater precision (IAPE, CV and D) than histological sections and no detectable bias among reads, whereas read 3 of the histological sections were consistently assigned older ages than read 2. This suggested that the gross sections were easier to read. This may be due to inexperience with the histological process, in which the hematoxylin stain affects different species differently. Additionally, the sledge microtome tended to tear the vertebral sections. As a result, the histological sections often had uneven stain and additional marks that decreased precision and accuracy. Despite the reader's increased precision and reduced bias with the gross sections, the histological technique is an invaluable tool to assess poorly calcified structures such as skate vertebrae. In most cases, histological preparation has increased the precision and readability of skate vertebrae (Ainsley 2009, Maurer 2009, Winton 2011).

The periodicity of band pair deposition is a crucial component in determining the life history characteristics of a species. The seasonal trade-off between an opaque and a 
translucent band present on the distal edge of the corpus calcareum is a strong indicator that one band pair is deposited annually in R. stellulata (Fig. 15). The change in MIR over a year's period also supports one band pair deposited per year (Fig. 15). Both CEA and MIR were significantly different among months for gross sections (CEA $p=0.042$; MIR $p=0.044)$, which supports annual band pair deposition. Several skate species also deposit one band pair a year (Natanson 1993, Sulikowski et al. 2003, Sulikowski et al. 2005, Matta and Gunderson 2007, Natanson et al. 2007). These validations support the underlying assumption that skates have one band pair deposited a year.

Annual band pair deposition was not expected to change between age structure preparation techniques. Vertebral sections prepared by the histological technique did not exhibit the same obvious band pair deposition pattern as in the gross sections.

Discrepancies in trends between preparation methods are likely because of differences in sample sizes and the reader's inexperience with the histological technique. CEA and MIR measurements were available for gross sections for all months except May, whereas the sample size for histological sections was lower, with samples not available for May, August, November, and December. An increased sample size processed with the histological technique that represented the entire year would likely help distinguish differences of edge type among months.

Additionally, some difficulty was encountered with assigning edge types to the histological sections. The hematoxylin stain, which colored opaque bands, gave pigment to the distal edge of the corpus calcareum. It was difficult to determine the type of edge band for CEA because the distal edge was characterized by dark purple (opaque) pigment 
that was not necessarily representative of a true band. More experience with this preparation technique and its effect specifically on the vertebrae of $R$. stellulata could elucidate this problem.

Marginal increment ratio analysis is based on the comparison between the penultimate band pair and the forming band pair. The ultimate or forming band pair is expected to be narrower than the penultimate band pair. This was not the case with $R$. stellulata, in which there were many instances that the forming band pair was broader than the penultimate band pair. This phenomenon has been exhibited by several skate species endemic to the eastern North Pacific (Ainsley 2009, Maurer 2009, Winton 2011). This result may confound MIR's usefulness for verification as width of the band pair is likely based on growth, which varies among individuals (Officer et al. 1997). Consequently, seasonal growth is a factor that cannot be accounted for when calculating average MIR.

The two age structure preparation techniques, gross sectioning and histology, provided similar life history parameter estimates for $R$. stellulata. At least five of the seven growth functions applied to each preparation technique described the growth of $R$. stellulata adequately. For gross sections, the best model based on $\mathrm{AIC}_{\mathrm{c}}$, and biological relevance was the 2 VBGF. For histological sections, the best model based on the same criteria was the Gompertz model. The theoretical maximum TLs, $L_{\infty}$, varied by only 20 $\mathrm{mm}$, and the estimated length at birth, $L_{0}$, varied by only $32 \mathrm{~mm}$ (Table 2 ). Both age preparation techniques resulted in similar life history parameters, but due to the older age 
estimates of the histological technique its parameters should be used for fisheries management.

The life history characteristics of $R$. stellulata fall within the range of other skate species that are found in the California Current ecosystem. Raja binoculata and $R$. rhina exhibit similar maximum estimated ages, 12 and 13 years respectively using the gross sectioning technique (Zeiner and Wolf 1993). Raja binoculata is a larger skate and has a larger growth coefficient than $R$. stellulata due to its relatively short longevity (Zeiner and Wolf 1993). The largest specimen of R. binoculata in Zeiner and Wolf's (1993) study was only 1,610 mm TL rather than the reported maximum length of 2,400 mm TL; therefore the maximum age estimate from Zeiner and Wolf (1993) may be an underestimate for the species as a whole. The final member of the Rajidae family that belongs to the California shallow water species complex, Raja inornata, has a maximum age estimate of 13 years using the gross sectioning technique, which is similar to $R$. stellulata (Wade Smith and Dave Ebert, unpubl. data). The two sympatric bathyrajid skates, B. kincaidii and B. trachura, attain older maximum ages, and have growth coefficients both greater and smaller than $R$. stellulata (Davis et al. 2007, Perez et al. 2011). These differences are likely due to taxonomic or habitat differences.

The $L_{\infty}$ and maximum age of medium-sized rajid skates worldwide are similar to those estimated for $R$. stellulata. Raja texana from the Gulf of Mexico has a maximum TL of $630 \mathrm{~mm}$ and a $L_{\infty}$ of $682 \mathrm{~mm}$ TL for females and $526 \mathrm{~mm}$ TL males (Sulikowski et al. 2007). This species also has a younger maximum age estimate using gross sections (9 years) than $R$. stellulata (Sulikowski et al. 2007). Also in the same range is Raja 
montagui from the Irish Sea, which has a slightly greater maximum TL, $770 \mathrm{~mm}$, but lesser $L_{\infty}, 784 \mathrm{~mm}$ TL for females and $724 \mathrm{~mm}$ TL for males, and a maximum estimated age of 7 years old using gross sections (Gallagher et al. 2004). Malacoraja senta sampled in the Gulf of Maine attains $680 \mathrm{~mm}$ TL, and is one of the few other species of rajid that was assessed for age and growth using the histological preparation (Natanson et al. 2007). Despite its smaller size, its maximum age estimate was 15 years old and the $L_{\infty}$ was $754 \mathrm{~mm}$ TL for females and $696 \mathrm{~mm}$ TL for males. These comparisons lead to the conclusion that $R$. stellulata has life history characteristics typical of similarly sized species of rajids. 


\section{Literature Cited}

Ainsley, S.M. 2009. Age, growth and reproduction of the Bering Skate, Bathyraja interrupta (Gill and Townsend, 1897), from the Eastern Bering Sea and Gulf of Alaska. M.S. Thesis. California State University, Monterey Bay.

Beamish, R.J. and D.A. Fournier. 1981. A method for comparing the precision of a set of age determinations. Canadian Journal of Fisheries and Aquatic Sciences 38: 982983.

Bowker, A.H. 1948. A test for symmetry in contingency tables. American Statistical Association. 43(244): 572-574.

Burnham, K.P. and D.R. Anderson. 2002. Model selection and multimodal inference: a practical information-theoretical approach. $2^{\text {nd }}$ edition. Springer, New York. 488 pp.

Cailliet, G.M. and K. Goldman 2004. Age determination and validation in chondrichthyan fishes. In. J.C. Carrier, J.A. Musick, and M.R. Heithaus (eds.) Biology of sharks and their relatives. pp. 399-447. Boca Raton, FL: CRC Press LLC.

Cailliet, G.M., W.D. Smith, H.F. Mollet and K.J. Goldman. 2006. Age and growth studies of chondrichthyan fishes: the need for consistency in terminology, verification, validation and growth function fitting. Environmental Biology of Fishes 77: 211-228.

Campana, S.E., Annand, M.C. and J.I. McMillan. 1995. Graphical methods for determining consistency of age determinations. Transactions of the American Fisheries Society 124: 131-138.

Campana, S.E. 2001. Accuracy, precision, and quality control in age determination, including a review of the use and abuse of age validation methods. Journal of Fish Biology 59: 197-242.

Chang, W.Y.B. 1982. A statistical method for evaluating the reproducibility of age determination. Canadian Journal of Fisheries and Aquatic Sciences 39: 12081210 .

Conrath, C.L., J. Gelsleichter and J.A. Musick. 2002. Age and growth of the smooth dogfish, Mustelus canis, in the northwest Atlantic. Fishery Bulletin 100: 674-682. 
Davis, C.D, G.M. Cailliet and D.A. Ebert. 2007. Age and growth of the roughtail skate Bathyraja trachura (Gilbert 1892) from the eastern North Pacific. Environmental Biology of Fishes 80: 325-336.

Ebert, D.A. 2003. Sharks, Rays and Chimaeras of California. University of California Press. 284 pp.

Ebert, D.A. 2005. Reproductive biology of skates, Bathyraja (Ishiyama along the eastern Bering Sea continental slope. Journal of Fish Biology 66: 618-649.

Ebert, D.A., J.R. Maurer, S.M. Ainsley, L.A.K. Barnett and G.M. Cailliet. 2009. Life history and population dynamics of four endemic Alaskan skates: determining essential biological information for effective management of bycatch and target species. North Pacific Research Board Final Report 715. 120pp.

Ebert, D.A., W.D. Smith, D.L. Haas, S.M. Ainsley and G.M. Cailliet. 2007. Life history and population dynamics of Alaskan skate: Providing biological information for effective management of bycatch and target species. North Pacific Research Board Final Report 510. 124 pp.

Evans, G.T. and J.M. Hoenig. 1998. Testing and viewing symmetry in contingency tables, with applications to readers of fish ages. Biometrics 54: 620-629.

Fabens, A.J. 1965. Properties and fitting of the von Bertalanffy growth curve. Growth, Development and Aging 29: 265-289.

Gallagher, M.J. 2000. The fisheries biology of commercial ray species from two geographically distinct regions. Ph.D. Thesis, Department of Zoology, University of Dublin, Trinity College, Dublin 2, Ireland.

Gallagher, M.J., M.J. Green and C.P. Nolan. 2006. The potential use of caudal thorns as a non-invasive ageing structure in the thorny skate (Amblyraja radiata Donovan, 1808). Environmental Biology of Fishes 77: 265-272.

Gallagher, M.J., C.P. Nolan and F. Jeal. 2004. Age, growth, and maturity of the commercial ray species from the Irish Sea. Journal of Northwest Atlantic Fisheries Science 35: 47-66.

Gallagher, M.J., C.P. Nolan, and F. Jeal. 2005. The structure and growth processes of caudal thorns. Journal of Northwest Atlantic Fisheries Science 35: 125-129.

Goldman, K.J. 2004. Age and growth of elasmobranch fishes. In: Musick, J.A. and R. Bonfil (eds.) Elasmobranch fisheries management techniques. Asia Pacific Economic Cooperation, Singapore. pp 97-132. 
Haddon, M. 2001. Modeling and quantitative measures in fisheries. Chapman \& Hall/CRC Press, Boca Raton FL.

Hoenig, J.M., M.J. Nirgab, C.A. Brown. 1995. Analyzing differences between two age determination methods by tests of symmetry. Canadian Journal of Fisheries and Aquatic Sciences 52: 364-368.

Kimura, D.K. 1980. Likelihood methods for the von Bertalanffy growth curve. Fishery Bulletin 77(4): 765-776.

Licandeo, R.R., J.G. Lamilla, P.G. Rubilar and R.M. Vega. 2006. Age, growth and sexual maturity of the Yellownose Skate Dipturus chilensis, in the south-eastern Pacific. Journal of Fish Biology 68: 488-506.

Matta, M.E. and D.R. Gunderson. 2007. Age, growth, maturity and mortality of the Alaska skate, Bathyraja parmifera, in the eastern Bering Sea. Environmental Biology of Fishes 80: 309-323.

Maurer, J.R.F. 2009. Life history of two Bering Sea slope skates: Bathyraja lindbergi and B. maculata. M.S. Thesis. California State University, Monterey Bay.

McFarlane, G.A. and J.R. King. 2006. Age and growth of Big Skate (Raja binoculata) and Longnose Skate (Raja rhina) in British Columbia waters. Fisheries Research 78: $169-178$.

McPhie, R.P., and S.E. Campana. 2009. Bomb dating and age determination of skates (family Rajidae) off the eastern coast of Canada. ICES Journal of Marine Science 66: 546-560.

Moura, T., I. Figueiredo, I. Farias, B. Serra-Pereira, R. Coelho, K. Erzini, A. Neves and L.S. Gordo. 2007. The use of caudal thorns for ageing Raja undulata from the Portuguese continental shelf, with comments on its reproductive cycle. Marine and Freshwater Research 58: 983-992.

Natanson, L.J. 1993. Effect of temperature on band deposition in the Little Skate, Raja erinacea. Copeia 1993(1): 199-206.

Natanson, L.J., J.A. Sulikowski, J.R. Kneebone and P.C. Tsang. 2007. Age and growth estimates for the smooth skate, Malacoraja senta, in the Gulf of Maine. Environmental Biology of Fishes 80(2-3): 293-308. 
Neer, J.A. and B.A. Thompson. 2005. Life history of the cownose ray, Rhinoptera bonasus, in the northern Gulf of Mexico, with comments on geographic variablility in life history traits. Environmental Biology of Fishes 73: 321-331.

Officer, R.A., R.W. Day, J.G. Clement and L.P. Brown. 1997. Captive gummy sharks, Mustelus antarcticus, form hypermineralised bands in their vertebrae during winter. Canadian Journal of Fisheries and Aquatic Sciences 54: 2677-2683.

Perez, C.R, G.M. Cailliet and D.A. Ebert. 2011. Age and growth of the Sandpaper Skate, Bathyraja kincaidii, using vertebral centra, with an investigation of caudal thorns. Journal of the Marine Biological Association of the United Kingdom 91(6): 11491156.

Quinn, T.J. and R.B. Deriso. 1999. Quantitative Fish Dynamics. Oxford University Press: New York.

Ricker, W.E. 1979. Growth rates and models. In. W.S. Hoar, D.J. Randall, J.R. Brett (eds.) Fish Physiology, Volume III. New York: Academic Press. pp. 677-743.

Schnute, J. 1981. A versatile growth model with statistically stable parameters. Canadian Journal of Fisheries and Aquatic Sciences 38:1128-1140.

Simpfendorfer, C.A., J. Chidlow, R. McAuley and P. Unsworth. 2000. Age and growth of the whiskery shark, Furgaleus macki, from southwestern Australia.

Environmental Biology of Fishes 58: 335-343.

Smith, W.D., G.M. Cailliet and E.M. Melendez. 2007. Maturity and growth characteristics of a commercially exploited stingray, Dasyatis dipterura. Marine and Freshwater Research 58: 54-66.

Sulikowski, J.A., S.B. Irvine, K.C. DeValerio, and J.K. Carlson. 2007. Age, growth and maturity of the Roundel Skate, Raja texana, from the Gulf of Mexico, USA. Marine and Freshwater Research 58: 41-53.

Sulikowski, J.A., J. Kneebone, S. Elzey, J. Jurey, P.D. Danley, W.H. Howell and P.C.W. Tsang. 2005. Age and growth estimates of the thorny skate (Amblyraja radiata) in the western Gulf of Maine. Fishery Bulletin 103: 161-168.

Sulikowski, J.A., M.D. Morin, S.H. Suk, and W.H. Howell. 2003. Age and growth estimates of the winter skate (Leucoraja ocellata) in the western Gulf of Maine. Fishery Bulletin 101: 405-413. 
Tanaka, S. and K. Mizue. 1979. Studies on Sharks - XV: Age and growth of Japanese Dogfish Mustelus manazo, Bleeker, in the East China Sea. Bulletin of the Japanese Society of Scientific Fisheries 45(1): 43-50.

Winton, M.V. 2011. Age, growth, and demography of the Roughtail Skate, Bathyraja trachura (Gilbert, 1892), from the eastern Bering Sea. M.S. Thesis. California State University, Monterey Bay.

Zeiner, S.J. and P. Wolf. 1993. Growth characteristics and estimates of age at maturity of two species of skates (Raja binoculata and Raja rhina) from Monterey Bay, California. NOAA Technical Report NMFS 115: 87-99. 
Chapter Two: Reproduction 


\section{Introduction}

Reproductive parameters are important in establishing population estimates and predicting how a population may respond to different stressors, such as fishing pressure. One essential parameter is age or size at maturity. This parameter strongly regulates population growth rates through its influence on the productivity of a species (Holden 1973, Smith et al. 1998). Another important parameter is the periodicity of reproduction. This seasonality in reproduction affects the lifetime fecundity of an individual, which in turn affects the population size, growth rate, and management options. Therefore, research into species-specific reproductive parameters is imperative for determining population sizes, potential growth rates, and creating management strategies.

Age at maturity is a fundamental component of demographic analyses. Smith et al. (1998) showed, using a demographic model, that there is a close relationship between age at maturity and the potential population rebound rates of twenty-six eastern Pacific shark species. Shark species that mature late in life have lesser rates of population increase whereas species that mature early in life have higher rates of population increase (Smith et al. 1998). Another study on the demography of eight species of Alaskan skates revealed population growth rates were so low that based on the criteria of Musick (1999),

four of the eight are vulnerable to depletion by fishing pressure (Ebert et al. 2007, 2009). Thus, age at maturity is a crucial parameter to determine for a species.

Elasmobranchs exhibit an array of reproductive cycles that range from distinct annual (or longer) cycles to year-round reproduction with no discernable reproductive peaks. Hamlett and Koop (1999) showed that skates and oviparous sharks tend to exhibit 
year-round reproduction sometimes with seasonal peaks. A species with seasonal peaks has egg cases present in utero year-round, but exhibit a distinct seasonal peak in the number of gravid females or other reproductive indicators (Holden 1975, Braccini and Chiaramonte 2002, Mabragana and Cousseau 2004). Since Hamlett and Koop (1999)

many skate species have been found to exhibit year-round reproductive cycles including: Bathyraja kincaidii (Perez et al. 2011), B. interrupta (Ainsley et al. 2011), B. trachura (Davis et al. 2007), B. parmifera (Matta and Gunderson 2007), Amblyraja radiata, and Malacoraja senta (Kneebone et al. 2007). Examples of skate species that exhibit yearround reproduction with seasonal peaks include Leucoraja erinacea (Richards et al. 1963), Psammobatis extenta (Braccini and Chiaramonte 2002), Raja clavata (Holden 1975) and Rioraja agassizi (Oddone et al. 2007). The presence of these reproductive cycles influences the appropriate management technique for these species; seasonal closures would not be effective with year-round reproduction, but with seasonal peaks in reproduction, timely protection from fishing would allow females to deposit more eggs.

The purpose of this chapter is to provide knowledge on the reproductive parameters of Raja stellulata. The objectives were to 1) estimate size and age at first, $50 \%$, and $100 \%$ maturity, and 2) determine the periodicity of the reproductive cycle.

\section{Methods}

\section{Collection}

Specimens of $R$. stellulata were obtained from two separate surveys along the U.S. West Coast. From 2002 through 2005, the National Marine Fisheries Survey 
(NMFS) Southwest Fisheries Science Center Santa Cruz Laboratory (SWFSC-SCL) conducted demersal longline and trawl surveys off central California from Davenport (ca. $37^{\circ} 00^{\prime} \mathrm{N}, 122^{\circ} 11^{\prime} \mathrm{W}$ ) to Monterey (ca. $36^{\circ} 36^{\prime} \mathrm{N}, 121^{\circ} 53^{\prime} \mathrm{W}$ ). Additional specimens were collected from 2006 to 2010 by the NMFS Northwest Fisheries Science Center Fishery Resource and Monitoring division (NWFSC-FRAM) during the annual coastwide groundfish survey extending from the U.S. border with Canada (ca. $48^{\circ} 28^{\prime} \mathrm{N}, 124^{\circ}$ $54^{\prime} \mathrm{W}$ ) to the U.S. border with Mexico (ca. $32^{\circ} 31^{\prime} \mathrm{N}, 117^{\circ} 11^{\prime} \mathrm{W}$ ).

Specimens were returned whole to Moss Landing Marine Laboratories (MLML) for processing. Individual total lengths (TL) from snout tip to tail tip, and disc width (DW) from one wing tip to the other wing tip, were measured to the nearest one millimeter, each was weighed and assigned a sex and maturity status following the system of Ebert (2005). Three reproductive classifications were used for both sexes: juvenile, adolescent, and adult. Males were considered mature when the claspers were well calcified, including the terminal cartilage elements, and extended beyond the pelvic fin tips. Maturity was confirmed internally if the epididymis and testes were greatly coiled. Males were considered adolescent when the claspers extended beyond the pelvic fin tips, but lacked calcification and moderate internal coiling was present. Males were considered juvenile when flexible claspers did not extend beyond the pelvic fin tips and there was minimal internal coiling. Females were considered mature when large ( $>10$ $\mathrm{mm}$ ) circular oocytes were present in the ovaries, the oviducal gland was kidney-shaped and well-differentiated from the uterus, and/or egg cases were present. Females were considered adolescent when mature oocytes were not present, but the oviducal gland was 
partially differentiated from the uterus. Females were considered juvenile when no oocytes were present and the oviducal gland was not or poorly differentiated from the uterus. The ratio of females to males was determined and analyzed with a chi-squared test. A two-sample t-test was used to detect a difference in sizes collected between sexes.

Additional reproductive measurements were recorded during processing including the oviducal gland width $(\mathrm{mm})$, largest ovum diameter $(\mathrm{mm})$, and total number of mature ( $>10 \mathrm{~mm}$ ) oocytes in each ovary for females, and inner clasper length $(\mathrm{mm})$ for males. Oviducal gland width and inner clasper length were plotted against TL for females and males, respectively. The relationships were examined for trends, where an abrupt change in slope indicated maturation.

\section{Maturity}

First and $100 \%$ maturity at size and age (from histological age estimates, Chapter One) were determined. Age and size at 50\% maturity also was determined for each sex with a logistic regression using SigmaPlot version 12.0 (Systat Software Inc., 2011):

$$
Y=\frac{1}{\left(1+e^{-(a+b x)}\right)}
$$

where $Y$ is the maturity status $(0=$ immature, $1=$ mature $)$ and $x$ is the TL in $\mathrm{mm}$. Binomial data were binned into $30 \mathrm{~mm}$ size and one year age classes. Age and size at which $50 \%$ of the population was mature $\left(\mathrm{TL}_{50}\right)$ was calculated as:

$$
T L_{50}=\frac{-a}{b}
$$

where $a$ is the y-intercept and $b$ is the regression coefficient. 


\section{Reproductive Seasonality}

To assess potential seasonality of reproduction an average gonadosomatic index (GSI) for both sexes was plotted by month (Flammang et al. 2008) and oceanographic season. GSI was calculated as:

$$
G S I=\frac{G M}{T M} * 100
$$

where $G M$ is the gonad mass in $\mathrm{g}$ and $T M$ is total mass of the skate in $\mathrm{g}$. Differences in average GSI among months or oceanographic seasons were tested using a non-parametric Kruskal-Wallis test due to violated assumptions and a two-sample t-test (Zar 1999).

Oceanographic seasons are specific to the region being studied. Subsurface water movement between approximately 100 and $300 \mathrm{~m}$ depth along the West Coast of the U.S. is dominated by the California Undercurrent (CU), which is a northward flow of warmer, saltier southern water along the coast (Hickey 1979, Chelton 1984, Tisch et al. 1992, Hickey 1998). The CU is present coast-wide year-round, but does exhibit seasonality with a peak flow in summer and early fall and a second peak in winter when it is augmented by the Davidson Current, a northward surface current that occurs in winter from Point Conception northward (Hickey 1998, Di Lorenzo 2003, Breaker 2005). This season of strong CU flow will be referred to as the California Undercurrent Season (CUS) and for the purposes of this study ranges from June until February. The CU experiences a minimum during spring due to overwhelming effect of equatorward winds driving upwelling and equatorward flow along the coast that brings cold, nutrient-rich water south from the Pacific subarctic (Hickey 1998, Di Lorenzo 2003). This season of minimal CU flow will be referred to as the Upwelling Season (UPS) and for the purposes 
of this study ranges from March through May. Despite differences between surface currents north of Point Conception and in the Southern California Bight (SCB) the CU is present in the SCB and expresses the same semiannual pattern found north of Point Conception (Di Lorenzo 2003).

A second method that compares ovum size among months was used to assess seasonality of ovulation in females (Conrath 2004, Ebert et al. 2007, 2009). The largest ovum diameters of each mature female and the number of mature ova were averaged and plotted by month and oceanographic season. Differences among months in mean maximum ovum diameter and number of mature ova were tested using a one-way ANOVA or non-parametric Kruskal-Wallis tests (Matta and Gunderson 2007). Differences between oceanographic seasons in mean maximum ovum diameter and number of mature ova were tested using a two-sample t-test. Month of collection was recorded for gravid females to determine possible seasonality of egg deposition.

\section{Results}

\section{Collection}

A total of 194 R. stellulata was collected as described in Chapter One. The ratio of females to males was 1:09:1 and the observed female to male ratio was not significantly different from $1: 1\left(\chi^{2}=0.25, \mathrm{df}=1, \mathrm{p}=0.615\right)$. A two-sample t-test detected no significant difference in TLs between sexes $(t=0.97, \mathrm{df}=192, \mathrm{p}=0.333)$.

The relationship between oviducal gland width of females and TL increased at $550 \mathrm{~mm}$ TL, which indicated the onset of maturity (Fig. 1). The relationship between 
inner clasper length of males and TL showed an increase of slope at $500 \mathrm{~mm}$ TL, which indicated the onset of maturity (Fig. 2).

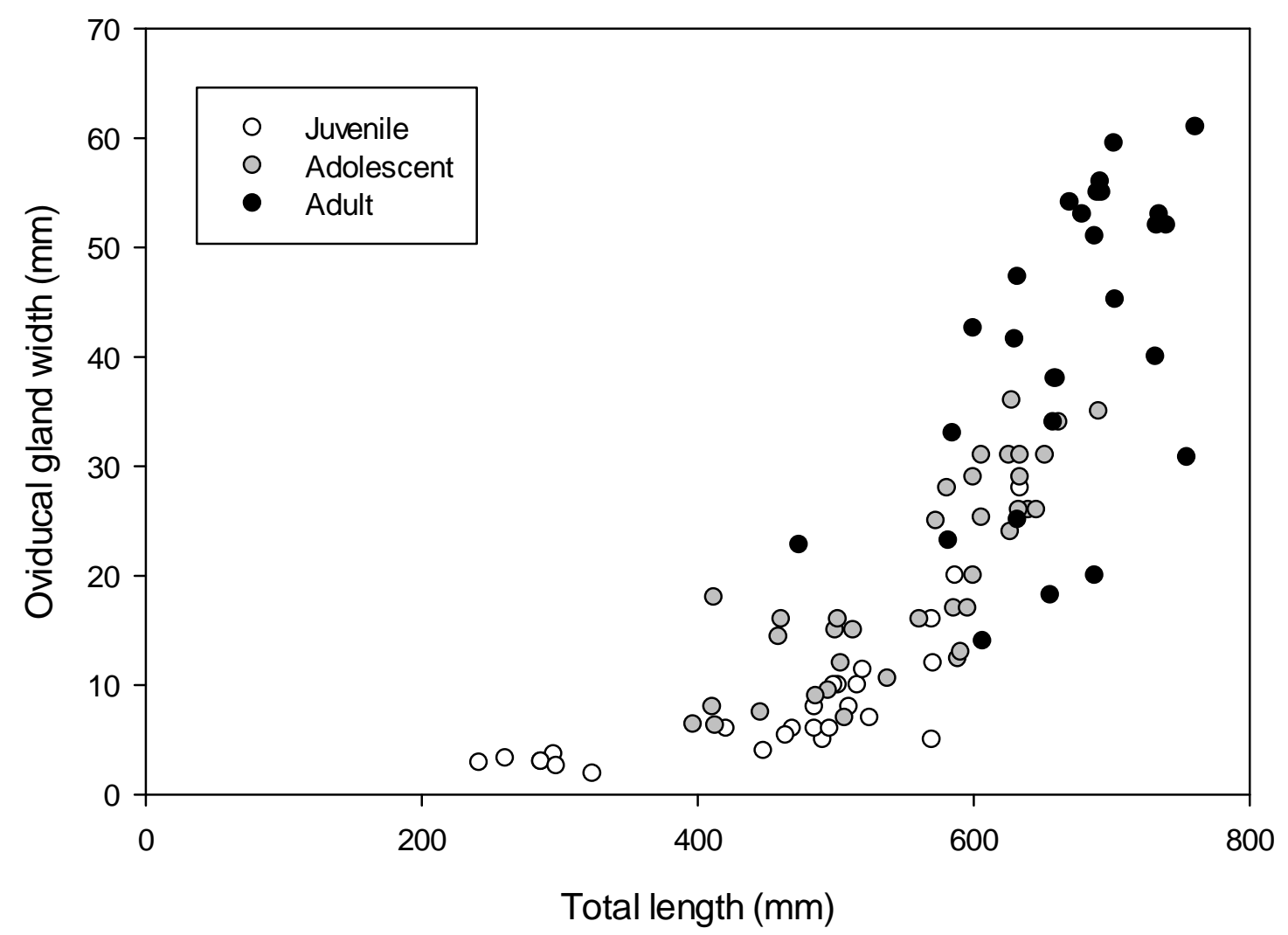

Figure 1. Relationship between oviducal gland width and total length $(n=101)$. 


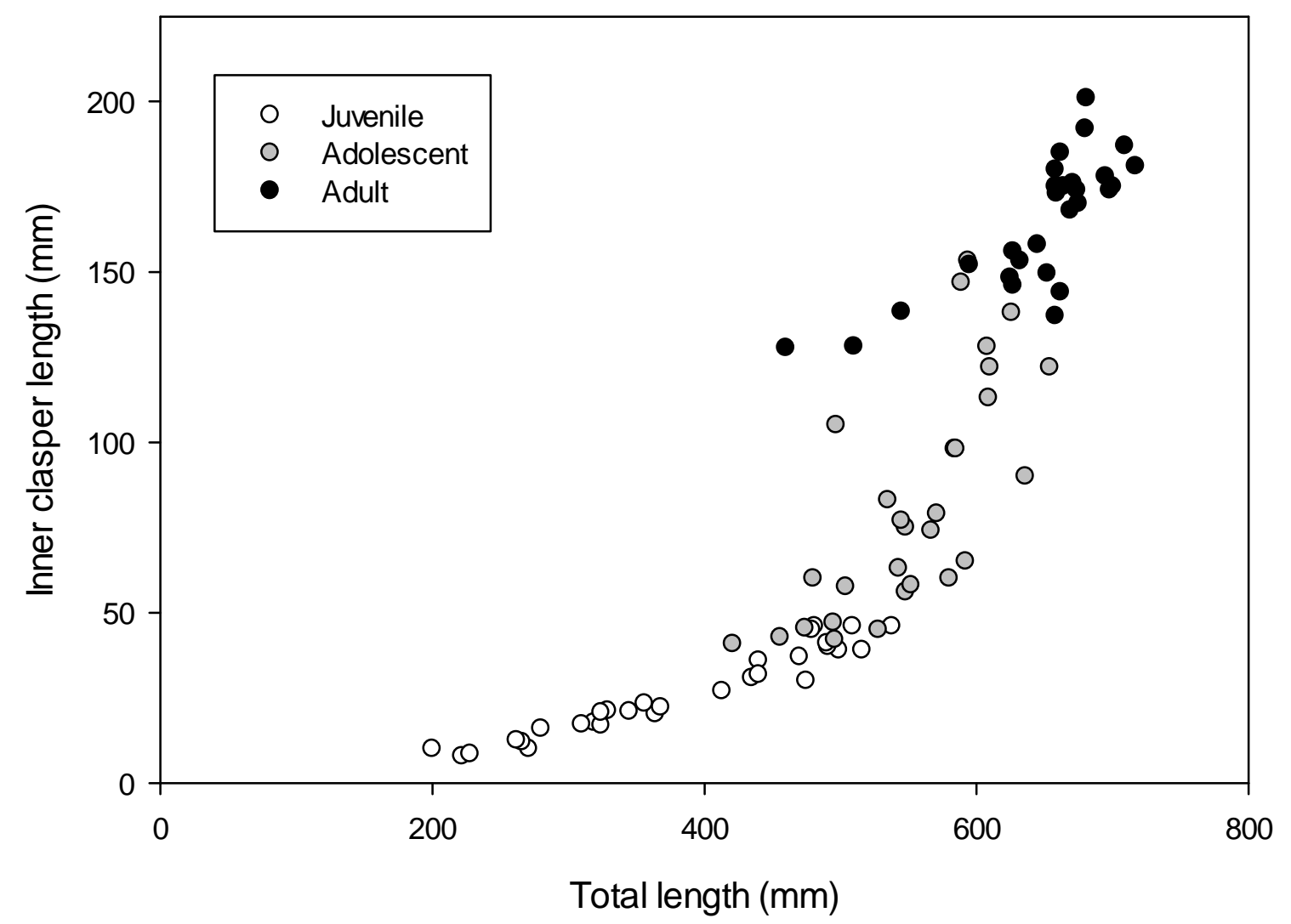

Figure 2. Relationship between inner clasper length and total length $(n=93)$. 


\section{Maturity}

First maturity of females occurred at $474 \mathrm{~mm}$ TL and 9 years, 50\% maturity at $632 \mathrm{~mm}$ TL (p < 0.001; Fig. 3) and 11.2 years ( $<$ < 0.001; Fig. 4), and 100\% of females were mature at $\geq 692 \mathrm{~mm}$ TL and 15 years. The lengths corresponded to $62.3 \%, 83.0 \%$ and $90.9 \%$ of the maximum TL. The ages corresponded to $60.0 \%, 74.4 \%$ and $100.0 \%$ of the maximum age.

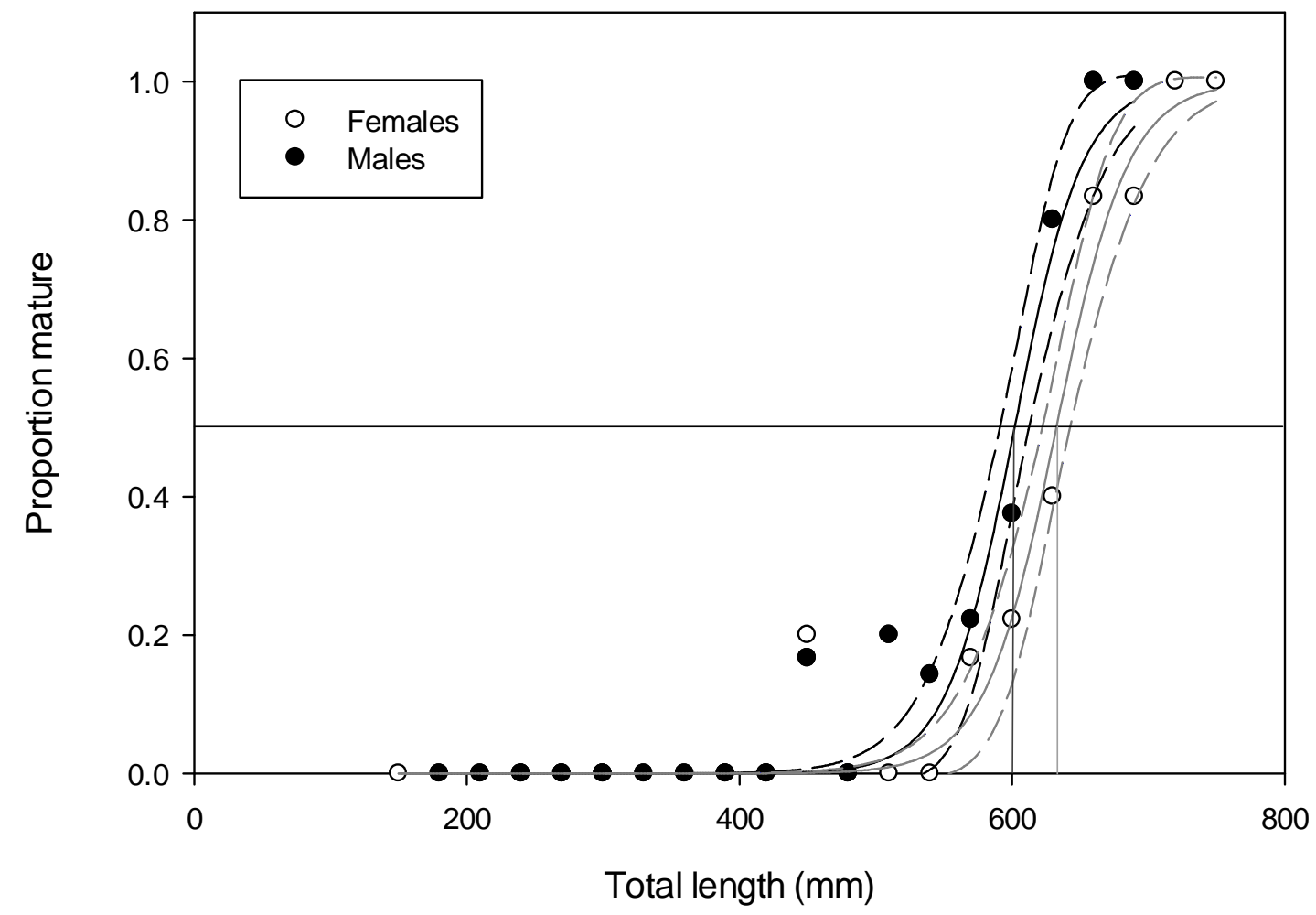

Figure 3. Maturity ogives for males and females by total length. Dashed lines are $95 \%$ confidence intervals for female (grey) and male (black) ogives. 50\% maturity is indicated by the black solid line with the male estimate shown with the perpendicular black line and the female estimate shown with the perpendicular grey line. Total length is binned by $30 \mathrm{~mm}$. 


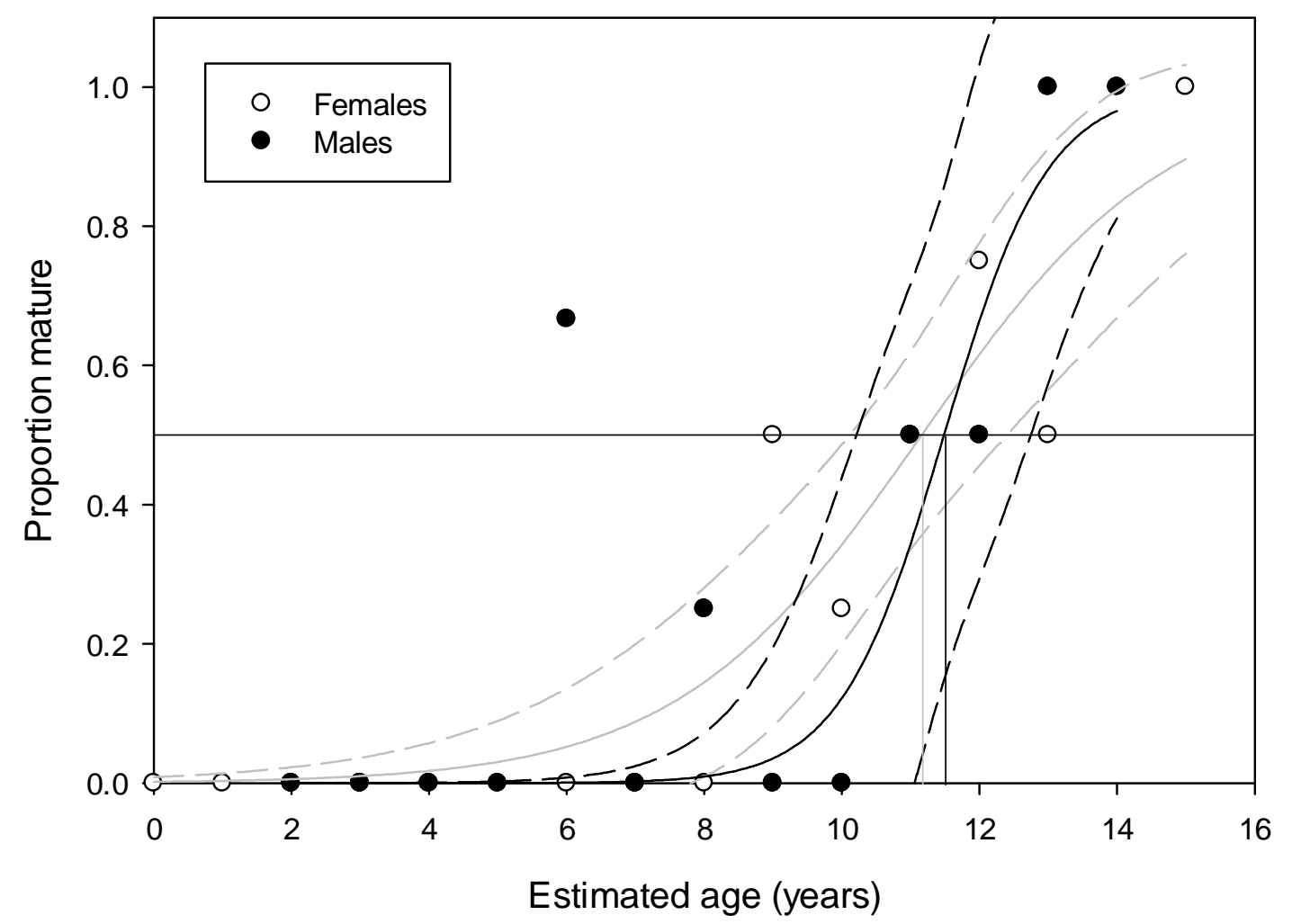

Figure 4. Maturity ogives for males and females by estimated age. Dashed lines are 95\% confidence intervals for female (grey) and male (black) ogives. 50\% maturity is indicated by the black solid line with the male estimate shown with the vertical black line and the female estimate shown with the vertical grey line. Age is binned by one year.

First maturity of males occurred at $460 \mathrm{~mm}$ and 6 years, $50 \%$ maturity occurred at $603 \mathrm{~mm}(\mathrm{p}<0.001$; Fig. 3$)$ and 11.5 years (p<0.001; Fig. 4) and $100 \%$ of males were mature at $\geq 658 \mathrm{~mm}$ TL and $\geq 13$ years. These lengths corresponded to $60.4 \%, 79.2 \%$, and $86.5 \%$ of the maximum TL. The ages corresponded to $40.0 \%, 76.5 \%$ and $86.7 \%$ of the maximum age. Males matured at similar sizes and ages as females and logistic regressions were not significantly different between sexes (Size: $\mathrm{F}=1.58, \mathrm{df}=20, \mathrm{p}=$ 0.143; Age: $\mathrm{F}=2.05, \mathrm{df}=14, \mathrm{p}=0.088$ ). 


\section{Reproductive Seasonality}

Average female GSI did not differ significantly among months (Kruskal-Wallis: $\mathrm{K}=2.68, \mathrm{df}=4, \mathrm{p}=0.612 ;$ Fig. 5 ) or between oceanographic seasons $\mathrm{t}=-0.36, \mathrm{df}=11$, $\mathrm{p}=0.726$ ). A nonsignificant peak in average GSI was observed in July with lesser values occurring in winter. Average male GIS was not significantly different among months (K $=3.93, \mathrm{df}=4, \mathrm{p}=0.415$; Fig. 6$)$ or between oceanographic seasons $(\mathrm{t}=-1.26, \mathrm{df}=20, \mathrm{p}$ $=0.222$ ). A nonsignificant peak in average GSI was observed in March.

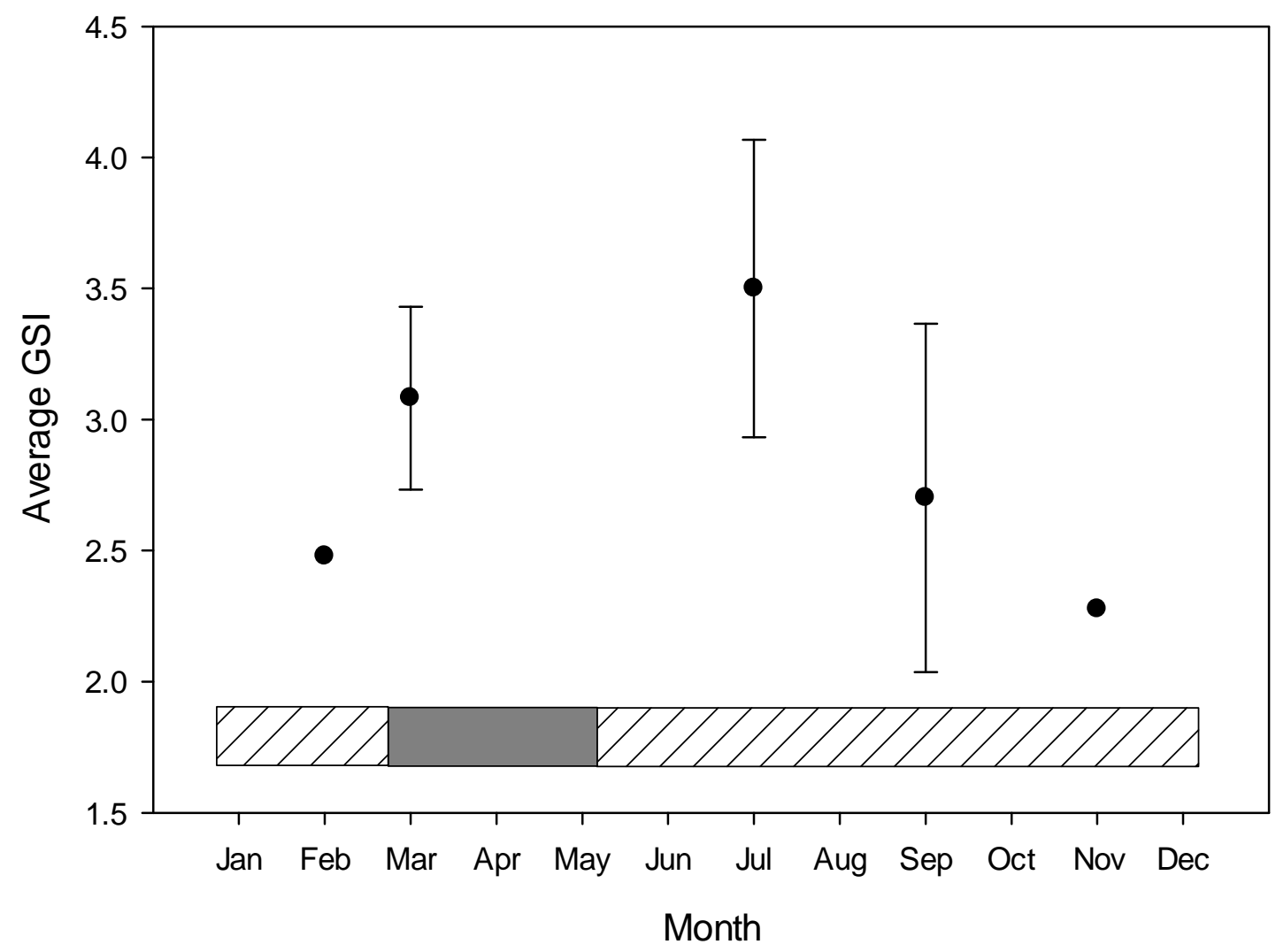

Figure 5. Average female GSI by month $(n=13)$. Grey bar represents UPS and hatched bar represents CUS. Error bars represent one standard error. 


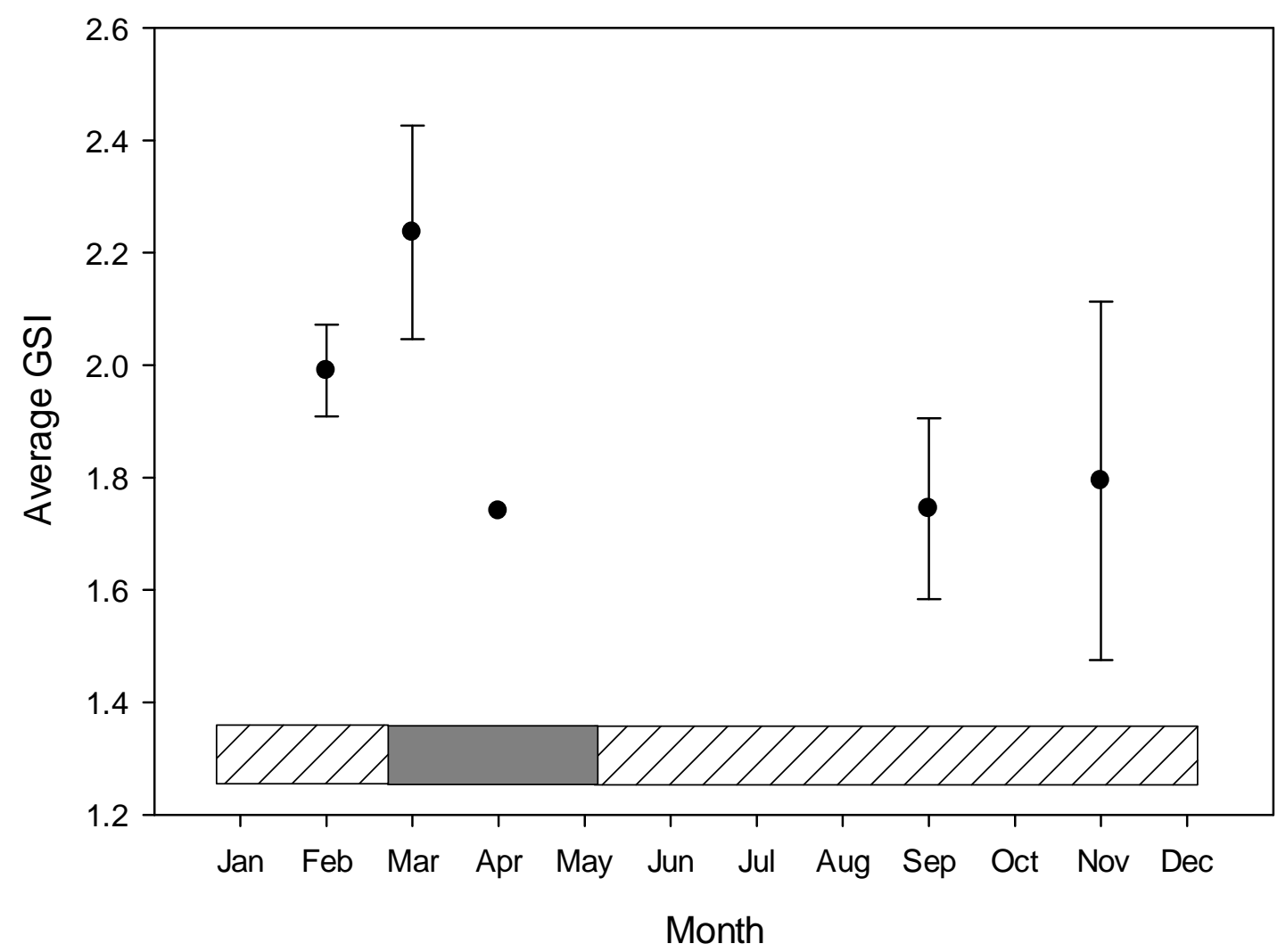

Figure 6. Average male GSI by month $(n=22)$. Grey bar represents UPS and hatched bar represents CUS. Error bars represent one standard error.

Average maximum ovum diameter was not significantly different among months $(\mathrm{K}=5.85, \mathrm{df}=5, \mathrm{p}=0.321 ;$ Fig. 7$)$ or between oceanographic seasons $(\mathrm{t}=-1.23, \mathrm{df}=11$, $\mathrm{p}=0.245$ ). There was a broad, nonsignificant peak in average maximum ovum diameter during winter and spring. Average number of mature ova also was not significantly different among months $(\mathrm{K}=6.39, \mathrm{df}=5, \mathrm{p}=0.270$; Fig. 7$)$, however it was significant between oceanographic seasons $(t=-2.55, \mathrm{df}=13, \mathrm{p}=0.024)$ with a greater average number of mature ova during UPS. 


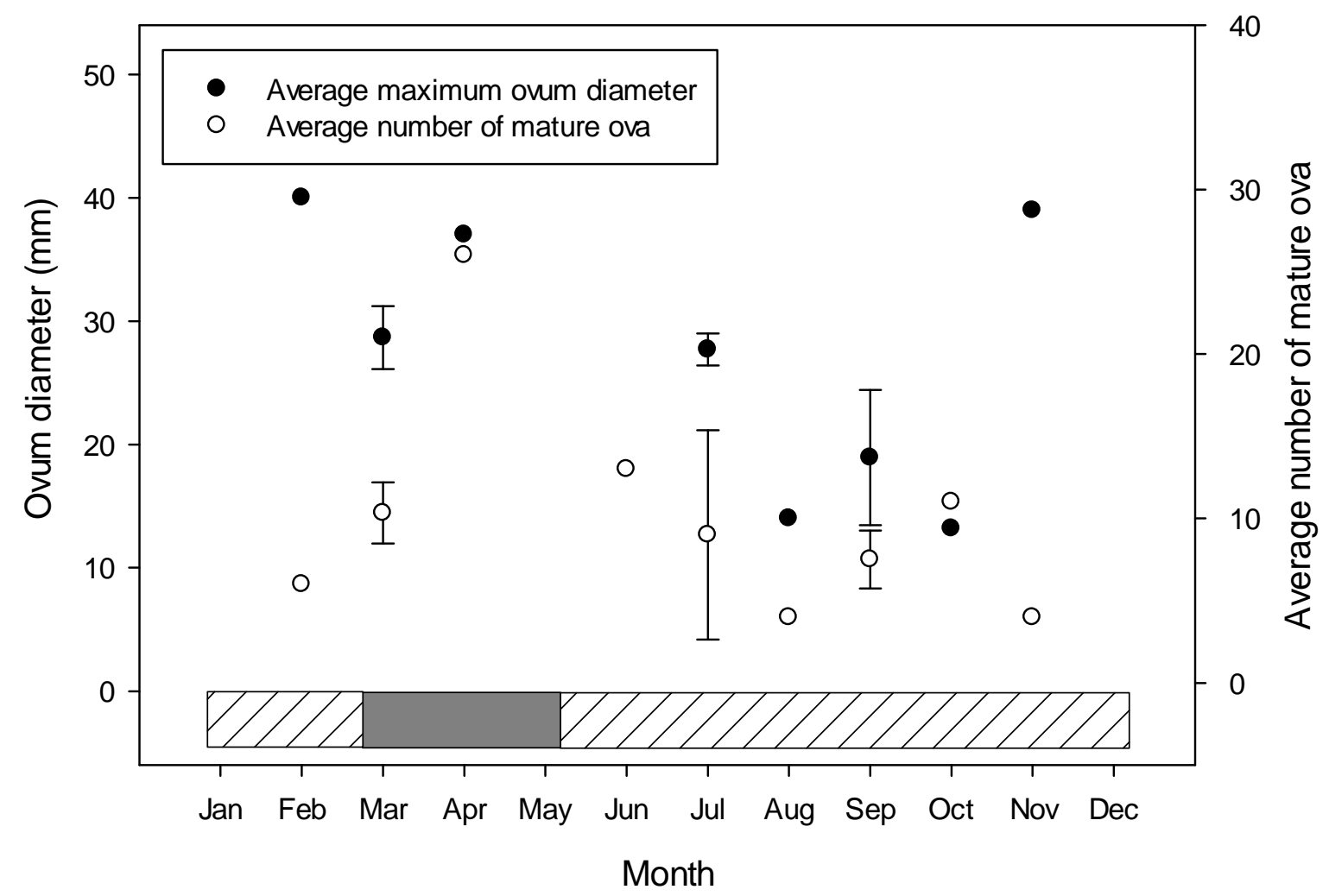

Figure 7. Average maximum ovum diameter and average number of mature ova by month. Grey bar represents UPS and hatched bar represents CUS. Error bars represent one standard error.

Three gravid females were encountered in this study: one was collected in April off Santa Cruz, California, one in July off Morro Bay, California and one in September off Florence, OR. Both individuals from April and July had fully formed egg cases, whereas the individual from September had a partially formed egg case. 


\section{Discussion}

The known size range of $R$. stellulata was well represented in this study. The largest individual collected, a female of $761 \mathrm{~mm}$, matched known maximum TL for $R$. stellulata (Ebert 2003), whereas the largest male was $717 \mathrm{~mm}$, only $44 \mathrm{~mm}$ smaller than the maximum female TL. The smallest individual collected, also a female, was just longer than the documented range of size at birth of 120 to $150 \mathrm{~mm}$ (Ebert 2003).

Both sexes of Raja stellulata matured at similar lengths and ages. There were only small, nonsignificant differences between sexes; females attained 50\% maturity $40 \mathrm{~mm}$ TL longer than males. Small differences in maturation between sexes are common features exhibited by skates in the Northeast Pacific: Raja binoculata, Raja rhina (Zeiner and Wolf 1993, McFarlane and King 2006, Ebert et al 2008b), Bathyraja interrupta (Ainsley 2009) and Bathyraja parmifera (Matta and Gunderson 2007) and by skates worldwide: Amblyraja radiata (Sulikowski et al. 2006), Dipturus polyommata (Kyne et al. 2008), Leucoraja erinacea (Cicia et al. 2009), Raja brachyura, $R$. clavata, $R$. montagui, $R$. naevus (Gallagher et al. 2004), R. texana (Sulikowski et al. 2007), $R$. miraletus, $R$. straeleni, Malacoraja spinacidermis, Rajella barnardi, Rajella caudaspinosa, Rajella dissimilis, and Rajella leopardus (Ebert et al. 2008a). These data on Raja stellulata corroborates the hypothesis that oviparous species and smaller sized skates $(<150 \mathrm{~cm}$ maximum TL) tend not to exhibit significant size differences between sexes (Ebert et al. 2008a, b).

Raja stellulata matures at large sizes and at approximately $75 \%$ of its maximum estimated age. The estimates of TL at 50\% maturity were slightly greater, approximately 
$80 \%$ of the maximum TL, than estimates of age at $50 \%$ maturity, approximately $75 \%$ of the maximum age. Two closely related species in the eastern North Pacific, $R$. binoculata and R. rhina, also attain 50\% maturity at a greater percent of maximum TL than percent maximum estimated age (McFarlane and King 2006). This trait is prevalent in other species in the family Rajidae, regardless of maximum TL, including A. radiata (Sulikowski et al. 2006), D. innominatus, D. nasutus, (Francis et al. 2001), D. laevis (Gedamke et al. 2005), D. trachyderma (Licandeo et al, 2007), L. erinacea (Cicia et al. 2009), Malacoraja senta (Sulikowski et al. 2009), R. brachyuran, $R$. montagui, $R$. naevus (Gallagher et al. 2004), R. texana (Sulikowski et al. 2007) and is exhibited by many shark species as well (Cortés 2000).

A distinct reproductive cycle was not observed for $R$. stellulata. The GSI results did not reveal any significant seasonal trends for either females or males. Furthermore, average maximum ovum diameter also did not present any significant seasonal trends. Average number of mature ova was significantly greater during the UPS, however this was likely driven by the presence of one female in April with 26 mature ova. Despite this one significant seasonal trend, $R$. stellulata appears to exhibit a year-round reproductive cycle. The presence of gravid females in April, July, and September lends support for this conclusion. This cycle type is exhibited by at least four species from the northeast Pacific: Bathyraja kincaidii (Perez et al. 2011), B. interrupta, (Ainsley 2009), Bathyraja trachura (Davis et al. 2007), and B. parmifera (Matta and Gunderson 2007) and several species worldwide including: Amblyraja radiata, Malacoraja senta, (Kneebone et al. 
2007), Bathyraja albomaculata, (Ruocco et al. 2006) and Fenestraja plutonia (Quattrini et al. 2009).

Skates, along with other oviparous elasmobranchs, generally, exhibit greater fecundities than viviparous elasmobranchs (Lucifora and García 2004, Musick and Ellis 2005). Estimates of fecundity for skates are rare however, mainly due to the difficulty of assessing fecundity of oviparous species. Estimates of annual egg production of several rajid species range from 2 to 360 eggs per year (Musick and Ellis 2005, Ebert et al. 2008b). Holden (1975) estimated fecundity of 60 to 140 eggs per year for captive Raja clavata, whereas captive Raja binoculata lays > 350 eggs annually (Ebert et al. 2008b). Matta and Gunderson (2007) estimated wild B. parmifera fecundity as 21 to 37 egg cases per year based on natural mortality and GSI. Obviously estimated skate egg production varies widely among and within species. The large ranges are likely due to uncertainty in estimates, differences in methodology of captive observations (Holden 1975, Ebert et al. 2008b) and differences in numerical calculations (Matta and Gunderson 2007). A fecundity table of Musick and Ellis (2005) included several species of similar maximum TL as R. stellulata: Leucoraja naevus, Raja asterias, R. eglanteria, R. miraletus and $R$. montagui, who have fecundities ranging from 25 to 112 with a mean value of 65 eggs per year. It is likely that the fecundity of $R$. stellulata would fall into this range, but more research such as captive observations or numerical estimates is needed to produce an accurate estimate of fecundity. 


\section{Literature Cited}

Ainsley, S.M., D.A. Ebert, and G.M. Cailliet. 2011. A comparison of reproductive parameters of the Bering Skate, Bathyraja interrupta, from two Alaskan large marine ecosystems. Marine and Freshwater Research 62: 557-566.

Braccini, J.M. and G.E. Chiaramonte. 2002. Reproductive biology of Psammobatis extenta. Journal of Fish Biology 61: 272-288.

Breaker, L.C. 2005. What's happening in Monterey Bay on seasonal to interdecadal time scales. Continental Shelf Research 25: 1159-1193.

Cicia, A.M., W.B. Driggers III, G.W. Ingram Jr., J. Kneebone, P.C.W. Tsang, D.M. Koester, and J.A. Sulikowski. 2009. Size and age estimates at sexual maturity for the little skate Leucoraja erinacea from the western Gulf of Maine, U.S.A. Journal of Fish Biology 75: 1648-1666.

Chelton, D.B. 1984. Seasonal variability of along-shelf geostrophic velocity off central California. Journal of Physical Oceanography 12: 757-784.

Conrath, C.L. 2004. Reproductive biology. In. J.A. Musick, R. Bonfil (eds.). Technical manual for the management of elasmobranchs. Asia Pacific Economic Cooperation and IUCN Shark Specialist Group Publication. pp. 133-164.

Cortés, E. 2000. Life history patterns and correlations in sharks. Reviews in Fishery Science 8: 299-344.

Davis, C.D., G.M. Cailliet, and D.A. Ebert. 2007. Age and growth of the roughtail skate Bathyraja trachura (Gilbert 1892) from the eastern North Pacific. Environmental Biology of Fishes 80: 325-336.

Di Lorenzo, E. 2003. Seasonal dynamics of the surface circulation in the Southern California Current System. Deep Sea Research II 50: 2371-2388.

Ebert, D.A. 2003. Sharks, rays and chimaeras of California. University of California Press, 284 pp.

Ebert, D.A. 2005. Reproductive biology of skates, Bathyraja (Ishiyama) along the eastern Bering Sea continental slope. Journal of Fish Biology 66: 618-649.

Ebert, D.A., L.J.V. Compagno, and P.D. Cowley. 2008a. Aspects of the reproductive biology of skates (Chondrichthyes: Rajiformes: Rajoidei) from southern Africa. ICES Journal of Marine Science 65: 81-102. 
Ebert, D.A., J.R. Maurer, S.M. Ainsley, L. Barnett and G.M. Cailliet. 2009. Life history and population dynamics of four endemic Alaskan skates: determining essential biological information for effective management of bycatch and target species. North Pacific Research Board Final Report, 715. 120 pp.

Ebert, D.A., W.D. Smith and G.M. Cailliet. 2008b. Reproductive biology of two commercially exploited skates, Raja binoculata and $R$. rhina, in the western Gulf of Alaska. Fisheries Research 94: 48-57.

Ebert, D.A., W.D. Smith, D.L. Haas, S.M. Ainsley and G.M. Cailliet. 2007. Life history and population dynamics of Alaskan skates: Providing essential biological information for effective management of bycatch and target species. North Pacific Research Board Final Report 510. 124 pp.

Flammang, B.E., D.A. Ebert and G.M. Cailliet. 2008. Reproductive biology of deep-sea catsharks (Chondrichthyes: Scyliorhinidae) in the eastern North Pacific.

Environmental Biology of Fishes 81: 35-39.

Francis, M.P., C.O. Maolagáin and D. Stevens. 2001. Age, growth, and sexual maturity of two New Zealand endemic skates, Dipturus nasutus and D. innominatus. New Zealand Journal of Marine and Freshwater Research 35: 831-842.

Frisk, M.G. and T.J. Miller. 2009. Maturation of Little Skate and Winter Skate in the Western Atlantic from Cape Hatteras to Georges Bank. Marine and Coastal Fisheries: Dynamics, Management, and Ecosystem Science 1: 1-11.

Gallagher, M.J., C.P. Nolan and F. Jeal. 2004. Age, Growth and Maturity of the Commerical Ray Species from the Irish Sea. Journal of Northwest Atlantic Fisheries Science 35: 47-66.

Gedamke, T., W.D. DuPaul and J.A. Musick. 2005. Observations on the Life History of the Barndoor Skate, Dipturus laevis, on Georges Bank (Western North Atlantic). Journal of Northwest Atlantic Fisheries Science 35: 67-78.

Hamlett, W.C. and T.J. Koop. 1999. Female reproductive system. In: W.C. Hamlett (ed.) Sharks, Skates and Rays. The John Hopkins University Press, Baltimore, MD (1999). pp. 398-443.

Hickey, B.M. 1979. The California current system: hypotheses and facts. Progress in Oceanography 8: 191-279.

Hickey, B.M. 1998. Coastal oceanography of western North America from the tip of Baja California to Vancouver Island. In. A.R. Robinson, K.H. Brink (eds.). Coastal Segment, The Sea Vol. 11. Wiley, New York. pp. 345-391. 
Holden, M.J. 1973. Are long-term sustainable fisheries for elasmobranchs possible? Rapports et Procès Verbaux des Rèunions du Conseil International pour l'Exploration de la Mer 164: 360-367.

Holden, M.J. 1975. The fecundity of Raja clavata in British waters. Journal du conseil international pour l'exploration de mer 36(2): 110-118.

Joung, S-J., P-H. Lee, K-M. Liu and Y-Y. Liao. 2011. Estimates of life history parameters of the sharpspine skate, Okamejei acutispina, in the northeastern waters of Taiwan. Fisheries Research 108: 258-267.

Kneebone, J., D.E. Ferguson, J.A. Sulikowski and P.C.W. Tsang. 2007. Endocrinological investigation into the reproductive cycles of two sympatric skate species, Malacoraja senta and Amblyraja radiate, in the western Gulf of Maine. Enviornmental Biology of Fishes 80: 257-265.

Kyne, P.M., A.J. Courtney and M.B. Bennett. 2008. Aspects of reproduction and diet of the Australian endemic skates Dipturus polyommata (Ogilby) (Elasmobranchii: Rajidae), by-catch of a commercial prawn trawl fishery. Journal of Fish Biology 72: 61-77.

Licandeo, R. and F.T. Cerna. 2007. Geographic variation in life-history traits of the endemic kite skate Dipturus chilensis (Batoidea: Rajidae), along its distribution in the fjords and channels of southern Chile. Journal of Fish Biology 71:421-440.

Licandeo, R., F. Cerna and R. Céspedes. 2007. Age, growth, and reproduction of the roughskin skate, Dipturus trachyderma, from the southeastern Pacific. ICES Journal of Marine Science 64: 141-148.

Licandeo, R.R., J.G. Lamilla, P.G. Rubilar and R.M. Vega. 2006. Age, growth, and sexual maturity of the yellownose skate Dipturus chilensis in the south-eastern Pacific. Journal of Fish Biology 68: 488-506.

Lucifora, L.O. and V.B. García. 2004. Gastropod predation on egg cases of skates (Chondrichthyes, Rajidae) in the southwestern Atlantic: quantification and life history implications. Marine Biology 145: 917-922.

Mabragana, E. and M.B. Cousseau. 2004. Reproductive biology of two sympatric skates in the south-west Atlantic: Psammobatis rudis and Psammobatis normani. Journal of Fish Biology 65: 559-573. 
Matta, M.E. and D.R. Gunderson. 2007. Age, growth, maturity and mortality of the Alaska skate, Bathyraja parmifera, in the eastern Bering Sea. Environmental Biology of Fishes 80: 309-323.

McFarlane, G.A. and J.R. King. 2006. Age and growth of big skate (Raja binoculata) and longnose skate (Raja rhina) in British Columbia waters. Fisheries Research 78: 169.178 .

Musick, J.A. and J.K. Ellis. 2005. Reproductive evolution of chondrichthyans. In: W.C. Hamlett (ed). Reproductive Biology and Phyologeny of Chondrichthes: Sharks, Batoids, and Chimaeras. Science Publishers Inc. Enfield, NH. pp. 45-79.

Oddone, M.C., A.F. Amorim, P.L. Mancini, W. Norbis, and G. Velasco. 2007. The reproductive biology and cycle of Rioraja agassizi (Muller and Henle, 1841) (Chondrichthyes: Rajidae) in southeastern Brazil, SW Atlantic Ocean. Scientia Marina 71(3): 593-604.

Perez, C.R., G.M. Cailliet and D.A. Ebert. 2011. Age, growth of the sandpaper skate, Bathyraja kincaidii, using vertebral centra, with an investigation of caudal thorns. Journal of Marine Biological Association of the United Kingdom 91(6): 11491156.

Quattrini, A.M., M.L. Partyka, and S.W. Ross. 2009. Aspects of the reproductive biology of the skate Fenestraja plutonia (Garman) off North Carolina. Southeastern Naturalist 8(1): 55-70.

Richards, S.W., D. Merriman, and L.H. Calhoun. 1963. Studies on the Marine Resources of Southern New England. IX. The biology of the little skate, Raja erinacea (Mitchell). Bulletin of the Bingham Oceanographic Collection 18(3): 1-67.

Ruocco, N.L, L.O. Lucifora, J.M. Díaz de Astarloa, and O. Wöhler. 2006. Reproductive biology and abundance of the white-dotted skate, Bathyraja albomaculata, in the Southwest Atlantic. ICES Journal of Marine Science 63: 105-116.

Smith, S.E., D.W. Au and C. Show. 1998. Intrinsic rebound potentials of 26 species of Pacific sharks. Marine and Freshwater Research 49: 663-678.

Sulikowski, J.A., J. Kneebone, S. Elzey, J. Jurek, W.H. Howell and P.C.W. Tsang. 2006. Using the composite variables of reproductive morphology, histology and steroid hormones to determine age and size at sexual maturity for the thorny skate Amblyraja radiata in the western Gulf of Maine. Journal of Fish Biology 69: 1449-1465. 
Sulikowski, J.A., S.B. Irvine, K.C. DeValerio and J.K. Carlson. 2007. Age, growth and maturity of the roundel skate, Raja texana, from the Gulf of Mexico, USA. Marine and Freshwater Research 58: 41-53.

Sulikowski, J.A., A.M. Cicia, J.R. Kneebone, L.J. Natanson and P.C.W. Tsang. 2009. Age and size at sexual maturity of the smooth skate Malacoraja senta from the western Gulf of Maine. Journal of Fish Biology 75: 2832-2838.

Tisch, T.D., S.R. Ramp and C.A. Collins. 1992. Observations of the geostrophic current and water mass characteristics off Point Sur, California from May 1988 through November 1989. Journal of Geophyscial Research 97(C8): 12535-12556.

Zar, J.H. 1999. Biostatistical Analysis. $4^{\text {th }}$ Edition. Prentice Hall, Upper Saddle River, N.J. 663 pp. 
Chapter Three: Habitat Classification and Distribution 


\section{Introduction}

Habitat can be loosely defined as the space and conditions where a species can be found. Different chondrichthyan species, as with all species, have different geographic ranges from the Mekong Freshwater Stingray, Dasyatis laosensis, which only inhabits the limited waters of the Mekong and Chao Phraya Rivers in Southeast Asia (Compagno 2005) to the blue shark, Prionace glauca, which globally occupies most of the upper open ocean environment (Stevens 2010). Investigation of a species' geographic range and the habitats therein is a crucial part of fisheries management and the life history of a species.

One method to reduce fishing pressure on a species is to protect specific habitats within its geographic range. Amendments to the Magnuson-Stevens Fishery Conservation and Management Act in 1996 required coastal states to identify what is known as Essential Fish Habitat (EFH), which is described as "those waters and substrate necessary to fish for spawning, breeding, feeding or growth to maturity" (USDOC 2007). The determination and subsequent protection of this marine habitat, or parts of it, will allow organisms living in these areas to maintain or increase the species' population, which in turn promotes sustainable fishing practices.

The first step in determining EFH is to describe the factors that characterize a marine habitat. Key habitat characteristics that determine species distribution include depth, temperature, and sediment composition (Mueter and Norcross 1999, Mahon and Smith 1989). These characteristics are relatively easy to discern for most marine habitats and can be further described using temperature and depth data loggers and large scale 
habitat mapping projects. The same characteristics also describe a species' vulnerability to fishing when combined with known local fishing pressures such as fishing gear type and target fisheries.

EFH reports that include sediment composition, depth, and temperature have been published for at least seven western Atlantic skate species (Packer et al. 2003a-g). All seven occur on soft sediment bottoms of either mud, sand, broken shell, or gravel, from zero to $1,200 \mathrm{~m}$ depth, but most commonly near or above $100 \mathrm{~m}$ depth and within a $10^{\circ} \mathrm{C}$ range (Packer et al. 2003a-g). Skates worldwide typically inhabit soft sediment habitats, which can be detrimental because soft sediment is the ideal substrate for trawl fisheries, the largest fishery on skates (Stevens et al. 2000).

Assessments of EFH also have been conducted for three species of skate that occur in the eastern North Pacific: $R$. binoculata, $R$. inornata, and R. rhina. All three species occur on soft sediments of either mud, urchins, or cobble from zero to $1,069 \mathrm{~m}$ depth, most commonly occurring at $100 \mathrm{~m}$ depth (McCain et al. 2005). This also conforms to the convention that skates occur on soft sediments.

Another skate of the eastern North Pacific is the Starry Skate, R. stellulata, that inhabits rocky habitats. Raja stellulata was referred to as the Rock Skate by fishermen (Starks 1918), which alludes to its use of rocky habitat. This is confirmed by photographs taken by SCUBA divers of $R$. stellulata throughout its geographic range (Fig. 1). Despite this exception to the convention that skates live on soft bottoms, no research has been conducted to describe the habitat of $R$. stellulata. 


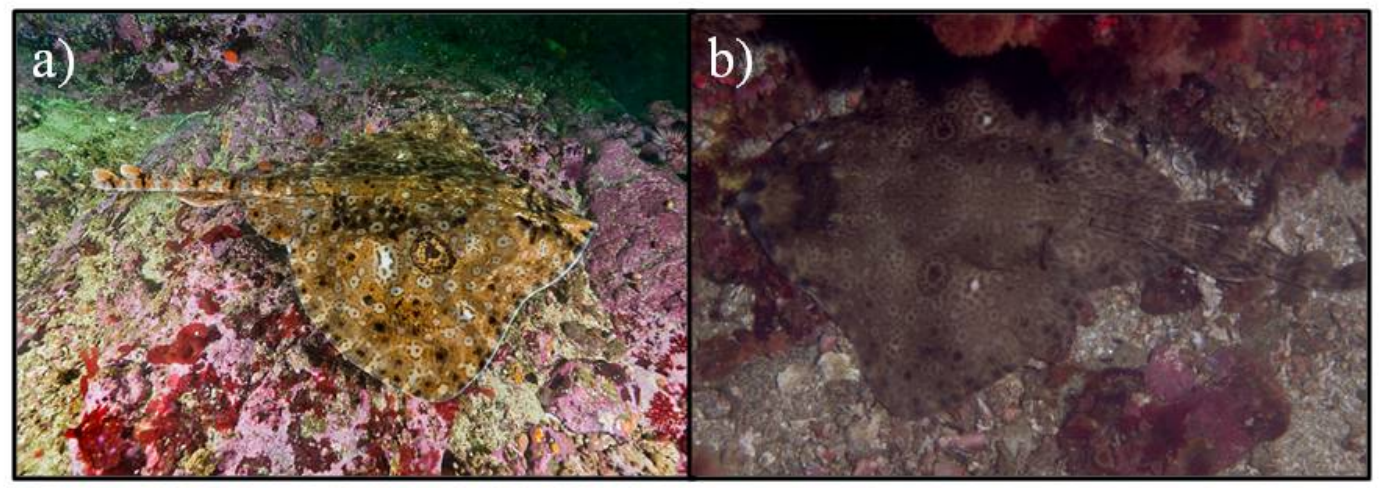

Figure 1. Photographs by SCUBA divers of $R$. stellulata on rocky habitat. a) in Barkley Sound, British Columbia (Photo Credit: Scott Stevenson); and b) at Santa Barbara Channel Islands (Photo Credit: Chris Grossman).

Differences in life history characters may be driven in part by differences in habitat. It has been observed that in the eastern North Pacific skate species tend to segregate by depth (Dave Ebert, pers. comm.). In addition, a recent study by Winton (2011) determined for Alaskan bathyrajids that as habitat depth of a species increased the longevity of that species increases relating life history to habitat. If this convention is true of other skate assemblages worldwide then it would be a powerful tool to apply to skate species that are not available for a thorough life history study.

The goal of this chapter is to provide knowledge on the habitat and distribution of Raja stellulata and relate the knowledge to other skate species in central California. The main objectives were to 1 ) characterize $R$. stellulata habitat using the variables: substrate consolidation, depth, and temperature, 2) compare gear type efficacy on $R$. stellulata collection, and compare with substrate consolidation, depth, and temperature, 3) determine spatial trends of $R$. stellulata habitat throughout its geographic range, and 4) examine age and depth trends in the central California skate assemblage. 


\section{Methods}

\section{Collection}

Raja stellulata specimens were collected by Southwest Fisheries Science Center Santa Cruz Laboratory (SWFSC-SCL) from 2002 to 2005 and by Northwest Fisheries Science Center Fishery Resource and Monitoring division (NWFSC-FRAM) from 2006 to 2010 by trawl and demersal longline along the coast of California and Oregon (ca. $45^{\circ}$ $16^{\prime} \mathrm{N}, 124^{\circ} 28^{\prime} \mathrm{W}$ to $\left.32^{\circ} 20^{\prime} \mathrm{N}, 119^{\circ} 40^{\prime} \mathrm{W}\right)$. Geographic coordinates, depth, temperature, and gear type were recorded for each collection site.

\section{Habitat Description}

Geographic coordinates were mapped using ArcMap (ArcGIS version 9.0). Maps of substrate consolidation from the California State University, Monterey Bay (CSUMB) Seafloor Mapping Laboratory and the Pacific States Marine Fisheries Commission (PSMFC) Pacific Coast Marine Habitat Program were applied to the collection site map. Each coordinate pair was used once regardless that multiple specimens were often collected at one site. Each collection site was assigned a substrate consolidation type based on its location: hard outcrop, mixed substrate, or soft sediment (Greene et al. 1999, Greene et al. 2007). Percentage occurrence of each substrate consolidation was calculated to observe habitat trends. Trends between substrate type and sex and substrate type and TL were examined using a Kruskal-Wallis (K-W) test, due to violated assumptions, and a linear regression, respectively. 
Minimum, maximum and mean depths were calculated to determine depth trends. Minimum, maximum, and mean temperatures were calculated to determine temperature trends. A t-test was conducted to compare depth and sex and a linear regression examined the relationship between depth and TL to determine possible spatial segregation of sexes or sizes. K-W tests were conducted, due to violated assumptions, between substrate type and depth, and substrate type and temperature.

\section{Gear Effects}

A comparison using a t-test was made between collection gear types, longline and trawl, to determine potential gear selectivity or bias on the sizes of skates collected. To further examine gear type and habitat trends t-tests were conducted between gear type and depth, gear type and temperature, collection survey (NWFSC-FRAM or SWFSCSCL), and depth, and collection survey and temperature. Further comparisons examined substrate type and gear type, and substrate and collection survey.

\section{Spatial Trends}

Spatial trends were examined with linear regressions for latitude and TL, and longitude and TL. T-tests were conducted to test for differences between latitude and sex, longitude and sex, latitude and gear type, longitude and gear type, latitude and survey, and longitude and survey. Finally, K-W tests were conducted, due to violated assumptions, to test differences between latitude and substrate type and longitude and substrate type. 


\section{Age/Depth Trend}

Average depth for six central California skate species, B. kincaidii, B. trachura, $R$.

binoculata, $R$. inornata, $R$. rhina and $R$. stellulata, was calculated from collection data from SWFSC-SCL and NWFSC-FRAM surveys. Maximum estimated age from gross section age estimates were plotted against average depth and the trend was examined with a linear regression.

\section{Results}

\section{Collection}

The surveys sampled at over 3,600 sites during the study period. Geographic coordinates, depths and gear type for $R$. stellulata collections were available for 58 locations, which corresponded to 182 specimens out of 194 used for this study (Chapter One, Two). Temperatures were available for 31 locations, which corresponded to 122 individuals. Additional data were provided by NWFSC-FRAM in which $R$. stellulata was collected, but not retained. This provided an additional 47 collection sites, depths and gear types and 89 additional individuals. Temperature also was available for these data adding 44 temperature points. Total combined number of collection sites with geographic coordinates, depth and gear type for $R$. stellulata was 105 and total combined number of temperature points was 75 . 


\section{Habitat Description}

One thousand three hundred and sixty-eight sites of both surveys were assigned a substrate type. In total, $350(26 \%)$ were designated hard outcrop, $356(26 \%)$ as mixed substrate, and $652(48 \%)$ as soft sediment. One hundred of $R$. stellulata's collection sites were assigned a substrate consolidation (Fig. 2). Fifty-three (53\%) were designated hard outcrop, thirty-two (32\%) were designated soft sediment, and fifteen (15\%) were designated mixed substrate. Collection sites were represented by 259 individuals, with $56.8 \%$ of the individuals occurring on hard outcrop, $30.1 \%$ occurring on soft sediment, and $13.1 \%$ occurring on mixed substrate. Substrate type did significantly differ with skate TL $(K=37.20, \mathrm{df}=2, \mathrm{p}<0.001)$, where mixed substrate had smaller sizes than either hard outcrop or soft sediment (Fig. 3). Sexes did not exploit different substrate types because the female to male ratio did not differ significantly from $1: 1$ for any substrate type $\left(\chi^{2}<2.22\right.$, df $\left.=2, \mathrm{p}>0.136\right)$.

The minimum depth that $R$. stellulata were collected was $54.2 \mathrm{~m}$; the maximum depth was a new record of $982.4 \mathrm{~m}$ and the average collection depth was $129.1 \mathrm{~m}$. Eighty-one of the 105 collections sites (77.1\%) occurred between 70 and $150 \mathrm{~m}$ depth. The average temperature was $8.9^{\circ} \mathrm{C}$ (range: $4.1-11.6^{\circ} \mathrm{C}$ ). Depth was not different between sexes (two-sample t-test: $\mathrm{t}=-0.94, \mathrm{df}=264, \mathrm{p}=0.348$ ) and was not significantly correlated with TL $(\mathrm{p}=0.311)$. Substrate types used by $R$. stellulata did not differ significantly with depth (Kruskal-Wallis test: $\mathrm{K}=0.42$, df $=2, \mathrm{p}=0.810$ ), it did however differ significantly with temperature $(\mathrm{K}=16.25$, $\mathrm{df}=2, \mathrm{p}<0.001)$. Cooler temperatures were found on soft sediments than on hard outcrop or mixed substrate. 


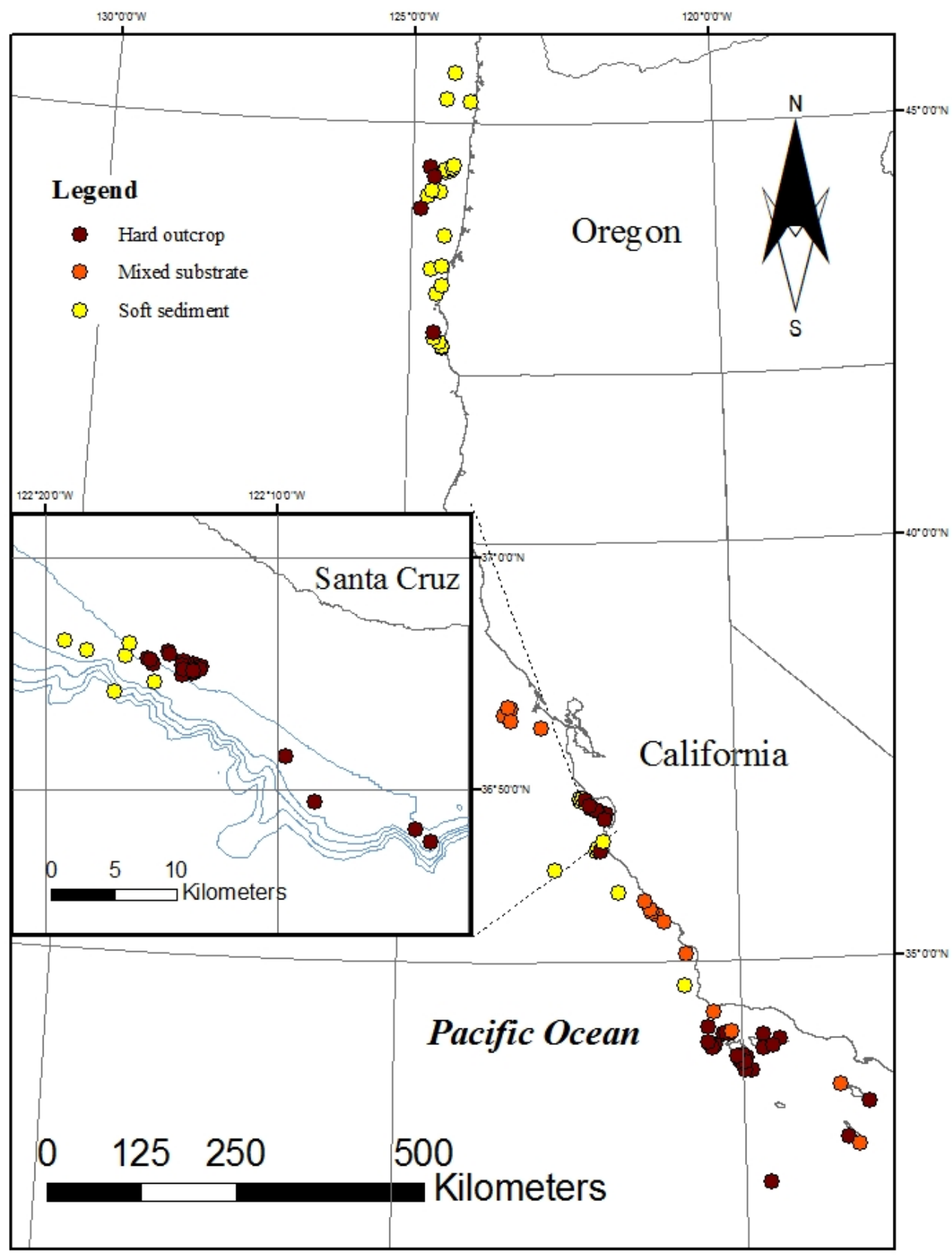

Figure 2. Map of $R$. stellulata collection sites assigned a substrate consolidation ( $\mathrm{n}=$ 100). Inset of northwest Monterey Bay. 


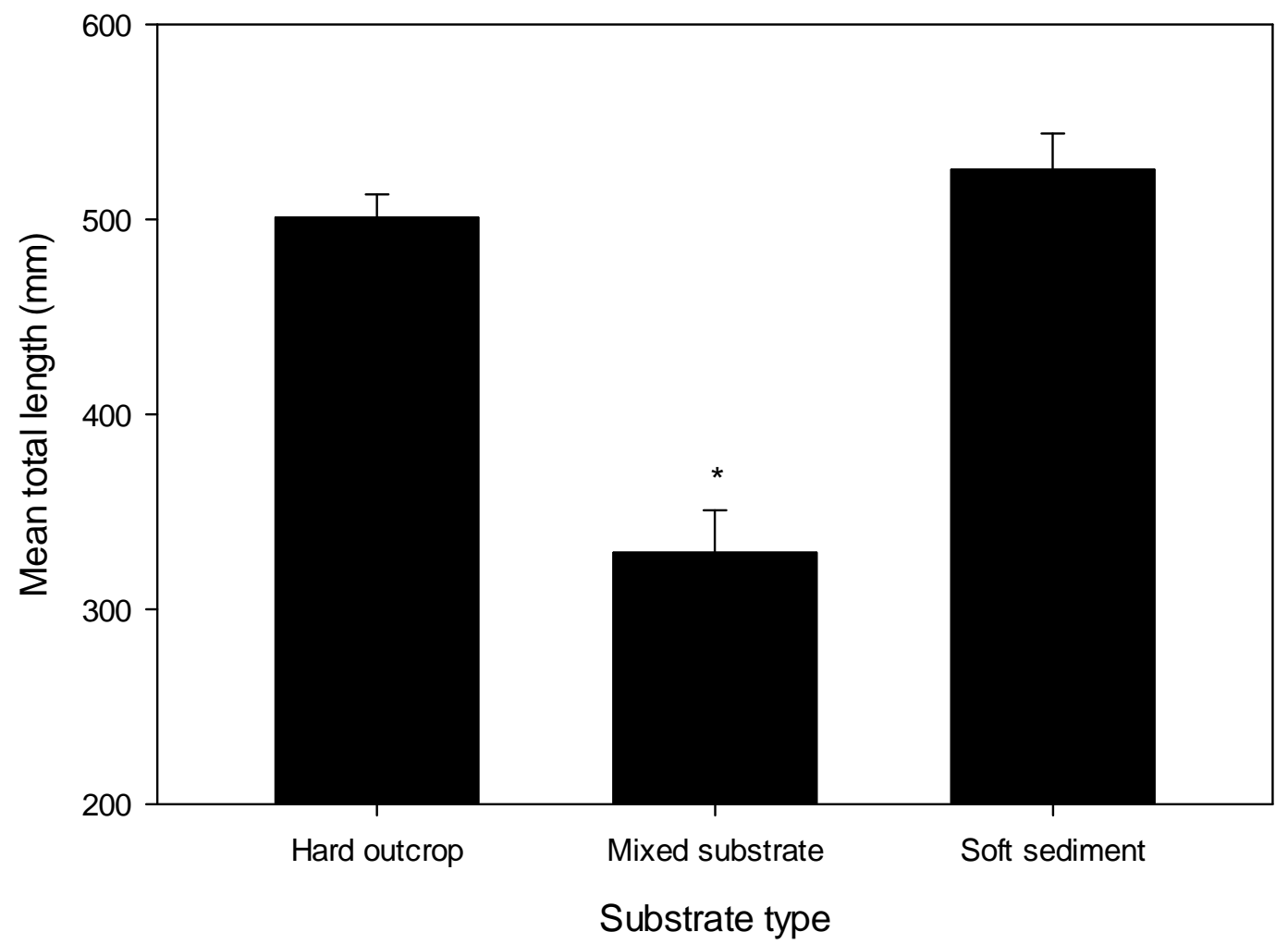

Figure 3. Substrate type with TL $(\mathrm{n}=261)$. Asterisk indicates significant difference $(\mathrm{p}<$ 0.001). 


\section{Gear Effects}

Gear type, trawl or longline, exhibited a significant difference in sizes of $R$. stellulata collected $(\mathrm{t}=-10.86, \mathrm{df}=268, \mathrm{p}<0.001)$. Trawls collected 156 individuals with a mean TL of $402 \mathrm{~mm}$ and a range of 151 to $761 \mathrm{~mm}$ TL, whereas longlines collected 114 individuals with a mean TL of $584 \mathrm{~mm}$ and a range from $413 \mathrm{~mm}$ to 735 mm TL. Gear types did not sample significantly different depths $(t=1.12, \mathrm{df}=103, \mathrm{p}=$ $0.266)$ or temperatures $(\mathrm{t}=-0.77, \mathrm{df}=73, \mathrm{p}=0.445)$. Trawl gear was used at 77 of the 100 collection sites. When trawl gear was used, it collected $R$. stellulata 34 times on hard outcrop (44.2\%), 28 times on soft sediment (36.4\%) and 15 times on mixed substrate (19.5\%). Longline gear was used at the other 23 collection sites. When longline gear was used, it collected $R$. stellulata 19 times on hard outcrop (82.7\%), 4 times on soft sediment (17.4\%), and never on mixed substrate.

Collection surveys, SWFSC-SCL and NWFSC-FRAM, were spatially different, however, there was no difference between survey and depth $(\mathrm{t}=-1.04$, $\mathrm{df}=103, \mathrm{p}=$ $0.301)$ or between survey and temperature $(t=0.64, \mathrm{df}=73, \mathrm{p}=0.523)$. A majority of the collection sites was from the NWFSC-FRAM survey $(n=74), 34$ of the sites were on hard outcrop (45.9\%), 25 of the sites were on soft sediment (33.8\%), and 15 sites were on mixed substrate (20.3\%). NWFSC-FRAM exclusively used trawl gear for collection. The SWFSC-SCL collected $R$. stellulata at 26 sites with 19 on hard outcrop (73.1\%), 7 on soft sediment (26.9\%), and none on mixed substrate. SWFSC-SCL used mostly longline gear for collection with a few sites collected with trawl gear $(n=3)$. 


\section{Spatial Trends}

Latitude did not correlate with TL $(\mathrm{p}=0.533)$, but longitude was significantly correlated with TL $\left(\mathrm{r}^{2}=0.012, \mathrm{TL}=-14.92 *\right.$ Longitude $\left.-1341.72, \mathrm{p}=0.040\right)$ where as longitude decreased, TL decreased. Sex did not vary significantly with either latitude or longitude (Latitude: $\mathrm{t}=-1.36, \mathrm{df}=264, \mathrm{p}=0.174$; Longitude: $\mathrm{t}=1.45, \mathrm{df}=264, \mathrm{p}=$ 0.149). Gear type, longline or trawl, was not significantly different with latitude $(\mathrm{t}=$ 1.24, $\mathrm{df}=103, \mathrm{p}=0.217)$ or longitude $(\mathrm{t}=-0.29, \mathrm{df}=103, \mathrm{p}=0.775)$. Collection survey also was not significantly different with latitude $(\mathrm{t}=-1.34$, $\mathrm{df}=103, \mathrm{p}=0.185)$ or longitude $(\mathrm{t}=-0.33, \mathrm{df}=103, \mathrm{p}=0.740)$. Substrate type was significantly different with latitude and longitude (Latitude: $\mathrm{K}=32.07$, $\mathrm{df}=2, \mathrm{p}<0.001$; Longitude: $\mathrm{K}=34.71$, $\mathrm{df}=$ $2, \mathrm{p}<0.001)$, in that soft sediment was encountered more often than the other substrate types at higher latitudes (Fig. 4a). Soft sediment was encountered more often at western latitudes (Fig. 4b). 
a)

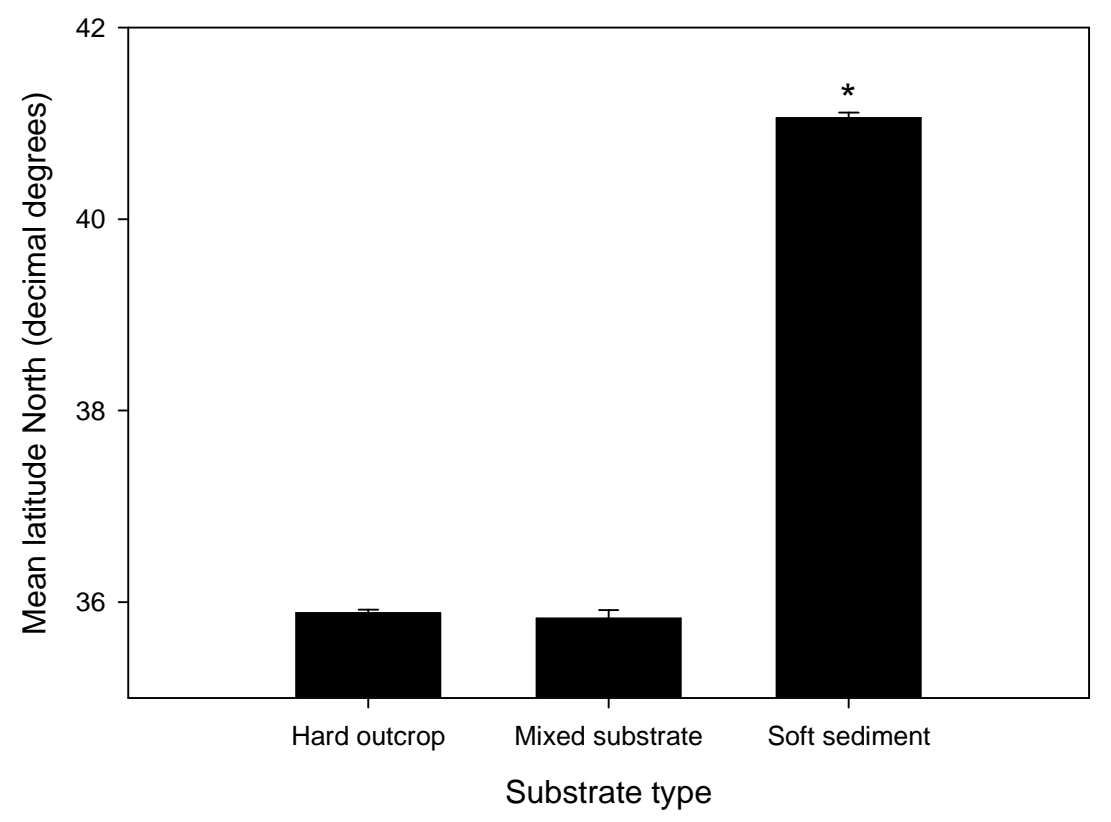

b)

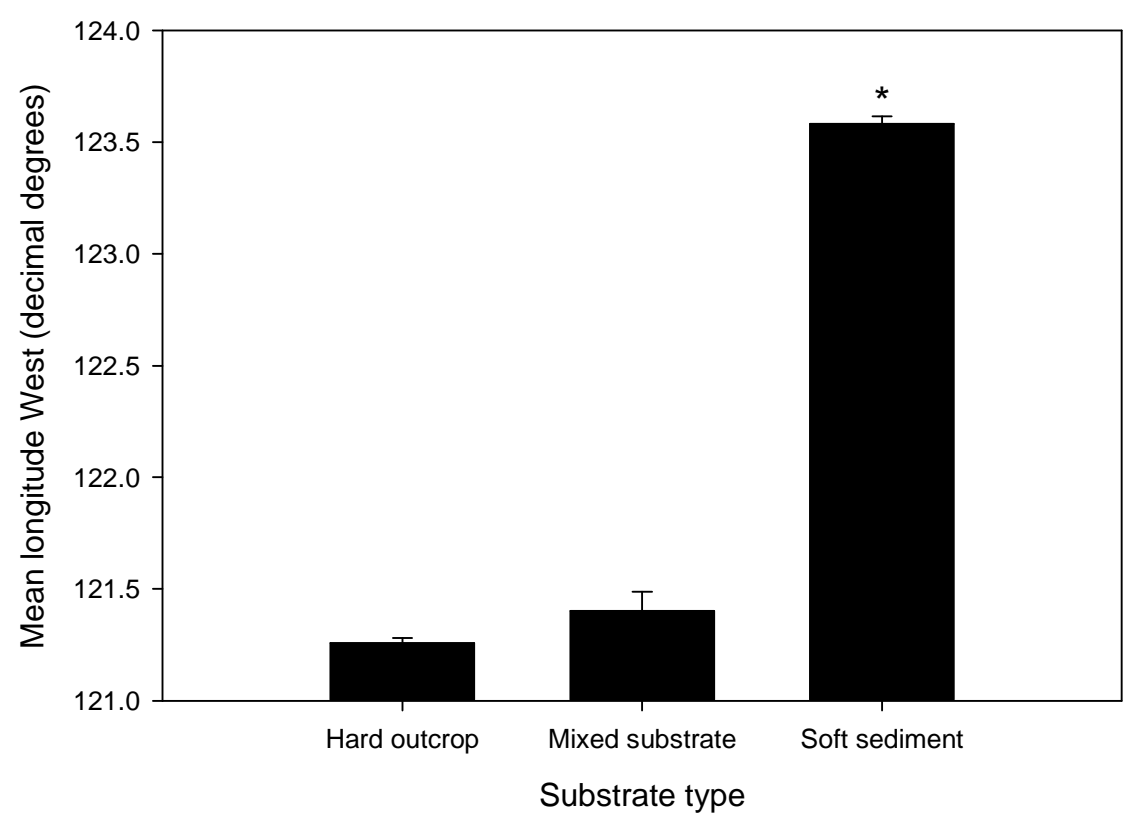

Figure 4. Mean a) latitude and b) longitude of different substrate types $(n=100)$. Error bars represent one standard error. Asterisk indicates significant difference $(p<0.001)$. 


\section{Age/Depth Trend}

Average depth ranged among species from $65 \mathrm{~m}$ for $R$. binoculata to $956 \mathrm{~m}$ for $B$. trachura. Maximum estimated age ranged from 11 years for $R$. stellulata to 20 years for B. trachura. Age was significantly correlated with depth among central California skate species $\left(\mathrm{r}^{2}=0.760\right.$, Age $=0.01 *$ Depth $\left.+11.45, \mathrm{p}<0.001\right)$ where an increase in habitat depth resulted in an increase in maximum estimated age (Fig. 5).

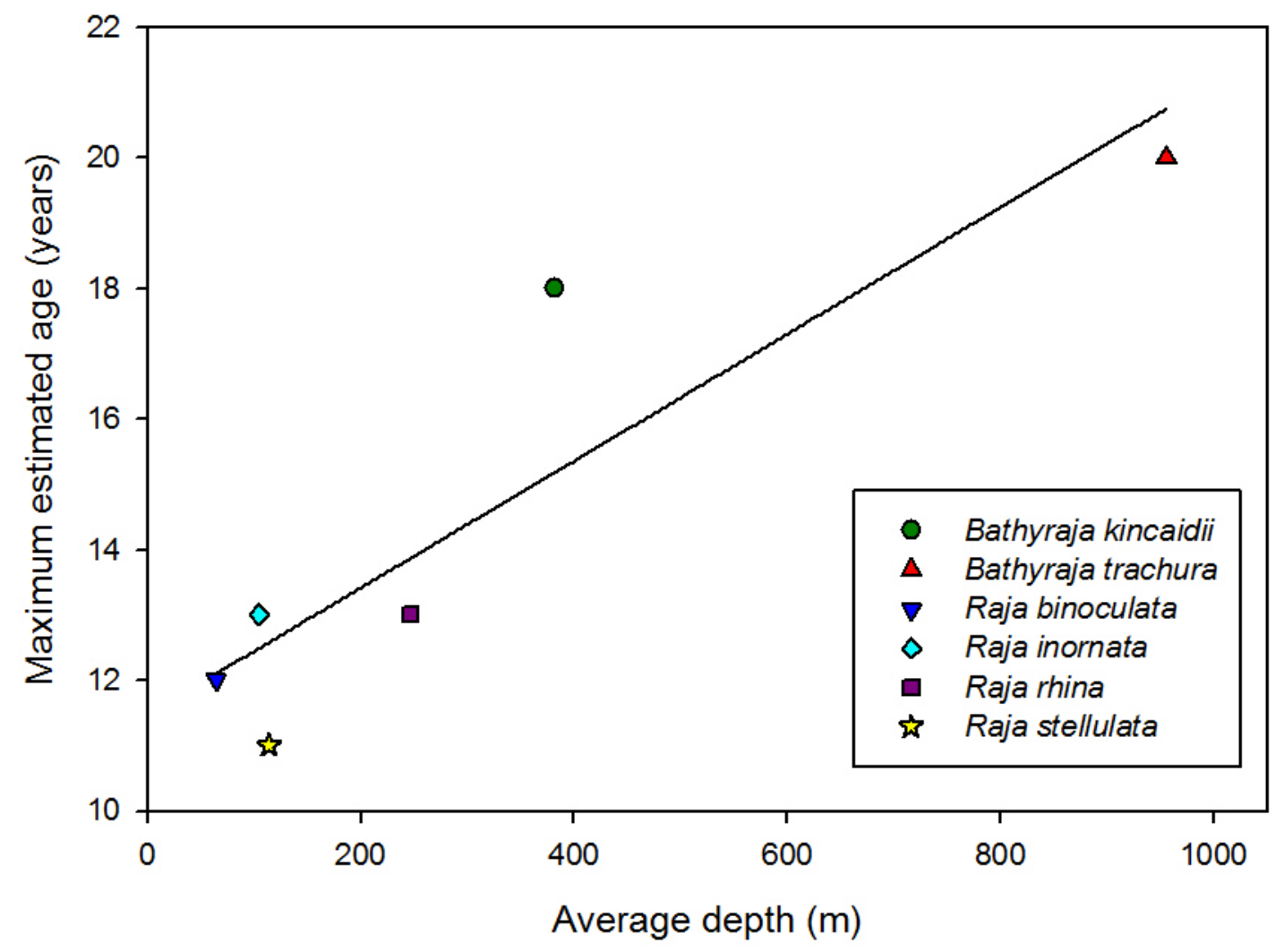

Figure 5. Relationship of the maximum estimated age of central California skates with mean depth $\left(\operatorname{adj} r^{2}=0.760\right)$. Standard error of mean depth (not shown) was less than 15 $\mathrm{m}$ for each species. 


\section{Discussion}

The occurrence of $R$. stellulata on hard outcrop rather than soft sediment may be a driving factor as to why it is not a major component of California skate bycatch.

Historically, its alternate common name was the Rock Skate referring to its occurrence on rocky outcrops (Starks 1918). Furthermore, in this study it was most often collected on hard outcrops (53\%) followed by soft sediment (32\%) and mixed substrate (15\%), whereas the distribution of substrate sampled was $48 \%$ soft sediment and $26 \%$ hard outcrop and mixed substrate each. The largest fishery for skates is trawl fisheries, which are most effective on soft sediment (Stevens et al. 2000). EFH descriptions in the Western Atlantic and eastern North Pacific designate soft sediment habitats, which included mud, sand, broken shell, urchins, gravel, and cobble for ten skate species (Packer et al. 2003a-g, McCain et al. 2005). These skate species exemplify the habitat generalization that skates occur on soft sediments and are documented bycatch mostly in trawl fisheries (Martin and Zorzi 1993, Stevens et al. 2000, Packer et al. 2003a-g, CDFG 2009).

The depth range collected in this study reflected the previously observed depth trends (Ebert 2003). A depth range extension from $732 \mathrm{~m}$ (Ebert 2003) to $982.4 \mathrm{~m}$ is quite a large extension, but is likely a rare case since $77.1 \%$ of the collections sites were between 70 and $150 \mathrm{~m}$ depth and only five collections below $300 \mathrm{~m}$. The temperature range was representative of the depth range as would be expected since depth and temperature are correlated. 
Gear selectivity is well documented and utilized in fishing practices to increase intentional catch and reduce bycatch. Not surprisingly, trawl and demersal longline gear exhibited selectivity in the size distribution of $R$. stellulata $(\mathrm{p}<0.001)$ and substrate type sampled. Trawl gear successfully collected the entire size range, 151 to $761 \mathrm{~mm}$ TL whereas longline gear only collected individuals greater than $400 \mathrm{~mm}$ TL. Trawl gear was the dominant sampling method $(n=77)$ and sampled all three substrate types, mostly hard outcrop (44.2\%) and soft sediment (36.4\%) with only 19.5\% sampled on mixed substrate. Longline gear was used less $(n=28)$ and was more selective sampling most often on hard outcrop and never on mixed substrate. The collection surveys reflected the gear type selectivity because the NWFSC-FRAM surveys used exclusively trawl gear and the SWFSC-SCL surveys used mostly longline gear with only three sites collected with trawl gear. Large R. stellulata were most often caught using longline gear on hard outcrop, whereas small $R$. stellulata were most often caught using trawl gear on any substrate type.

Habitat factors are often inter-related where significant relationships can be described through understood trends such as increasing depth and decreasing temperature. For R. stellulata, substrate type differed significantly with temperature ( $\mathrm{p}<$ 0.001) with cooler temperatures recorded from soft sediment sites. Because both substrate type and temperature are correlated with latitude and longitude the difference in temperature between substrate types is likely due to the spatial trends where temperatures decrease with increasing latitude and soft sediment occurs more often in higher latitudes. Another example is that substrate type also differed significantly with TL $(\mathrm{p}<0.001)$ 
with mixed substrate sites having smaller sizes than either other substrate type. This result is likely an artifact of gear type because trawl gear effectively sampled small $R$. stellulata on all substrates and longline gear failed to sample small $R$. stellulata and never sampled mixed substrate. Finally, longitude was correlated with TL $(p=0.040)$. This is likely because there were fewer samples at western latitudes that could not adequately represent the full size range. The adjusted $\mathrm{r}^{2}$ is very small $\left(\operatorname{adj} . \mathrm{r}^{2}=0.012\right)$ indicating that this correlation describes very little of the variation.

A potentially biologically significant result was that both the relationships between substrate types and latitude and substrate types and longitude were significant ( $\mathrm{p}$ $<0.001$. Raja stellulata was collected on soft sediment more often at higher latitudes and western longitudes (Fig. 4). This can stem from two causes: that the substrate type of the U.S. West coast differs with latitude and longitude or that $R$. stellulata exhibits a shift in habitat use from mostly hard outcrop and mixed substrates to soft sediments at higher latitudes and western longitudes. Soft sediment was sampled more often than hard outcrop at higher latitudes and western longitudes, so this may be an artifact of sampling methods. The application of a more uniform sampling design using both longline and trawl throughout $R$. stellulata's geographic range would resolve issues potentially related to gear type.

The central California skate assemblage, B. kincaidii, B. trachura, $R$. binoculata, $R$. inornata, $R$. rhina, and $R$. stellulata, exhibits an inter-species trend of increasing longevity with increasing depth (Fig. 5). There are distinct taxonomic and environmental differences between Raja and Bathyraja; they belong to different families (Rajidae and 
Arynchobatidae) and inhabit different depth and temperature habitats. The same interspecies trend of increased longevity with increased habitat depth was observed in the Alaskan skate assemblage among bathyrajid species (Winton 2011). The trend is likely driven by the effects of temperature, which is directly related to depth, on an organism's metabolism. Beverton and Holt (1959) determined that the growth rate of a poikiolothermic fish decreased with decreasing temperature. Therefore, slower growth and increased longevity would be expected in cooler temperatures or deeper depths. This trend may be helpful in assessing life history characteristics of species that have little data available for them and have yet to be collected in large enough numbers for a full life history study. 


\section{Literature Cited}

Beverton, R.J.H., and S.J. Holt. 1959. A review of the lifespans and mortality rates of fish in nature and the relation to growth and other physiological characterisitics. In: Ciba Foundation, Colloquia in ageing V. The life span of animals. pp. 142-177. Churchill, London.

California Department of Fish and Game (CDFG) 2009. Review of selected California fisheries for 2008: Coastal pelagic finfish, market squid, ocean salmon, groundfish, California spiny lobster, spot prawn, white seabass, kelp bass, thresher shark, skates and rays, Kellet's whelk, and sea cucumber. Fisheries Review: CalCOFI Report 50: 14-42.

Compagno, L.J.V. 2005. Dasyatis laosensis. In: IUCN 2010. IUCN Red List of Threatened Species. Version 2010.3. 〈www.iucnredlist.org>. Downloaded on 10 October 2010.

Ebert, D.A. 2003. Sharks, rays, and chimaeras of California. University of California Press, 284 pp.

Ebert, D.A., W.D. Smith and G.M. Cailliet. 2008. Reproductive biology of two commercially exploited skates, Raja binoculata and $R$. rhina, in the western Gulf of Alaska. Fisheries Research 94: 48-57.

Gburski, C.M., S.K. Gaichas, and D.K. Kimura. 2007. Age and growth of big skate (Raja binoculata) and longnose skate (R. rhina) in the Gulf of Alaska. Environmental Biology of Fishes 80: 337-349.

Greene, H.G., M.M. Yoklavich, R.M. Starr, V.W. O'Connell, W.W. Wakefield, D.E. Sullivan, J.E. McRea Jr. and G.M. Cailliet. 1999. A classification scheme for deep seafloor habitats. Oceanologica Acta 22(6): 663-678.

Greene, H.G., J.J. Bizzarro, V.M. O’Connell and C.K. Brylinsky. 2007. Construction of digital potential marine benthic habitat maps using a coded classification scheme and its application. In. Todd, B.J. and H.G. Greene (eds.). Mapping the Seafloor for Habitat Characterization. Geological Association of Canada Special Paper 47: 141-155.

Licandeo, R. and F.T. Cerna. 2007. Geographic variation in life-history traits of the endemic kite skate Dipturus chilensis (Batoidea: Rajidae), along its distribution in the fjords and channels of southern Chile. Journal of Fish Biology.71:421-440. 
Mahon, R. and R.W. Smith. 1989. Demersal Fish Assemblages on the Scotian Shelf, Northwest Atlantic: Spatial Distribution and Persistence. Canadian Journal of Fisheries and Aquatic Sciences 46 (Suppl. 1): 134-152.

Martin, L. and G.D. Zorzi. 1993. Status and review of the California skate fishery. NOAA Technical Report NMFS 115: 39-52.

McCain, B.B., S.D. Miller and W.W. Wakefield II. 2005. Life history, geographical distribution, and habitat associations of 82 West coast groundfish species: a literature review. Pacific Coast Groundfish Fishery Management Plan. Appendix B. Part 2. 266 pp.

McFarlane, G.A. and J.R. King. 2006. Age and growth of Big Skate (Raja binoculata) and Longnose Skate (Raja rhina) in British Columbia waters. Fisheries Research 78: $169-178$.

Mueter, F.J. and B.L. Norcross. 1999. Linking community structure of small demersal fishes around Kodiak Island, Alaska, to environmental variables. Marine Ecology Progress Series 190: 37-51.

Packer, D.B., C.A. Zetlin and J.J. Vitaliano. 2003a. Essential fish habitat source document: Barndoor Skate, Dipturus laevis, life history and habitat characteristics. NOAA Tech Memo, NMFS NE, 173. 23 p.

Packer, D.B., C.A. Zetlin and J.J. Vitaliano. 2003b. Essential fish habitat source document: Clearnose Skate, Raja eglanteria, life history and habitat characteristics. NOAA Tech Memo, NMFS NE, 174. 50 p.

Packer, D.B., C.A. Zetlin and J.J. Vitaliano. 2003c. Essential fish habitat source document: Little Skate, Leucoraja erinacea, life history and habitat characteristics. NOAA Tech Memo, NMFS NE, 175. 66 p.

Packer, D.B., C.A. Zetlin and J.J. Vitaliano. 2003d. Essential fish habitat source document: Rosette Skate, Leucoraja garmani virginica, life history and habitat characteristics. NOAA Tech Memo, NMFS NE, 176. 17 p.

Packer, D.B., C.A. Zetlin and J.J. Vitaliano. 2003e. Essential fish habitat source document: Smooth Skate, Malacoraja senta, life history and habitat characteristics. NOAA Tech Memo, NMFS NE, 177. 26 p.

Packer, D.B., C.A. Zetlin and J.J. Vitaliano. 2003f. Essential fish habitat source document: Thorny Skate, Amblyraja radiata, life history and habitat characteristics. NOAA Tech Memo, NMFS NE, 178. 39 p. 
Packer, D.B., C.A. Zetlin and J.J. Vitaliano. 2003g. Essential fish habitat source document: Winter Skate, Leucoraja ocellata, life history and habitat characteristics. NOAA Tech Memo, NMFS NE, 179. 57 p.

Starks, E.C. 1918. The adult of Raja montereyensis Gilbert. Copeia 52: 2-5.

Stevens, J.P. 2010. Epipelagic Oceanic Elasmobranchs. In. Carrier, J.C., J.A. Musick and M.R. Heithaus (eds.) Sharks and their relatives II: biodiversity, adaptive physiology and conservation. pp. 3-35.

Stevens, J.D., R. Bonfil, N.K. Dulvy and P.A. Walker. 2000. The effects of fishing on sharks, rays and chimaeras (chonrichthyans), and the implications for marine ecosystems. ICES Journal of Marine Science 57: 476-494.

Swain, D.P. and H.P. Benoit. 2006. Change in habitat associations and geographic distribution of thorny skate (Amblyraja radiata) in the southern Gulf of St. Lawrence: density-dependent habitat selection or response to environmental change? Fisheries Oceanography 15(2): 166-182.

USDOC (U.S. Department of Commerce). 2007. Magnuson-Stevens Fishery Conservation and Management Act as amended through January 12, 2007. National Oceanic and Atmospheric Administration Technical Memorandum. P.L. pp. 94-265.

Winton, M.V. 2011. Age, growth, and demography of the Roughtail Skate, Bathyraja trachura (Gilbert, 1892), from the eastern Bering Sea. M.S. Thesis. California State University, Monterey Bay.

Zeiner, S.J. and P. Wolf. 1993. Growth characteristics and estimates of age at maturity of two species of skates (Raja binoculata and Raja rhina) from Monterey Bay, California. NOAA Technical Report NMFS 115: 87-99. 
Synthesis 
The objectives of this study were to describe the life history characteristics of the Starry Skate, Raja stellulata. Overall, $R$. stellulata is a medium-sized skate with moderate longevity and moderate growth. It matures at a large size and relatively late in life with both sexes maturing about the same sizes and ages. It is primarily found on hard outcrops between 70 and $150 \mathrm{~m}$ depth, secondarily on soft sediment, and smaller individuals are most frequently found on mixed substrate. Raja stellulata is not a large percentage of California trawl fisheries bycatch, however, as recently as $2008,99 \%$ of skate landings were marketed as "unspecified skate" (CDFG 2009).

The age and growth parameters of $R$. stellulata were assessed using two preparation techniques: gross sectioning and histological sectioning. The histological technique, despite the additional equipment, labor and expenses, unmistakably enhanced the banding pattern within the centra where up to seven additional band pairs were counted. The enhancement capabilities of the histological technique were invaluable in determining the age of other species of skate, especially bathyrajids whose vertebrae are notoriously poorly calcified (Natanson et al. 2007, Ainsley 2009, Maurer 2009, Winton 2011). This technique is strongly recommended for future skate age and growth studies. A large and imperative accomplishment for any chondrichthyan life history study is to validate or verify band pair deposition periodicity. This study was able to verify annual deposition of one band pair for $R$. stellulata using both CEA and MIR on gross sections. This finding lends support to other studies of skates that assume an annual band pair deposition, but could not validate it. The difference in edge analyses between gross and histological sections in this study is likely due to the much reduced, almost half, 
sample size processed with the histological technique. The mechanisms behind band deposition in chondrichthyans are still not well understood, therefore, observed variability in edge type or MIR could be a result of reader error or unknown environmental or internal processes affecting the organism. More research into band deposition processes is required because conflicting species-specific patterns have been observed (Waring 1984, Natanson et al. 1993, Officer et al. 1997).

The size and age at maturity occurred at almost $80 \%$ of the maximum TL and $60 \%$ of the maximum estimated age. This result conforms to the generalization that elasmobranchs mature late in life and at relatively large sizes (Holden 1973, Stevens et al. 2000). There also were no significant differences in maturation between sexes. This supports the hypothesis that skates $<150 \mathrm{~cm}$ TL tend not to exhibit sexual dimorphism in sizes (Ebert et al. 2008a, b).

The reproductive cycle of $R$. stellulata is year-round with no significant seasonal peaks. However, all reproductive indicators examined (GSI, maximum ovum diameter, and number of mature ova) were somewhat elevated between early spring and summer. More samples are required to determine if an increase in reproductive activity occurs from spring to summer, or if it reflects individual variability. Egg cases were present in April, July and September, which supports a year-round reproductive cycle with no seasonal peaks.

Raja stellulata is typical of both congeners in the eastern North Pacific and rajid skates worldwide of similar TL. Raja inornata attains the same approximate maximum TL, ( 760 mm), and a similar maximum age, 13 years versus 15 years of $R$. stellulata and 
has similar age at maturity of 7-8 years (Wade Smith and Dave Ebert, unpubl. data). The other two rajid congeners, $R$. binoculata and $R$. rhina attain larger sizes, but slightly younger ages when compared with $R$. stellulata (Zeiner and Wolf 1993). Rajid species of similar maximum TLs in other locations like the Gulf of Mexico, $R$. texana, the Irish Sea, R. montagui, the western North Atlantic, A. radiata, L. erinacea, M. senta, and northeast Taiwan, Okamejei acutspina have similar maximum ages ranging from 7 to 15 years and age at maturities ranging from 4 to 10 years (Gallagher et al. 2004, Natanson et al. 2007, Sulikowski et al. 2005, Sulikowski et al. 2007, McPhie and Campana 2009, Sulikowski et al. 2009, Joung et al. 2011). These species comparisons indicate that skates of similar maximum TL and similar phylogenetic position have similar life history characteristics.

In contrast to the similarities among rajid skates are the bathyrajid skates, a group with similar morphology and habits, but different life history characteristics. Two common bathyrajid skates, B. kincaidii, and B. trachura, both attain similar maximum TLs as $R$. stellulata ( 630 to $940 \mathrm{~mm}$ TL), but attain much older ages of 18 years for $B$. kincaidii (Perez et al. 2011) and 20 years for B. trachura in central California waters (Davis et al. 2007). There is a distinct taxonomic difference between the two families, but the two groups also inhabit different depth and temperature habitats.

Raja stellulata is likely not a large component of fisheries bycatch due to the habitat it uses. Its occurrence on hard outcrop is a beneficial trait because trawl gear is mostly excluded from this habitat, therefore, reducing fishing pressure on $R$. stellulata. The lack of demersal longline fishing in rocky areas in California also has aided the incidental protection of this species. The moderate longevity and growth and the year- 
round reproduction lends this species to be more resilient to fishing pressure than other longer-lived, slower growing species. However, demographic analyses using the life history parameters determined in this study must be conducted before the vulnerability of R. stellulata can be assessed accurately.

Age and depth are correlated among central California skates in that longevity increases with depth. This is potentially a useful concept to apply to skates with unknown life history characters. The trend should be applied to other skate assemblages worldwide to determine its validity. The same correlation was determined for Alaskan bathyrajid species (Winton 2011), and likely is a trend that could be applied worldwide. 


\section{Literature Cited}

Ainsley, S.M. 2009. Age, growth and reproduction of the Bering Skate, Bathyraja interrupta (Gill and Townsend, 1897), from the Eastern Bering Sea and Gulf of Alaska. M.S. Thesis. California State University, Monterey Bay.

Braccini, J.M. and G.E. Chiaramonte. 2002. Reproductive biology of Psammobatis extenta. Journal of Fish Biology 61: 272-288.

Beverton, R.J.H., and S.J. Holt. 1957. On the dynamics of exploited fish populations. Fishery Investigations, Series II, Volume XIX. London. 533 pp.

California Department of Fish and Game (CDFG). 2009. Review of selected California fisheries for 2008: Coastal pelagic finfish, market squid, ocean salmon, groundfish, California spiny lobster, spot prawn, white seabass, kelp bass, thresher shark, skates and rays, Kellet's whelk, and sea cucumber. Fisheries Review: CalCOFI Report 50: 14-42.

Davis, C.D., G.M. Cailliet and D.A. Ebert. 2007. Age and growth of the roughtail skate Bathyraja trachura (Gilbert 1892) from the eastern North Pacific. Environmental Biology of Fishes 80: 325-336.

Ebert, D.A., L.J.V. Compagno, and P.D. Cowley. 2008a. Aspects of the reproductive biology of skates (Chondrichthyes: Rajiformes: Rajoidei) from southern Africa. ICES Journal of Marine Science 65: 81-102.

Ebert, D.A., J.R. Maurer, S.M. Ainsley, L.A.K. Barnett and G.M. Cailliet. 2009. Life history and population dynamics of four endemic Alaskan skates: determining essential biological information for effective management of bycatch and target species. North Pacific Research Board Final Report 715. 120pp.

Ebert, D.A., W.D. Smith and G.M. Cailliet. 2008b. Reproductive biology of two commercially exploited skates, Raja binoculata and $R$. rhina, in the western Gulf of Alaska. Fisheries Research 94: 48-57.

Ebert, D.A., W.D. Smith, D.L. Haas, S.M. Ainsley and G.M. Cailliet. 2007. Life history and population dynamics of Alaskan skate: providing biological information for effective management of bycatch and target species. North Pacific Research Board Final Report 510. 124 pp.

Frisk, M.G. and T.J. Miller. 2006. Age, growth, and latitudinal patterns of two Rajidae species in the northwestern Atlantic: little skate (Leucoraja erinacea) and winter skate (Leucoraja ocellata). Canadian Journal of Fisheries and Aquatic Sciences 63: 1078-1091. 
Gallagher, M.J., C.P. Nolan and F. Jeal. 2004. Age, growth, and maturity of the commercial ray species from the Irish Sea. Journal of Northwest Atlantic Fisheries Science 35: 47-66.

Holden, M.J. 1973. Are long-term sustainable fisheries for elasmobranchs possible? Rapports et Procès Verbaux des Rèunions du Conseil International pour l'Exploration de la Mer 164: 360-367.

Joung, S-J., P-H. Lee, K-M. Lui and Y-Y Liao. 2011. Estimates of life history parameters of the sharpspine skate, Okamejei acutispina, in the northeastern waters of Taiwan. Fisheries Research 108: 258-267.

Licandeo, R. and F.T. Cerna. 2007. Geographic variation in life-history traits of the endemic kite skate Dipturus chilensis (Batoidea: Rajidae), along its distribution in the fjords and channels of southern Chile. Journal of Fish Biology 71:421-440.

Mabragana, E. and M.B. Cousseau. 2004. Reproductive biology of two sympatric skates in the south-west Atlantic: Psammobatis rudis and Psammobatis normani. Journal of Fish Biology 65: 559-573.

Maurer, J.R.F. 2009. Life history of two Bering Sea slope skates: Bathyraja lindbergi and B. maculata. M.S. Thesis. California State University, Monterey Bay.

McPhie, R.P. and S.E. Campana. 2009. Bomb dating and age determination of skates (family Rajidae) off the eastern coast of Canada. Journal of Marine Science 66: 546-560.

Natanson, L.J. 1993. Effect of temperature on band deposition in the Little Skate, Raja erinacea. Copeia 1993(1): 199-206.

Natanson, L.J., J.A. Sulikowski, J.R. Kneebone and P.C. Tsang. 2007. Age and growth estimates for the smooth skate, Malacoraja senta, in the Gulf of Maine. Environmental Biology of Fishes 80(2-3): 293-308.

Officer, R.A., R.W. Day, J.G. Clement and L.P. Brown. 1997. Captive gummy sharks, Mustelus antarcticus, form hypermineralised bands in their vertebrae during winter. Canadian Journal of Fisheries and Aquatic Sciences 54: 2677-2683.

Perez, C.R., G.M. Cailliet, and D.A. Ebert. 2011. Age and growth of the Sandpaper Skate, Bathyraja kincaidii, using vertebral centra, with an investigation of caudal thorns. Journal of the Marine Biological Association of the United Kingdom 91(6): 1149-1156. 
Sulikowski, J.A., A.M. Cicia, J.R. Kneebone, L.J. Natanson, and P.C.W. Tsang. 2009. Age and size at sexual maturity of the Smooth Skate Malacoraja senta from the western Gulf of Maine. Journal of Fish Biology 75: 2832-2838.

Sulikowski, J.A., S.B. Irvine, K.C. DeValerio, and J.K. Carlson. 2007. Age, growth, and maturity of the Roundel Skate, Raja texana, from the Gulf of Mexico, USA. Marine and Freshwater Research 58: 41-53.

Sulikowski, J.A., J. Kneebone, S. Elzey, J. Jurey, P.D. Danley, W.H. Howell and P.C.W. Tsang. 2005. Age and growth estimates of the thorny skate (Amblyraja radiata) in the western Gulf of Maine. Fishery Bulletin 103: 161-168.

Stevens, J.D., R. Bonfil, N.K. Dulvy and P.A. Walker. 2000. The effects of fishing on sharks, rays and chimaeras (chonrichthyans), and the implications for marine ecosystems. ICES Journal of Marine Science 57: 476-494.

Waring, G.T. 1984. Age, growth, and mortality of the little skate off the northeast coast of the United States. Transactions of the American Fisheries Society 113: 314321.

Winton, M.V. 2011. Age, growth, and demography of the Roughtail Skate, Bathyraja trachura (Gilbert, 1892), from the eastern Bering Sea. M.S. Thesis. California State University, Monterey Bay.

Zeiner, S.J., and P. Wolf. 1993. Growth characteristics and estimates of age at maturity of two species of skates (Raja binoculata and Raja rhina) from Monterey Bay, California. NOAA Technical Report NMFS 115: 87-99. 